\title{
Geospatial Technology Applications and Infrastructure in the \\ Biological Resources Division
}

Information and Technology Report

USGS/BRD/ITR - 1998-0001

U.S. Department of the Interior

U.S. Geological Survey

Biological Resources Division

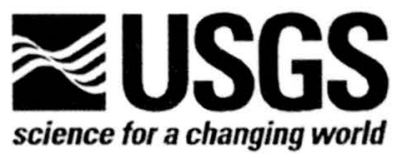




\section{Technical Report Series}

The Biological Resources Division publishes scientific and technical articles and reports resulting from the research performed by our scientists and partners. These articles appear in professional journals around the world. Reports are published in two report series: Biological Science Reports and Information and Technology Reports.

\section{Series Descriptions}

Biological Science Reports

ISSN 1081-292X

This series records the significant findings resulting from sponsored and co-sponsored research programs. They may include extensive data or theoretical analyses. Papers in this series are held to the same peer-review and high quality standards as their journal counterparts.

Information and Technology Reports

ISSN 1081-2911

These reports are intended for publication of book-length monographs; synthesis documents; compilations of conference and workshop papers; important planning and reference materials such as strategic plans, standard operating procedures, protocols, handbooks, and manuals; and data compilations such as tables and bibliographies. Papers in this series are held to the same peer-review and high quality standards as their journal counterparts.

Copies of this publication are available from the National Technical Information Service, 5285 Port Royal Road, Springfield, Virginia 22161 (1-800-553-6847 or 703-487-4650). Copies also are available to registered users from the Defense Technical Information Center, Attn.: Help Desk, 8725 Kingman Road, Suite 0944, Fort Belvoir, Virginia 22060-6218 (1-800-225-3842 or 703-767-9050).

Cover graphic by Mi Ae Lipe-Butterbrodt

Printed on recycled paper 


\section{Geospatial Technology}

Applications and Infrastructure in the

Biological Resources Division

Information and Technology Report

USGS/BRD/ITR-1998-0001

September 1998

by

Geospatial Technology Strategic Planning Development Team 


\title{
Geospatial Technology Strategic Planning Development Team
}

\author{
Frank D'Erchia (Team Leader) \\ Central Regional Office \\ James Getter (Geospatial Technology Program Manager) \\ Center for Biological Informatics \\ NASA-GSFC Field Station \\ Terry D'Erchia \\ Ralph Root \\ Susan Stitt \\ Center for Biological Informatics \\ Barbara White ${ }^{1}$ \\ Midcontinent Ecological Science Center
}

'Currently with the U.S. Fish and Wild life Service

\begin{abstract}
A product of the Biological Resources Division Geospatial Technology Program, in support of the National Biological Information Infrastructure
\end{abstract}

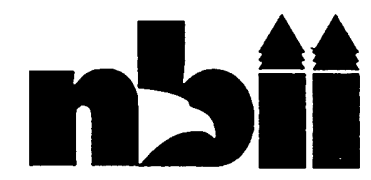

Suggested citation:

D'Erchia, F., J. Getter, T. D'Erchia, R. Root, S. Stitt, and B. White. 1998. Geospatial technology applications and infrastructure in the Biological Resources Division. U.S. Geological Survey, Biological Resources Division. Information and Technology Report USGS/BRD/ITR-1998-0001. v + 53 pp. 


\section{Contents}

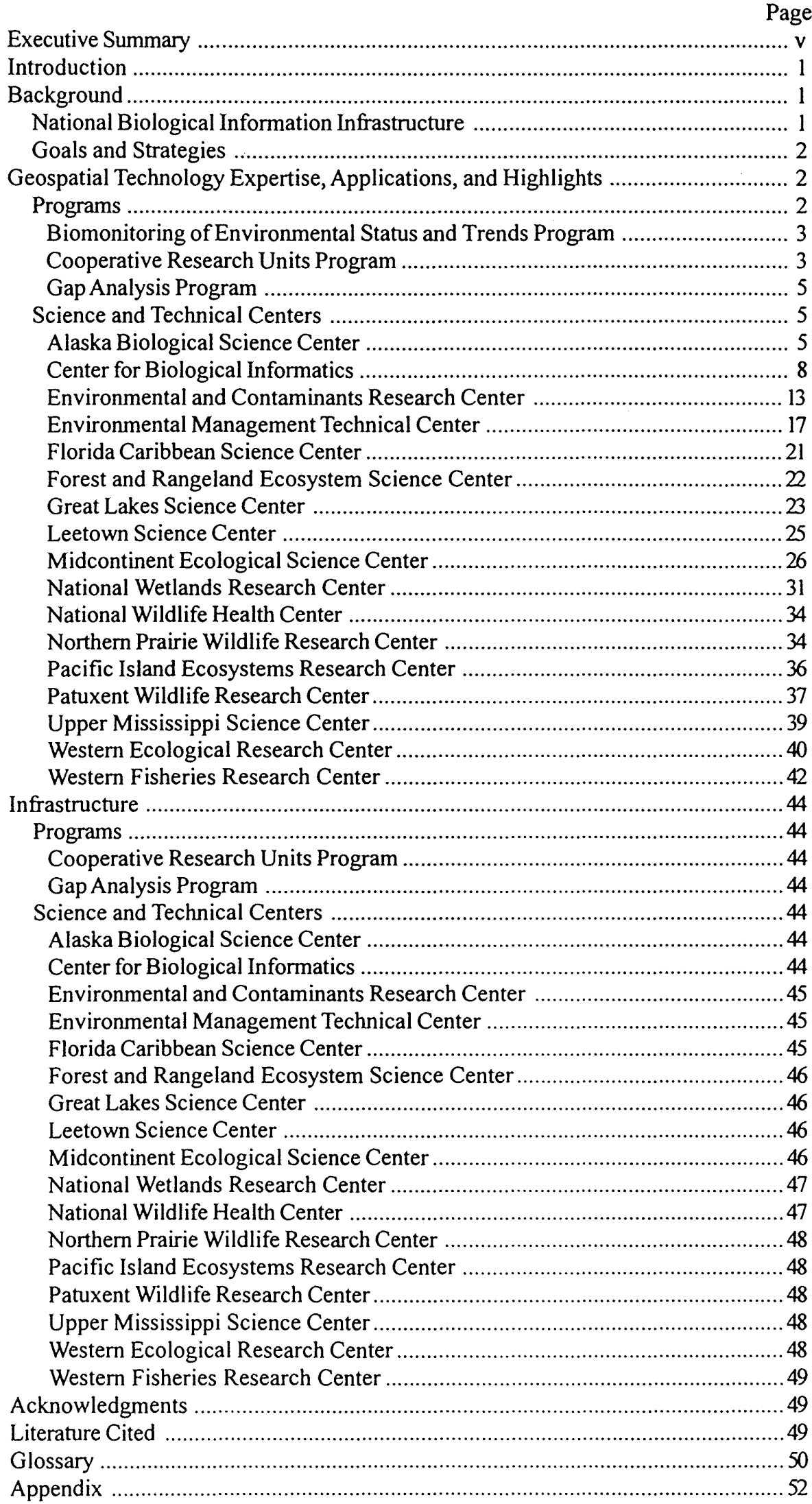





\section{Executive Summary}

Automated spatial processing technology such as geographic information systems (GIS), telemetry, and satellitebased remote sensing are some of the more recent developments in the long history of geographic inquiry. For millennia, humankind has endeavored to map the Earth's surface and identify spatial relationships. But the precision with which we can locate geographic features has increased exponentially with satellite positioning systems.

Remote sensing, GIS, thematic mapping, telemetry, and satellite positioning systems such as the Global Positioning System (GPS) are tools that greatly enhance the quality and rapidity of analysis of biological resources. These technologies allow researchers, planners, and managers to more quickly and accurately determine appropriate strategies and actions. Researchers and managers can view information from new and varying perspectives using GIS and remote sensing, and GPS receivers allow the researcher or manager to identify the exact location of interest. These geospatial technologies support the mission of the U.S. Geological Survey (USGS) Biological Resources Division (BRD) and the Strategic Science Plan (BRD 1996) by providing a cost-effective and efficient method for collection, analysis, and display of information

The BRD mission is "to work with others to provide the scientific understanding and technologies needed to support the sound management and conservation of our Nation's biological resources." A major responsibility of the BRD is to develop and employ advanced technologies needed to synthesize, analyze, and disseminate biological and ecological information. As the Strategic Science Plan (BRD 1996) states, "fulfilling this mission depends on effectively balancing the immediate need for information to guide management of biological resources with the need for technical assistance and long-range, strategic information to understand and predict emerging patterns and trends in ecological systems."

Information sharing plays a key role in nearly everything BRD does. The Strategic Science Plan discusses the need to (1) develop tools and standards for information transfer, (2) disseminate information, and (3) facilitate effective use of information. This effort centers around the National Biological Information Infrastructure (NBII) and the National Spatial Data Infrastructure (NSDI), components of the National Information Infrastructure. The NBII and NSDI are distributed electronic networks of biological and geographical data and information, as well as tools to help users around the world easily find and retrieve the biological and geographical data and information they need.

The BRD is responsible for developing scientifically and statistically reliable methods and protocols to assess the status and trends of the Nation's biological resources. Scientists also conduct important inventory and monitoring studies to maintain baseline information on these same resources. Research on those species for which the Department of the Interior (DOI) has trust responsibilities (including endangered species and migratory species) involves laboratory and field studies of individual animals and the environments in which they live. Research-both tactical and strategic - is conducted at the BRD's 17 science centers and 81 field stations, 54 Cooperative Fish and Wildlife Research Units in 40 states, and at 11 former Cooperative Park Study Units. Studies encompass fish, birds, mammals, and plants, as well as their ecosystems and the surrounding landscape. Biological Resources Division researchers use a variety of scientific tools in their endeavors to understand the causes of biological and ecological trends. Research results are used by managers to predict environmental changes and to help them take appropriate measures to manage resources effectively.

The BRD Geospatial Technology Program facilitates the collection, analysis, and dissemination of data and information for BRD Research, the Cooperative Research Program, and Office of Biological Informatics and Outreach programs. Within the BRD, hundreds of scientists and technologists are directly involved in work related to the production, use, and analysis of spatial data relating to the study of biological resources. These activities employ GIS, remote sensing and image processing, GPS technology, and telemetry.

Many BRD centers, field stations, and cooperative units throughout the country conduct geospatial technology activities to varying extents. The material presented in this document reflects only a sampling of the many projects being conducted at BRD facilities and can be viewed as a snapshot of the capabilities and infrastructure in place; new applications are implemented on a regular basis. 



\title{
Geospatial Technology Applications and Infrastructure in the Biological Resources Division
}

\author{
by \\ Geospatial Technology Strategic Planning Development Team \\ U.S. Geological Survey Biological Resources Division
}

\begin{abstract}
This report addresses the use and applications of geospatial technology in the Biological Resources Division (BRD) of the U.S. Geological Survey. Information on geospatial technology activities and resources at BRD centers and programs is linked to the BRD Geospatial Technology Strategic Plan. Activities listed represent only a sampling of ongoing geospatial applications and infrastructure; new projects are implemented on a regular basis. The use and application of geospatial technology is rapidly expanding Division-wide, as demonstrated by the breadth of applications discussed. This document provides an inventory of geospatial capabilities that currently exist within the centers, field stations, and programs of the BRD.
\end{abstract}

Key words: Biological Resources Division, geographic information systems, geospatial technology, Global Positioning System, metadata, remote sensing, satellite positioning systems, telemetry, U.S. Geological Survey

\section{Introduction}

This document provides highlights of the geospatial technology activities conducted by the Biological Resources Division (BRD) of the U.S. Geological Survey (USGS). Additional center and program information may be accessed over the Internet through the BRD Home Page (http://biology.usgs.gov) and the Geospatial Technology Program Home Page (http://biology.usgs.gov/geotech).

The information contained in this report was contributed by representatives from all BRD centers and programs and was coordinated and assembled by the Geospatial Technology Strategic Planning Development Team. Geospatial technology expertise, activities, projects, capabilities, and resources are summarized by center or program. Future research and operational support are expected to continue to expand. For more information about geospatial applications or infrastructure in a particular program or at a particular center, contact the geospatial technology coordinator for that program or facility. A list of Geospatial Technology Coordinators and contact information can be found in the Appendix of this report.

\section{Background}

The Office of Biological Informatics and Outreach (OBIO) Assistant Chief Biologist provides policy, standards, direction, management, and oversight of geospatial technology activities in the BRD. Geospatial Technology Coordinators representing BRD centers and programs provide recommendations to OBIO on geospatial technology issues through an elected council (Appendix).
Documentation and sharing of geospatial data and metadata, software, tools, and analytical models are critical factors in providing effective technical support to BRD activities. In collaboration with the Geospatial Technology Coordinators, OBIO provides leadership in developing data sets such as the National Biological Information Infrastructure (NBII) data dictionary and an inventory of biological data stored as metadata. Geospatial technology experts provide training in developing metadata for geospatial data.

\section{National Biological Information Infrastructure}

All Federal agencies are mandated to comply with the National Spatial Data Infrastructure (NSDI), "an umbrella of policies, standards, and procedures under which organizations and technologies interact to foster more efficient use, management, and production of geospatial data" (NSDI 1994). A complement to the NSDI, the NBII is a distributed federation of biological data and information sources established through a network of Federal, State, and non-government partners and cooperators. In addition to biological data and information, software tools are identified and made available through the NBII to help users analyze, integrate, and display biological data and information. The NBII also points to sources of biological expertise - the people and organizations users can contact for advice and assistance in finding and understanding biological data. Thus, the NBII is the BRD vehicle for compliance with the NSDI. 


\section{Goals and Strategies}

The BRD has developed a strategy to facilitate the use and application of geospatial technology. Geospatial technology goals, strategies, and objectives are defined in the BRD Geospatial Technology Strategic Plan (D'Erchia et al. 1997). These goals and strategies are provided here for reference.

\section{Goal 1: Provide leadership in geospatial technology ac-} tivities.

Strategy 1.1 Provide a clear vision of the role of geospatial technology in the BRD.

Strategy 1.2 Strengthen the organization of the Geospatial Technology Coordinating Group (GTCG).

Strategy 1.3 Establish policy recommendations and guidelines for geospatial technology activities.

Strategy 1.4 Promote the role of geospatial technology in support of better science.

Goal 2: Promote integration of geospatial technology within the biological research and resource management communities.

Strategy 2.1 Collaborate with USGS Divisions and Programs on geospatial activities.

Strategy 2.2 Develop new approaches to integrating geospatial data into a wide range of applications.

Goal 3: Develop and maintain cooperative efforts and partnerships to effectively access and disseminate geospatial information, data, and technological resources.

Strategy 3.1 Enter into cooperative efforts and partnerships to further BRD goals.

Strategy 3.2 Use and maintain existing BRD geospatial technology capabilities.

Goal 4: Facilitate development, use, and application of geospatial technology and expertise that support the biological research and resource management communities.

Strategy 4.1 Inventory existing BRD geospatial tools and technology.

Strategy 4.2 Identify geospatial technology needs of the biological research and resource management communities.

Strategy 4.3 Develop standards and guidelines for geospatial tools and technology.

Goal 5: Ensure availability and accessibility of geospatial technology and expertise to the biological research and resource management communities.
Strategy 5.1 Manage and maintain geospatial technology resources to ensure functionality and reliability.

Strategy 5.2 Facilitate geospatial information sharing and acquisition practices.

Goal 6: Manage geospatial data and information as valuable resources and incorporate their development as an integral part of the research and data sharing process.

Strategy 6.1 Inventory existing geospatial data available within the $\mathrm{BRD}$.

Strategy 6.2 Promote the use and development of geospatial data management standards and procedures.

Strategy 6.3 Manage geospatial data and information.

Strategy 6.4 Provide access to and distribute geospatial data and information.

Goal 7: Develop and implement a geospatial technology training program.

Strategy 7.1 Identify training needs.

Strategy 7.2 Develop a training program.

Strategy 7.3 Promote and provide training opportunities.

\section{Geospatial Technology Expertise, Applications, and Highlights}

The USGS BRD uses a variety of geospatial technologies in biological research applications. Through the use of these geospatial technologies, remotely sensed data, and dynamic spatial models, scientists analyze current habitat conditions to understand changing environmental effects on the biological resources of the Nation. The topics listed below are a sampling of the expertise or specializations of and applications carried out by BRD programs and science centers (Fig.).

\section{Programs}

\section{Biomonitoring of Environmental Status and Trends Program}

The Biomonitoring of Environmental Status and Trends (BEST) Program is a national BRD program designed to identify and understand the effects of environmental contaminants on biological resources, particularly those resources under the stewardship of the Department of the Interior (DOI).

To meet BEST goals at the national, regional, and local level, a wide range of expertise is obtained from BRD centers nationwide in the areas of biomonitoring for contaminants, development of biomonitoring tools, data management, 


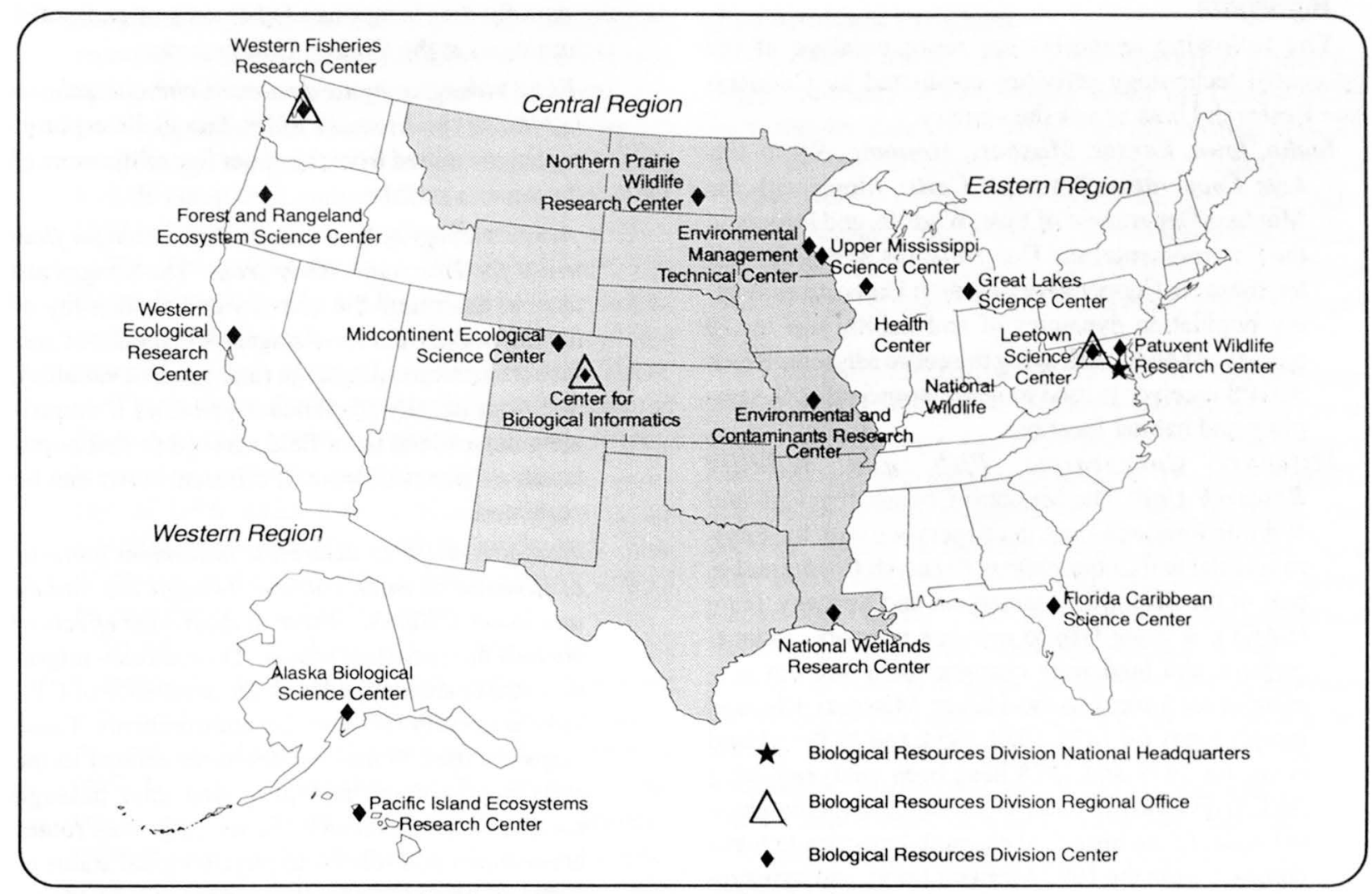

Fig. Locations of the 17 science and technical centers and 3 regional offices of the Biological Resources Division.

geographic information systems (GIS), and advanced Internet capabilities for online interactive manipulation of geospatial data sets.

\section{Highlights}

The BEST Program, in cooperation with the U.S. Fish and Wildlife Service (USFWS) Division of Environmental Contaminants, has funded the development of an Internet-accessible data management system with GIS capabilities. This UNIX-based system, the Contaminant Information Management and Analysis System (CIMAS), allows authorized users to review, enter, retrieve, and generate spatial displays of contaminant information for DOI land units and surrounding areas. In addition to displaying contaminant data, CIMAS provides the capability to retrieve select ancillary data. Developed by the Midcontinent Ecological Science Center Technology Applications Team, CIMAS can be accessed via the Internet at http://orion.mesc.nbs.gov.

\section{Cooperative Research Units Program}

The BRD contributes to 40 Cooperative Research Units in 38 states. These units provide research capabilities for virtually every type of North American ecological community. More than $110 \mathrm{Ph} . \mathrm{D}$. scientists oversee as many as 500 graduate students per year.
Each unit is a partnership among the USGS, a State fish and game agency, a host university, and the Wildlife Management Institute. With Federal staffing, units conduct research on renewable natural resource questions, participate in the education of graduate students destined to become natural resource scientists, provide technical assistance and consultation to parties who have legitimate interests in natural resource issues, and provide various forms of continuing education for natural resource professionals.

\section{Expertise or specialization}

Aquatic ecology

ARC/INFO

Aridland ecosystems

Fish ecology

Fisheries and wildlife biology

GIS analysis

Global change

Paleoecology

Plant ecology

Population ecology

Vector-borne disease ecology

Wetlands ecology

Zoology 


\section{Highlights}

The following examples are representative of the geospatial technology activities conducted by Cooperative Research Units across the country.

Idaho, Iowa, Kansas, Missouri, Montana, South Dakota Cooperative Research Units: Along with the Montana Department of Fish, Wildlife, and Parks and the Environmental and Contaminants Research Center, these six Cooperative Research Units are evaluating population dynamics of and habitat use by 26 species of benthic fish along the entire Missouri River. A GPS receiver is used to georeference all fish sampling and habitat locations.

Missouri Cooperative Fish and Wildlife Research Unit: The Missouri Cooperative Fish and Wildlife Research Unit, in cooperation with the Environmental and Contaminants Research Center and as part of the Scientific Assessment and Strategy Team (SAST), is using GIS to evaluate temporal channel patterns and landcover changes for a $300-\mathrm{km}$ segment of the lower Missouri River, Missouri. Channel morphometry for $1879,1920,1954$, and 1978 and land cover for 1879 and 1978 have been analyzed using ARC/INFO and FRAGSTATS to define an active channel zone, relate historical channel dynamics to levee damages from the 1993 Midwest flood, and assist resource managers in acquiring and managing floodplain habitat.

Oregon Cooperative Fish and Wildlife Research Unit: The Oregon Cooperative Fish and Wildlife Research Unit pioneered the use of forward-looking infrared (FLIR) videography to map the distribution of stream temperatures in watersheds. They found that disturbed watersheds radiate a different temperature signature (patchy patterns) than those that are relatively intact. Mapping has been completed for coldwater refugia for adult salmon in the high desert rivers of the upper Grande Ronde, Imnaha, Wenaha, Mainstem John Day, Middle Fork John Day, and North Fork John Day basins. Unit scientists confirmed these areas as critical habitats by using implanted temperature-sensitive radiotags and tracking fish movements. Using this technology, the Oregon Unit traced the sources of groundwater movement to streams. Digital, high 8$\mathrm{mm}$ videography was used to capture straight imagery simultaneously with the capture of thermal imagery. High 8-mm videography also was used to estimate frequencies of habitat type and availability, the extent of riparian vegetation, and large woody debris in streams. The videography is Global Positioning System (GPS)-referenced, as is habitat use by salmon as determined through radiotracking. Mosaics of the videography are used as GIS data layers, as are the data for fish locations. Other uses of geospatial technologies at the Oregon Unit include:

- FLIR videography to document chinook salmon habitat in the Klamath River. The FLIR captures radiation emitted from the upper few millimeters of the water's surface.

- Aerial videography to determine minimum flow needs for Deschutes River trout. The images are used to determine the quantity and availability of habitat at different river stages. A response of surface temperature, discharge (independent variable), and trout density (dependent variable) is empirically determined from field surveys so that population estimates of trout at different flows can be predicted.

- Radiotelemetry to determine movement patterns of juvenile chinook salmon through the middle and lower Columbia River to determine effects of various dam passage routes. Downstream migration routes are mapped with the assistance of GPS to help identify fish-friendly environments. These maps are used in making decisions related to the effects of present and proposed dam passage routes potentially taken by fishes. Migratory routes are mapped and related to physiological status of fishes to provide an understanding of how physical and hydrological features affect fish passage.

- Radiotelemetry and GPS to determine the behavior of transported and in-river migrating salmonids in the Lower Columbia. This study is being conducted to evaluate the success of management strategies, such as the U.S. Army Corps of Engineers (USACE) barging program, for salmonids that - have migrated freely in the Columbia River system. Fish migration routes from Bonneville Dam to the ocean (over 150 miles) are mapped by combining radiotelemetry observations of fishes with landmarks and GPS to provide an understanding of potential sources of mortality that limit population size. Coupled with clinical assays of stress and health, this information will be used to determine whether different physiological phenotypes vary in migration routes.

Texas Cooperative Fish and Wildlife Research Unit: The Texas Cooperative Fish and Wildlife Research Unit has developed methodologies that combine aerial videography, Landsat TM imagery, and field data for landcover classification from remotely sensed imagery. New databases are being constructed for remote areas of the Texas-Mexico border region. Spectrum software from Khoral Research Inc. was upgraded to provide the capability to conduct needed landcover 
classification routines, and new aerial videography recording and processing methods have been developed. Aerial videography software (SkyKing) has been supported; ER Mapper and IDRISI are the primary image analysis software packages used. Data include complete Landsat TM coverage of Texas for 1993 and more than 10,000 miles of aerial videography.

The Texas Gap Analysis Program (GAP) and Texas-Mexico Border GAP projects have developed several methodologies for landcover mapping. Because of the lack of access to public lands in Texas, staff have worked with the Mapping Science Lab at Texas A\&M University to develop a unique approach to aerial videography capture and processing. An array of GPS units allows video images to be georeferenced and projected to the ground. This promising system should further the move toward more accurate aerial videography.

In addition to these developments in aerial videography, the Texas Unit upgraded their Spectrum software to allow automation of the cluster labeling process for Multi-resolution Land Characteristics (MRLC) hyperclustered imagery. Point locations representing land cover taken from georeferenced videography or other imagery can be read into Spectrum and processed automatically. This system will be useful for classification of large land areas.

The Texas Unit also is working in cooperation with the Museum of Texas Tech University's Natural Science Research Laboratory to construct the Natural Science Database. The goal of the Natural Science Database is to document the biodiversity of Texasand of the United States - through a shared database of traditional collections and cryopreserved tissue samples with a spatial component.

Wisconsin Cooperative Wildlife Research Unit: The Wisconsin Cooperative Wildlife Research Unit constructed songbird habitat models using a GIS database developed by The Nature Conservancy. These models have been used to predict densities of several forest songbird species over the Baraboo Hills. Using the models and GIS, several scenarios for future land-use changes in the Baraboo Hills have been developed to predict how a variety of land-use decisions will affect regional songbird populations. Geospatial technologies are also being used to determine habitat selection by marine birds and mammals in the Gulf of Mexico. A GIS will overlay species distributions with a variety of habitat features. Other projects include using radiotelemetry in investigating bobwhite quail movements and habitat use and determining the movements of brown-headed cowbirds in pinyon-juniper woodland in relation to the rate of nest parasitism.

\section{Gap Analysis Program}

The GAP is a state-based cooperative effort to map the major indicators of biodiversity across the United States on a state-by-state basis, along with the existing network of conservation lands. These mapped indicators of biodiversity are (1) dominant vegetation types (e.g., oakhickory-hemlock forest, bluebunch wheatgrass-Idaho fescue grassland) and (2) distributions of native vertebrate species (e.g., chimney swift, woodchuck, spotted chorus frog).

These computer maps are used with GIS software programs to help manage the Nation's natural resources in many different ways, from day-to-day land management decision making to long-term planning. The information is used by biologists, planners, researchers, students, and decision makers in industry, county governments, State and Federal agencies, and schools. One use of this information is to identify "gaps" in the network of conservation lands to avoid future conservation crises. Another purpose of the GAP is to foster cooperation and partnerships around the development and application of shared information. Administered by the Center for Biological Informatics, the program includes 430 cooperating organizations nationwide, including businesses, agencies, and universities. Gap Analysis Program projects are now active in 43 states.

Maps of vegetation types are created from satellite images, aerial videography and photography, and field inventories. All maps are produced at a 1:100,000 scale.

The 1994-1995 National Gap Analysis Program Status Report (Jennings et al. 1995), Gap Analysis Bulletin Number 5 (National Biological Service 1996), and Wildlife Monographs Number 123 (Scott et al. 1993) provide in-depth descriptions of the program. These and other program materials, such as currently available geographic data, the GAP Handbook, related literature, and discussions can be found on the GAP Home Page at http://www.gap.uidaho/ gap or can be obtained from the Gap Analysis Program Field Office, 530 South Asbury Street, Suite 1, Moscow, Idaho 83843 (telephone: 208-885-3555; e-mail: gap@uidaho.edu).

\section{Science and Technical Centers}

\section{Alaska Biological Science Center, Anchorage Expertise or specialization}

Arctic/subarctic ecology

Avian ecology

Fisheries ecology

GIS analysis

Global Positioning System (GPS) technology

Inventory and monitoring

Mammalian ecology

Modeling

Molecular genetics 
Plant ecology

Plant restoration

Population dynamics

Population ecology

Radiotelemetry

Satellite remote sensing

Satellite telemetry

Videography

\section{Applications}

Arctic National Wildlife Refuge coastal plain geospatial database

Assessing annual productivity of black brant

Bering-Chukchi Seas database development

Black brant habitat use requirements

Brown bear ecology studies

Caribou ecology studies

Glacier Bay Ecosystem Initiative

Glacier Bay Marine Ecosystem Initiative

Historical climate trends of the Prince William Sound ecosystem

Near-shore vertebrate-predator ecology studies

Polar bear ecology studies

Predator-prey ecology studies

Prince William Sound Ecosystem Initiative

Remote sensing of sea surface temperature, Cook Inlet

Salmon reproductive habitat ecology studies

Sea otter ecology studies

Seasonal habitat conditions assessment

Seasonal movements and habitat use by murres and tufted puffin

Snow goose foraging ecology

Spectacled eider population status

Walrus ecology studies

\section{Highlights}

Arctic National Wildlife Refuge coastal plain database compilation: Collaborative project ( $B R D-N a-$ tional Mapping Division-USFWS) to compile, document, and distribute existing Earth and biological science data pertaining to the Arctic coastal plain of northeastern Alaska and surrounding areas. This collaborative effort will create a permanent, documented archive of the many geospatial databases for this area collected or developed by Federal and State agencies over the past decade.

Assessing annual productivity of black brant: Studies assessing productivity at five major black brant nesting colonies (about $70 \%$ of all black brant nests) on the Yukon-Kuskokwim Delta. Nesting density is estimated using aerial videography along systematic transects. Global Positioning System receivers are used to navigate aircraft and to record locations of transects and nests. Area of colonies, locations of nests, and sample areas are determined with a GIS. Spatial analysis (kriging) of data has improved sampling efficiency and precision of population estimates.
Bering-Chukchi Seas database compilation: Compilation and documentation of Bering and Chukchi Sea information, with an emphasis on geospatial data sets of bathymetry, sediments, and sea-ice dynamics. This study has automated several bathymetric maps of the region into digital GIS format.

Black brant habitat use and requirements: Studies of migration patterns, population status, and habitat requirements of black brant across the Pacific Flyway. Radiotelemetry, banding, and remote sensing are used to investigate the seasonal use of coastal habitats across the black brant's annual migration route between breeding grounds in Alaska and wintering areas in Mexico. Satellite remote sensing, aerial photography, GPS, and GIS are being used to delineate and monitor changes within eelgrass communities, a critical foraging habitat for the black brant.

Brown bear ecology: Studies of seasonal distributions, demographics, and population dynamics of brown bears inhabiting Kodiak Island and Denali National Park. Radiotelemetry is used for long-term monitoring of the demographics, fecundity, habitat use, and seasonal distribution of bears. Studies of home ranges and the distribution of sex and age classes relative to seasonally available food resources use GIS technology.

Caribou ecology: Studies of the migratory behavior, calving distributions, fecundity, and seasonal habitat use of the Porcupine Caribou Herd. Researchers used satellite telemetry to investigate the fidelity of individuals and groups to wintering areas, migration corridors, and calving grounds. Radiotelemetry was used to monitor a large sample of cows and calves during the calving season to study relationships between habitat use, fecundity, growth, and survivorship. Geographic information systems technology was used to quantify the relationships of habitat use with several environmental themes derived from remote sensing and cartographic maps.

Glacier Bay ecosystem initiative: Study soliciting, compiling, and documenting a comprehensive collection of scientific information pertaining to the Glacier Bay ecosystem. A complete bibliography and metadata catalog will be produced of all spatial and nonspatial data sources. Geospatial information was consolidated and released on CD-ROM in 1997. The GIS databases include land cover, bathymetry, shoreline attributes, digital elevation models, hydrography, transportation information, and political boundaries.

Glacier Bay marine ecosystem: Studies of ecosystem components and their interactions within Glacier Bay National Park. Research uses GPS and sonictagging to monitor the distribution and movements of humpback whales, halibut, and other aquatic animals. Effects of commercial fishing are examined through direct monitoring, research long-lining sets, 
crab-pot placement manipulations, and oceanographic sampling. Differential GPS processing (2-m circular error probable) is used with the Trimble PFINDER and Corvallis datalogger to map a substantial section of the coastline in a multiattribute ( 6 variables; 156 attributes) dynamic segmentation model. Differential processing (submeter) is also being used to establish control points to georeference coastal photography and orthophotos. Geographic information systems technology is used for analyses of spatial relationships among animal distributions, environmental characteristics, and resource exploitation. The precision lightweight GPS receiver ( $\mathrm{PLGR}+$ ) has been upgraded to improve accuracy and to allow interfacing with marine electronics for real-time navigation purposes and with an ArcView application to do real-time mapping during dive transects. The system will also be used to improve delineation of multiple sonic targets in close proximity and repeatability of gear placement.

Historical climate trends of the Prince William Sound ecosystem: Studies of long-term trends in environmental conditions and identification of seasonal and annual anomalies. Species populations affected by the 1989 Exxon Valdez oil spill are being examined for relationships with these largely climate-based data sets. Historical Advanced Very High Resolution Radiometer (AVHRR) images from National Oceanic and Atmospheric Administration (NOAA) polar-orbiting satellites are being used to examine the spatial and temporal role of natural ocean temperature regimes on specific species. Terrestrial primary productivity is also being monitored within local watersheds to identify potential interactions with marine systems.

Near-shore vertebrate-predator ecology: Multidisciplinary studies of vertebrate predators, invertebrate co-predators, and prey species within coastal areas affected and not affected by the Exxon Valdez oil spill in Prince William Sound. Research uses GPS and site sampling to derive estimates of predator abundance, prey abundance, and prey consumption. Side-scan sonar, bathymetry data, and GIS are used to derive study area maps for extrapolating animal density estimates to estimates of total abundance.

Polar bear ecology, Beaufort Sea: Studies of home range, population segregation, denning habitats, predator-prey relations, and sea-ice habitat associations of polar bears occupying the Beaufort Sea. Satellite and radiotelemetry are used to ascertain home range size and the degree of spatial separation among Alaskan and Canadian populations and to identify den sites. Geographic information systems technology is used to quantify a variety of home range spatial relationships, as well as to identify topographic features associated with terrestrial den sites. Use of high-resolution satellite radar data to examine fine-scale attributes of sea-ice habitats used by polar bears and their prey is also being investigated.

Polar bear ecology, Chukchi Sea and Russian Arctic: Studies of migratory behavior, seasonal distribution, population segregation, denning areas, and survey methodologies of polar bears inhabiting the Chukchi and Bering Seas of Alaska and the Russian Arctic. Satellite and radiotelemetry are used to monitor animal distributions and movements; because of the polar bear's extensive and seasonally dynamic sea-ice habitats, GIS and broad-scale satellite radar remote sensing (SMMI and Russian OKEAN) are used to help determine spatial relationships.

Predator-prey ecology: Studies of wolf-caribou dynamics in the northern regions of Denali National Park. Radiotelemetry is used to intensively monitor caribou calf survivorship and to determine causes and rates of mortality due to predators. Wolf packs are also monitored using radiotelemetry to investigate seasonal distributions, fecundity, and population dynamics. Using GPS collars, precise locations of wolves have been determined with sufficient frequency to provide new information about patterns and durations of den attendance and hunting forays.

Prince William Sound ecosystem initiative: Study that solicited, compiled, and documented a comprehensive collection of scientific information pertaining to the Prince William Sound ecosystem. Geospatial information from a variety of State and Federal sources was consolidated and released on CD-ROM. These GIS databases contain land cover, bathymetry, shoreline attributes, digital elevation models, hydrography, transportation information, and political boundaries in the Prince William Sound and Copper River Basin area. The CD-ROM is PC- and UNIX-compatible and includes ArcView 1.0 software.

Remote sensing of seasonal habitat conditions: Studies of the annual availability and condition of wildlife habitats using satellite remote sensing throughout Alaska and the circumpolar Arctic. Polar-orbiting NOAA weather satellites provide AVHRR imagery, which is used to document and map dynamic environmental processes such as the timing of snow melt and vegetation greenup and rates of net primary productivity, fire, and senescence. These data are also used for sea-ice and sea-surface temperature analyses of marine systems. Geographic information systems technology is used to investigate ranges in annual variability of habitats and to evaluate how wildlife populations respond in terms of migration patterns, distribution, and reproduction. Results are helping to establish links among climate, potential 
climate change, vegetative habitat, and wildlife population dynamics and migratory behaviors.

Remote sensing of sea-surface temperature, Cook Inlet: Studies of seasonal distributions, foraging activity, productivity, and resource partitioning among seabirds in Cook Inlet. Research uses AVHRR imagery from NOAA polar-orbiting satellites to map seasurface temperatures (SST) and sediment plumes. Foraging bird distributions and hydroacoustic fish school data collected on summer cruises are being merged with SST data to identify potential linkages. Geographic information systems analyses have been used to test the importance of distance to shore, distance to colony, and size of forage-fish schools among various seabird species.

Salmon reproductive habitat ecology: Studies of the seasonal and annual patterns of stream sites selected by salmon for spawning. Geospatial technologies (GPS and GIS) are used to produce very fine-scale, weekly maps of precise locations of salmon spawning redds. Geographic information systems overlay analyses investigate variability of within-year and between-year use of spawning sites.

Sea otter ecology: Studies of seasonal distribution, dispersal patterns, and foraging behavior and development of systematic survey methods of sea otter populations inhabiting the coastal waters of Kodiak Island and Prince William Sound. Radiotelemetry, GPS, and GIS technologies are used to investigate demographics and seasonal movements of otters and to design and implement aerial transect surveys.

Seasonal movements and habitat use by murres and tufted puffins: Studies of foraging patterns and migration of seabirds from the northwest coast of Alaska and lower Cook Inlet. Research relies on implanted satellite transmitters to track movements during the breeding season and through migration. Geographic information systems analyses are used to graphically display movements and to examine habitat use with respect to sea-surface temperatures and sea ice.

Snow goose foraging ecology: Studies of nutritional requirements, food preferences, and habitat-use patterns of snow geese using areas in Cook Inlet during migration. Aerial surveys with GPS document the timing and distribution of snow goose habitat use. Detailed ground data are collected to quantify the composition and nutritional properties of the vegetative habitat. Multispectral digital videography collected from aircraft is being used to develop a highresolution landcover map of the study area. This GIS map will be used to examine snow goose habitat preferences and to subsequently extrapolate and delineate important habitats based on ground-sampling results.
Spectacled eider population status: Studies of seasonal distributions, population numbers, and habitat use patterns of the spectacled eider throughout Alaska and the Russian Far East. Satellite transmitters, implanted within the bird's body cavity, are used to discover previously unknown migratory staging and wintering areas. Geographic information systems technology is used to analyze the spectacled eider's habitat with respect to bathymetric, sediment, coastal, and sea-ice characteristics.

Walrus ecology: Studies of migration patterns, seasonal distributions, foraging areas, and haulout behaviors of walruses inhabiting the Chukchi and Bering Seas. Satellite telemetry and satellite-linked GPS transmitters are used to investigate walrus movements and haulout locations and to identify important foraging areas. Walrus utilization areas are analyzed with GIS to examine relationships with sediment, bathymetry, and coastline characteristics.

\section{Center for Biological Informatics, Denver, Colorado}

\section{Expertise or specialization}

Aerial photointerpretation

Botany

BRD webmaster

Cartography

Contract technical representative

Database administration

Forestry/forest ecology

Geography

Geology

GIS/mapping technologies

GPS technology

HTML/World Wide Web

Information management/transfer

JAVA

Land-use planning

Metadata National Technical Means

Networking

PC system administration

Plant ecology

Programming (C, PERL, Fortran)

Remote sensing/image processing

Technical editing

Telecommunications

UNIX shell scripting

UNIX system administration

Wildlife biology

\section{Applications}

BRD coordination for cartographic data needs for DOI High-Priority Digital Base Data Program

California Environmental Resources Evaluation System (CERES) project 
Cartographic data needs, USGS A-16 Program

DOI coordination for use of Airborne Visible /Infrared Imaging Spectrometer (AVIRIS) in natural resources management

DOI coordination for Y-code (military-grade) GPS receivers

Gap Analysis Program (GAP) administration

GIS Sourcebook

Integrated Taxonomic Information System (ITIS)

Land Use History of North America (LUHNA) program

Metadata training and assistance

National Biological Information Infrastructure (NBII)/ Metadata Content Standard for NBII

National Spatial Data Infrastructure (NSDI) Geospatial

Data Clearinghouse

National Technical Means (NTM) Program

National vegetation standards

Participation in the Interior Geographic Data Committee (IGDC), the Federal Geographic Data Committee (FGDC), and the U.S. Geological Survey Geographic Data Committee (GSGDC)

USGS-National Park Service (NPS) Vegetation Mapping Program

\section{Highlights}

Biological Resources Division representation on national geospatial technology committees: Staff of the Center for Biological Informatics (CBI) represent BRD within the USGS Geographic Data Committee (GSGDC) and on the U.S. Coast Guard Civil GPS Service Interface Committee. Staff members also participate in the National Spatial Data Applications Consortium. The goal of the Consortium is to provide the means for land-use, environmental, and weatherrelated decisions to be made as close to the citizen and local level as possible. Center for Biological Informatics staff members are actively participating in the Hyperspectral Imaging DOI-National Aeronautics and Space Administration (NASA) Technical Transfer Project.

California Environmental Resources Evaluation System: Staff of the CBI work with the California Environmental Resources Evaluation System (CERES) to develop methods for the description, discovery, and exchange of environmental information. The BRD has a formal partnership with CERES to cooperate in the development of a controlled vocabulary database and user environment that will (1) provide picklists for selection of keywords, synonyms, and related concepts for use in metadata and queries; (2) provide a hierarchical organization of information to serve as a browsing structure for information discovery; and (3) allow simultaneous browsing and comparison of terms as presented in multiple standard thesauri in use nationally and internationally to index environmental information. The BRD is also cooperating with CERES in the development of thesaurus-assisted search tools for the National Biological Information Infrastructure (http://www.nbii.gov), Z39.50-compliance (international standard for information retrieval), and links to ITIS, the Integrated Taxonomic Information System (http://www.itis.usda.gov/ itis/).

Cartographic data needs (USGS A-16 Program): The $\mathrm{CBI}$ serves as the $\mathrm{BRD}$ coordination point for Office of Management and Budget (OMB) Circular A16 requirements, which directed creation of the Federal Geographic Data Committee (FGDC) and NSDI-related activities and directs the USGS to gather high-priority base cartographic data requirements from Federal and State agencies. Each year, the USGS solicits information about these data requirements from agencies, and the Interior Geographic Data Committee (IGDC) Base Mapping Working Group adjudicates the selection process. This selection process takes into account the funding (usually several million dollars) allocated to the USGS for A-16 data production, whether there are agency-matching or cost-sharing funds, whether multiple-agency requests have been made for the same data, and whether DOI or Presidential initiatives are involved.

Colorado Department of Natural Resources: The CBI provides technical direction, oversight, and product review to the State of Colorado project, "Colorado Natural Resource Information Infrastructure: Access to Information on Colorado's Biotic and Related Natural Resources." This project was one of 11 chosen nationally to receive BRD funding $(\$ 98,965)$ in 1995 under the BRD State Partnership Initiative.

Department of the Interior coordination for use of Airborne Visible/Infrared Imaging Spectrometer (AVIRIS) data: Through the CBI and the Office of Earth Science (OES), the DOI and NASA are coordinating a technology transfer project to use AVIRIS data and analysis on critical DOI environmental issues at four study sites throughout the United States. This work is being accomplished by four DOI study teams with support from NASA OES principal investigators and programs. The four sites were selected through a DOI competitive proposal process and include studies of mercury contamination at the Owyhee Reservior, Oregon; invasive species (leafy spurge) detection at Theodore Roosevelt National Park, North Dakota; National Vegetation Classification System delineation to the alliance level at Congaree Swamp, South Carolina; and separation of woody stems from grasses in the Great Plains Basin Region. A status report of the first year's efforts of this multiyear project detailing the objectives and plans for the four identified projects was presented at 
the NASA Jet Propulsion Laboratory, Pasadena, California (Getter and Wickland 1998).

Department of the Interior coordination for Y-code (military-grade) Global Positioning System receivers: Departmental coordination for encryption and procurement of Y-code GPS receivers resides at the CBI. The Denver Cooperative Site for DOI serves as the primary rekeying site, and when the DOI receiver population exceeds approximately 400 , additional sites will be established to split the workload. The CBI has facilitated BRD and National Mapping Division acquisition of Precise Positioning Service (PPS) handheld GPS receivers (approximately 200 units from FY 1995-98). Seven of the nine DOI bureaus attended the first civilian PPS users conference in 1995 in Fort Worth, Texas, and shared operational and equipment upgrade suggestions with each other, approximately 20 other civilian agency user groups, and vendors. Since 1996, BRD has sponsored this annual conference for 60-100 attendees at the Rocky Mountain Mapping Center in Denver. The conference has included a brief classified section to assist new custodians and candidate Federal civilian agency personnel needing to plan for their PPS program.

Federal Geographic Data Committee participation: The CBI represents the BRD on the FGDC Base Cartographic Subcommittee, the Vegetation Subcommittee, the Standards Working Group, the Clearinghouse Working Group, and the Land Cover Data (LCD) Working Group, and chairs the Biological Data Working Group; for GPS issues, CBI represents the division on the Federal Geodetic Control Subcommittee and the GPS Interagency Advisory Council, and a CBI staff member chairs the Fixed Reference Station Working Group of the Federal Geodetic Control Subcommittee (FGCS). As a subcommittee of the FGDC, the FGCS focuses on Federal coordination of base stations, standards for base station installations, the CORS (continuously operating reference stations) network for high-accuracy geodetic positioning, and the promotion of adoption of ties to the network for all base station efforts (i.e., NAD 83 and ITRF datums). The subcommittee will likely also be the focus of emergency response assistance with coordinate information to augment the efforts of the Civil Applications Committee for classified imagery assistance to disasters.

The FGDC is charged with the responsibility to coordinate the surveying, mapping, and spatial data activities of Federal agencies to meet the needs of the Nation. Major objectives are avoiding duplication and minimizing costs of mapping and spatial data activities. To meet these objectives, standards must be established and wider geospatial data access must be provided. The FGDC also has been charged with coordinating geospatial data-related activities with other levels of government and with the public, private, and academic sectors. The FGDC is composed of 12 or more subcommittees, at least 5 working groups, and a coordination group (chairs of the thematic subcommittees and working groups and other Federal agency representatives).

Gap Analysis Program: The CBI administers the GAP. Gap analysis is a scientific method for identifying the degree to which native animal species and natural communities are represented in our present-day mix of conservation lands. Those species and communities not adequately represented in the existing network of conservation lands constitute conservation "gaps." The purpose of the GAP is to provide broad geographic information on the status of ordinary species (those not threatened with extinction or naturally rare) and their habitats in order to provide land managers, planners, scientists, and policy makers with the information they need to make wellinformed decisions.

Geographic information systems, remote sensing, image processing: In the areas of GIS, remote sensing, and image processing, CBI provides support and technical guidance to DOI bureaus on an ongoing basis. This support includes assistance in hardware/software installation and troubleshooting; assistance in the use of remote sensing and GIS applications software; development of technical specifications for contracted remote sensing and GIS work; database development or applications linked to specialized CBI hardware/software (e.g., large-format, high-resolution, cartographic-quality color scanner and plotter); and assistance in organizing, reformatting, and copying $\mathrm{Na}$ tional Park Service (NPS) legacy GIS data sets for eventual metadata development and serving through the NSDI Clearinghouse or NBII.

National Advanced Remote Sensing Applications Program activities (see "National Technical Means Program" section) employ a combination of GIS, remote sensing, image processing, and orthorectification capabilities available at the Secured Applications Facility (SAF) in Denver. The CBI is co-located with the SAF, and several CBI staff members have SAF access. The CBI maintains a workstation which performs analogous applications on unrestricted data for use by visiting or resident staff not able to use the SAF capabilities.

The CBI is working with the Yosemite Field Station in exploring image processing techniques to develop time-dependent signatures from six orthorectified Landsat TM scenes as a means for identifying/distinguishing fire fuel types within Yosemite National Park. 
The CBI is conducting a research project sponsored by the DOI-NASA Hyperspectral Steering Committee on the feasibility of using AVIRIS for detecting and mapping invasions of leafy spurge at Theodore Roosevelt National Park. This work is being conducted in partnership with NASA, UC-Davis, the NPS, and the U.S. Department of Agriculture (USDA) Agricultural Research Service.

The large-format, high-resolution, cartographicquality Tangent scanner is regularly used by other DOI bureaus for data acquisition. The NPS and the Bureau of Reclamation are currently the most intensive users. The $\mathrm{CBI}$ provides scheduling and training support.

A large-format ink-jet plotter is maintained by the CBI to produce draft hardcopies of maps to meet requests from parks and cooperating BRD centers in a timely manner. Its multiple GIS/image processing software capabilities, including orthophoto/digital elevation model (DEM) generation are also provided to other DOI bureaus and interested partners.

Global Positioning System: The center provides introductory/overview information on GPS technology, input to Frequently Asked Questions, status information on the use of GPS technology in the BRD, information on the function of the Denver DOI cooperative site for PPS receiver encryption, metadata guidance for PPS users, information and updates on intergovernmental coordination efforts (by phone, in hardcopy format, and on the CBI web site), and assists with purchasing of GPS units.

Interior Geographic Data Committee participation: Within the IGDC, BRD representation in the Remote Sensing Working Group is provided by CBI staff. Department-wide issues addressed by the Remote Sensing Working Group include DOI input to NASA space programs (Landsat, Mission to Planet Earth, EOSDIS, and others); DOI activities, procedures, and policies related to remotely sensed data and GPS technology; and DOI policies and procedures for acquiring, sharing, and archiving space-based data.

Landcover data: The FGDC LCD Working Group has been established to foster development of an integrated nationwide approach to mapping land cover and vegetation in the United States. This approach will maximize use of government resources to produce more complete and usable maps and data products. The LCD Working Group promotes development of compatible landcover data to allow multiagency and multilevel government use. This approach will help identify agency landcover data needs, activities, and sources of data and information for use in planning and producing new landcover data. The LCD Working Group will develop the means to facilitate sharing and consistent use of standards, protocols, and data sources and to facilitate partnerships. Landcover data requirements and activities will be integrated into the FGDC NSDI Clearinghouse. The Working Group will also maintain a link with the MultiResolution Land Characteristics Consortium to ensure coordination of objectives and activities through cross-committee membership.

Land Use History of North America Program: The $\mathrm{CBI}$ serves and updates the Land Use History of North America (LUHNA) Home Page, integrates incoming data sets, and facilitates tools development for data synthesis and presentation. The goals of the LUHNA program are to (1) produce a well-documented history of patterns of land-use and environmental change by the year 2000; (2) demonstrate the educational value of a land use history; (3) convey the utility of such a history in guiding future resource management decisions; (4) generate interest in and participation by public and private research organizations, educational institutions, grant makers, and the public; (5) provide a conceptual foundation for such an undertaking; (6) identify essential components of LUHNA, such as a grounding in quantitative methods that will permit comparisons between locations and identification of trends through time; and (7) identify the major areas of new research needed to integrate approaches taken by different disciplines, such as anthropology, environmental history, ecology, and remote sensing.

The LUHNA program involves collaboration by a wide variety of individuals and agencies, both within and outside government. The BRD has been serving as convener, organizer, and home base for the project, providing the communication forum needed to develop the necessary interdisciplinary relationships. New and evolving computational and statistical tools are used to combine data from different sources and to extrapolate from a few points to larger geographic regions. The BRD will solicit statistical and computer science expertise to guide project development and ensure maximum benefit of these data integration tools. The initial LUHNA pilot studies are completed and summaries are published on the LUHNA web site at http://biology.usgs.gov/luhna/. A directory of LUHNA project cooperators and a bibliography of related publications have been assembled.

Metadata assistance: Office of Biological Informatics and Outreach and CBI staff facilitate assistance for metadata encoding through a NASA Cooperative Agreement for BRD science centers. Staff members of $\mathrm{CBI}$ and $\mathrm{OBIO}$ also serve as liaisons for State and regional government agencies, nongovernment 
organizations, and professional societies to further the development of NBII by helping to make their data and metadata accessible.

Metadata Content Standard for NBII: The CBI spearheaded the creation of, interprets, and updates the Content Standard for NBII Metadata. The term "metadata" refers to data used to describe a database (e.g., extent, coverage, scale, data collection methods, by whom and when the data were collected). Valid and complete metadata provide potential users with enough information about a database (without personal communication with the owner of the data) to determine whether a particular database would be useful for their purposes. As part of this effort, the American Institute of Biological Sciences reviewed and issued a report on the strawman Metadata Content Standard for NBII (Maroney 1995). The current Draft Content Standard for NBII Metadata (National Biological Service 1995) is based on the FGDC Content Standards for Digital Geospatial Metadata (Federal Geographic Data Committee 1994). The CBI, in coordination with the FGDC Biological Data Working Group, is leading efforts to update the Metadata Content Standard for NBII into a formal FGDC metadata profile for biological data based on the draft FGDC Content Standards for Digital Geospatial Metadata (revised March 1998).

Metadata training: Center for Biological Informatics and OBIO staff members provide training in and consultation on MetaMaker, a Windows application designed to standardize the format of metadata information. MetaMaker was developed by the USGS and is available to users at no cost through the NBII at http:// www.nbii.gov/metamaker/metamaker.html. Metadata workshops for NBII normally cover metadata and clearinghouse concepts, NBII/FGDC metadata structure, MetaMaker operation, NBII/FGDC metadata content, metadata preparsing and parsing operations, clearinghouse use, and metadata development and consistency. These workshops are open to all Federal, State, and local agencies, museums, universities, private organizations, and other potential data sharers. The workshop student workbook is available at $\mathrm{ftp}: / /$ ftp.cbi.usgs.gov/pub/nbii/nbiiwbk.wpd.

National Biological Information Infrastructure: The goal of the NBII is to establish a distributed federation of biological data and information sources, relying on a network of Federal, State, and local government agencies, as well as private organizations and cooperators to provide information on and access to biological databases, information products, directories, and guides. The NBII works with others to put biological data and information online; an inhouse infrastructure allows data sharing and creation of metadata to facilitate data discovery.
The CBI and OBIO coordinate and serve the NBII World Wide Web (WWW) pages, construct the inhouse infrastructure, establish partnerships with states and other organizations, create metadata standards, and develop tools to facilitate distributed computing and online data analyses.

National Spatial Data Infrastructure Geospatial Data Clearinghouse: Several CBI staff members are active participants in the FGDC NSDI Clearinghouse Working Group. The NSDI encompasses policies, standards, and procedures for organizations to cooperatively produce and share geospatial data. The FGDC has led the evolution of the NSDI in cooperation with State and local governments, academia, and the private sector. The CBI staff members coordinate the NBII Metadata Clearinghouse as an active node within the NSDI Geospatial Data Clearinghouse.

National Technical Means Program: Center for Biological Informatics staff members apply National Technical Means (NTM) Program technology in support of BRD projects. Through the National Advanced Remote Sensing Applications Program (NARSAP), the USGS assists civilian Federal agencies requiring access to classified data and technologies. Data applications research is performed through the NTM Program, which provides data and technology to civilian agencies. This assistance is coordinated through the Civil Applications Committee (CAC) and reports to the Director of Central Intelligence. The CAC provides a forum for civilian agencies to coordinate tasking requirements, applications, and research pertaining to the use of classified data. The CAC also provides secure facilities and equipment for application of the data in meeting Federal agency needs. The CBI participates in NARSAP projects, and several CBI staff members have access to the secure facilities.

The CBI has obtained equivalent software and hardware for analogous operations and applications outside the secured facilities. Current and proposed NTM projects include support of NPS vegetation mapping at Joshua Tree National Park, development of technologies for fire behavior prediction, and monitoring of noxious invasive weeds.

National vegetation standards: Center for Biological Informatics staff members have served on the FGDC Vegetation Subcommittee since its formation in early 1990. The objective of the FGDC Vegetation Subcommittee is to provide governmentwide leadership in coordinating multiagency interests in vegetation data. This effort includes facilitating the exchange of information and transfer of data; establishment and implementation of standards for quality, content, and transferability; and coordination of the collection of spatial data to minimize duplication where 
practicable and economical. The Subcommittee was established to promote standards of accuracy and timeliness for vegetative data collection financed in whole or in part by Federal funds, to exchange information on technological improvements for collecting vegetative data, to encourage the Federal and nonFederal community to identify and adopt standards and specifications for vegetative data, and to collect and process the requirements of Federal and nonFederal organizations for vegetative data.

NBII Metadata Clearinghouse: Staff members from CBI and OBIO coordinate the NBII Metadata Clearinghouse function and content. They also coordinate the submission of metadata to the NBII Metadata Clearinghouse from BRD offices and cooperators. The NBII Metadata Clearinghouse functions as a node within the NSDI Geospatial Data Clearinghouse but does not limit the metadata documentation to geospatial data. The NBII Metadata Clearinghouse is available at http://www.nbii.gov/clearinghouse.html

NBII tools development: Under the NBII Tools Development Initiative, online tools for network-based applications and analyses are being developed. This work supplements the more traditional mode of operation in which users download data sets to their own sites for conventional stand-alone analysis. The OBIO is cooperating with the San Diego Supercomputer Center to develop tools to run online ecological models.

Rocky Mountain Mapping Center: The CBI is colocated with the National Mapping Division's Rocky Mountain Mapping Center at the Denver Federal Center in an environment which fosters interdivisional, multifaceted technology development in geospatial data collection and analysis.

Standards development for biological resources management: The CBI is developing and maintaining standards for national vegetation classification and mapping and NBII metadata (see "Metadata Content Standard for NBII" section) which have been or are being formalized through the FGDC standards process. The $\mathrm{CBI}$ also reviews standards produced by others via this same FGDC standards process. As part of the NBII, CBI staff members are working cooperatively with other agencies and organizations on developing, adapting, and refining standards to allow users to access, compare, exchange, analyze, evaluate, and use a variety of data and information sets throughout a widely distributed electronic federation of sources. Standards for biological data (such as taxonomic nomenclature standards and national vegetation classification and mapping standards) and metadata (Metadata Content Standard for NBII) will help users compare and exchange data.
U.S. Geological Survey-National Park Service Vegetation Mapping Program: The major focus of this program is to obtain uniform, consistent baseline data on the composition and distribution of vegetation cover types for each of the Park units in the NPS Inventory and Monitoring Program. Since 1993, a partnership has been maintained with the NPS for developing and implementing vegetation cover mapping in 250. parks and other NPS units. These data will be used for various purposes at the park, regional, and national levels and, therefore, must be (1) consistent in detail and accuracy and (2) made available in a format that allows for ready transfer to various GIS databases within the NPS and elsewhere. This program is managed by the CBI in cooperation with the NPS. The CBI awards contracts, sets standards and protocols, performs quality assurance/quality control (QA/ $\mathrm{QC}$ ) on the data, manages the final database, and serves the data via the WWW. Work is being performed under contract with private and nongovernment organization (NGO) vendors in cooperation with other governmental organizations.

\section{Environmental and Contaminants Research Center, Columbia, Missouri \\ Expertise or specialization}

Aquatic ecology (freshwater)

ARC/INFO

Behavioral ecology (aquatic)

Behavioral toxicology

Database administration

Ecosystem ecology

Environmental chemistry

Environmental toxicology

Estuarine ecology

Field ecology

Field mapping and cartography

Fish ecology

Geospatial statistics

GIS analysis

GPS technology

Habitat analysis

Herpetology

Hydrographic survey

Invertebrate ecology

Landscape ecology

Organic/inorganic chemistry

Population dynamics

Quantitative ecology

Radiotelemetry

Remote sensing

Risk assessment

Sonic telemetry

Statistical analysis 
Status and trends

Terrestrial ecology

Wildlife ecology

\section{Applications}

Aquatic macroinvertebrate characterization

Bathymetric mapping

Endangered species studies

Environmental contaminants research

Floodplain geomorphology evaluations

Floodplain restoration planning

Hydroacoustic sediment mapping

Hydrographic surveys

Inventory and monitoring

Landcover mapping

Lower Missouri River Ecosystem Initiative

Lower Rio Grande Ecosystem Initiative

Microscale image analysis

Missouri River hydrography

Operation of GPS base station

Plant distribution surveys in Laguna Madre

Public lands mapping

Sea turtle movement tracking

Sediment quality assessment surveys

State-wide landcover mapping, Missouri

Surface water quality studies

Tracking sturgeon

Trout distribution and movement determination

\section{Highlights}

Aquatic macroinvertebrates: The Environmental and Contaminants Research Center (ECRC) is using artificial substrates and other sampling methods to characterize aquatic macroinvertebrates in the lower Missouri River. Global Positioning System units are being used to locate the samplers and specific habitats being surveyed by other methods. Studies are being conducted to examine longitudinal differences in community structure, to determine relative quality of habitats, to compare large river sampling methodologies, and to document the distribution of rare species.

Community base station: The ECRC operates a Trimble 12-channel Maxwell-based community base station that provides access to cooperating partners and agencies within a 300-mile radius of Columbia, Missouri. Modem access to the compressed 1-h data files will be augmented via the Internet through the ECRC Home Page.

Endangered species: The ECRC is assessing the effects of anthropogenic factors on ecosystems supporting the Neosho madtom (Noturus placidus). The objective is to determine the extent to which anthropogenic factors such as reservoir operation, gravel mining, and especially historical mining and mining site remediation may influence the distribution of $N$. placidus, a federally listed threatened species. The ECRC is using Rockwell Precision Lightweight GPS Receivers (PLGRs) to locate gravel bars from which abiotic and biotic data are collected. The information collected with the PLGRs is used to reference the sites in space and time.

Environmental contaminants: Biological Resources Division personnel located at Texas A\&M University, College Station, are conducting analyses of environmental contaminants in the Lower Rio Grande Valley in association with the USGS BEST program. Data on the distribution of contaminants in the region are being automated to facilitate analysis of patterns and identification of contaminant "hot spots" using GIS.

Floodplain geomorphology: The ECRC Environmental Technology Center is converting postflood (1993) Missouri River scour hole (blue hole) bathymetry collected by the Natural Resources Conservation Service from AutoCad (.DXF) to ARC/ INFO format. The data will be used by the Missouri Department of Conservation and the Missouri Cooperative Fish and Wildlife Unit to evaluate the longevity of these off-channel habitats as part of a multiyear investigation into the benefits of habitats created as the result of the 1993 flood.

Floodplain restoration planning: The ECRC Environmental Technology Center, in conjunction with the Missouri Cooperative Fish and Wildlife Unit, is investigating the use of historical landcover information to define the active channel zone on the Missouri River floodplain in Missouri. This information is being generated to provide State and Federal agencies involved in land acquisition with some indication of the management potential of floodplain lands based on historical geomorphology and hydrologic/ hydraulic activity.

Hydroacoustic sediment mapping: The ECRC is currently discussing the addition of a sediment mapping capability to the center's existing hydrographic survey activity with State and Federal partners.

Hydrographic survey: The ECRC Environmental Technology Center is converting the USACE 1994 Missouri River hydrographic survey from Intergraph (.DGN) to ARC/INFO format. Survey data cover the river from Rulo, Nebraska, to St. Louis, Missouri. The information will be used by the Missouri Department of Conservation to validate a sampling design (catfish) using wing dam and revetment information (habitat). These data will also be used as a base for the collection of Missouri River bathymetry supporting pallid sturgeon research conducted by ECRC scientists. 
Inventory and monitoring: The ECRC is using Trimble Pro-XLs to map channel changes (land-water interface) and bathymetry along a newly formed Missouri River chute throughout the water year. Biotic communities are also being inventoried and include juvenile and adult fishes, reptiles, amphibians, invertebrates, birds, and vegetation.

Land cover: The ECRC Environmental Technology Center has developed a landcover data layer for Missouri counties adjacent to the Missouri River from Kansas City to St. Louis, in support of the Big Muddy National Fish and Wildlife Refuge environmental impact statement process.

Lower Missouri River Ecosystem Initiative: In 1994, the ECRC received 3-year funding to provide GIS assistance to and facilitate information transfer among the State and Federal agencies involved in rehabilitation and management of the lower Missouri River and its floodplain. Several of the projects listed below are funded or partially funded by this ecosystem initiative. The funding has allowed ECRC to develop spatial analysis capabilities, establish Internet access, and create a Missouri River home page accessible through the ECRC web site. Spatial data assembled by the SAST on the 1993 flood and realtime hydrographs are also available. The ECRC Environmental Technology Center compiled a comprehensive bibliography for the Missouri River basin as part of the initiative. This bibliography includes a keyword index and references which will be searchable through the ECRC home page.

Lower Rio Grande Ecosystem Initiative: During 1995, ECRC assumed primary responsibility for BRD research efforts pertinent to the Lower Rio Grande region. Although ECRC is coordinating research activities for a broad array of issues, including endangered habitat assessments and contaminant identification, the center is also overseeing efforts to conduct a GAP project in Mexico adjacent to the Rio Grande. These efforts will be complementary to the GAP efforts being conducted in Texas by Texas Tech University's Cooperative Research Unit. The Mexico/ Rio Grande GAP project seeks to place the lower Rio Grande in a geographic/ecological context that incorporates land use/land cover, land management, vertebrate species distributions, and biodiversity indices. The project involves analysis of Landsat TM scenes and creation of GIS layers using museum records of species distributions and a variety of other sources. This project is the first officially designated international GAP project and is a cooperative effort between Mexico's agency CONABIO and the USGS BRD. After completion of the Rio Grande project, CONABIO will finance and oversee the extension of the GAP project for the remainder of the Mexico Rio Grande border area.

Microscale image analysis: The Histology Laboratory of the Biochemistry/Physiology Branch at ECRC has developed a microscopic image analysis capability. Equipment consists of an inverted Nikon Diaphot microscope with motorized stage and black-and-white video camera. An additional feature is a low light (night scope) adapter used in conjunction with a xenon light source for fluorescence measurements. The hardware is integrated through customized software such that stage movement, wavelength selection, and image capture can be controlled from one computer screen, allowing for complete automation. Image analysis is provided through Optimas software. Currently, research being conducted using these capabilities includes cellular effects of chemical induction of apoptosis (programmed cell death) and the effects of endocrine disrupting chemicals on sexual differentiation of primary germ cells in newly hatched fish.

Missouri River hydrography: The ECRC Environmental Technology Center is developing a hydrography layer for the Missouri River and major tributaries, from Yankton, South Dakota, to St. Louis, Missouri, for the Lower Missouri River Ecosystem Team (Region 3) of the USFWS. The information will be used to aid in the Big Muddy National Fish and Wildlife Refuge planning process and for the evaluation of cumulative impacts.

Pallid sturgeon habitat studies: Hydrographic survey data are currently being used at the ECRC to assess habitat used by pallid sturgeon (Scaphirhynchus albus) in the lower Missouri River. Several pallid sturgeon have been implanted with ultrasonic telemetry transmitters. The ultrasonic receivers, equipped with directional hydrophones, allow investigators to pinpoint the location of sturgeon in the river to within 2-3 $\mathrm{m}$ of their actual position. Using the same submeter GPS equipment as used with the depth sounder, investigators accurately record the coordinates of the fish's position and the prevailing habitat conditions. The area is then surveyed using the hydrographic survey system. Data are processed and a three-dimensional visual representation produced. Coordinates corresponding to the location of the sturgeon are then placed on the resulting map. The final product allows biologists to obtain information about the fish's surrounding environmentinformation not available when collecting only habitat information at the point of location. In addition to being a tremendous visualization tool, hydrographic data can now be incorporated into classification 
systems and spatial models relating habitat use and physical habitat features.

Plant distributional surveys in Laguna Madre: Researchers use GPS in seagrass distributional surveys in Laguna Madre, Texas, most particularly to document the effects of light reduction by a persistent phytoplankton bloom. In another GPS application, the possibility is being investigated that hydrological change brought about by dredge deposits is responsible for the invasion of wind-tidal flats by vascular vegetation at Laguna Atascosa National Wildlife Refuge. Biologists are concerned that the shift in habitat may be detrimental to endangered piping plovers and other shorebirds.

Public lands: The ECRC Environmental Technology Center is developing a public lands data layer for the Missouri River within the State of Missouri for the Lower Missouri River Ecosystem Team (Region 3) of the USFWS. This information will be used to aid in the Big Muddy refuge planning process.

Resource monitoring and mapping: The ECRC uses GPS technology to locate field sampling sites and for bathymetric mapping applications. Future uses will include mapping, field verification, and inventory. Real-time positioning, differential processing, and realtime differential processing technologies are used.

Sea turtle movement: The Padre Island Field Station is currently using implanted satellite tags to follow the long-term and long-distance movements of several green sea turtles captured at Mansfield Channel, Texas, during a directed capture netting study.

Sediment: The Texas Gulf Coast Field Station uses GPS in all sediment quality assessment surveys and plans to use GIS technology to map and assess the data from these same surveys.

State-wide landcover mapping, Missouri: The ECRC helps to develop State-wide landcover data through participation in the Missouri Resource Assessment Partnership (MoRAP). The partnership is co-located in the Environmental Technology Center at ECRC. A landcover and land-use data layer is currently being developed using Landsat TM satellite data. In order to complete this process, a hierarchical unsupervised classification approach had been adopted. Level $I$ in this hierarchy includes open water, urban, cropland, grassland, and forest. A Level II classification, including up to 30 or more classes, is scheduled for initiation.

The land-use/landcover database will serve the needs of GAP and other initiatives. Current users of the landcover data include the Missouri Department of Conservation, the Natural Resources Conservation Service (NRCS), the U.S. Forest Service (USFS), the USFWS, and regional planners. New initiatives for 1997 included a joint venture with the
Missouri Department of Natural Resources and the U.S. Environmental Protection Agency (USEPA) to determine the utility and cost effectiveness of identifying wetlands using a number of different sensors (SPOT, TM, photographs/photogrammetry, Indian satellite data) and a project with the University of Missouri designed to determine the utility of photogrammetry for the development of high accuracy (horizontal and vertical) digital elevation models for watershed applications.

Surface water quality: The ECRC Environmental Technology Center, in cooperation with the USDA Agricultural Research Service, is studying the relationship between hydrologic and topographic features and herbicide contamination of northern Missouri streams under runoff and baseflow conditions. Regional-scale properties influencing the magnitude and duration of herbicide concentration spikes during runoff events is also being investigated using GIS tools. Improving the understanding of landscape-scale factors that influence herbicide concentrations in streams will provide resource managers, planners, and environmental regulatory agencies with criteria for identifying streams that are vulnerable to herbicide contamination.

Trout distribution and movement: Staff from the Jackson Field Research Station have been investigating movement patterns and habitat use of native Snake River cutthroat trout in the Upper Snake River, Wyoming, including Grand Teton National Park. Resource managers are concerned with the effects of winter conditions and low stream flows on habitat availability and behavior of trout in this tailwater fishery. Using radiotelemetry, the movements and habitat use of adult trout are being monitored. The results of this study. will provide resource agencies, including the Wyoming Game and Fish Department, U.S. Bureau of Reclamation, Teton County Natural Resource District, USACE, and the NPS, with information necessary for the continued maintenance of this fishery and for implementing habitat improvement projects. Fish locations have been fixed by using precision GPS units, and these locations have been compiled in a GIS system to create detailed maps of individual fish during the study period.

Personnel from the ECRC Jackson Field Research Station will investigate the distribution of trout in the Firehole River with radiotelemetry and spawning and population surveys. An extensive survey of the water quality in the Firehole River will also be performed and the physiological status of resident trout will be studied. Global Positioning System and GIS technologies will be used extensively in this project. Precision GPS units will be used to accurately fix fish positions during the telemetry study; to fix sites for water 
quality, trout population, and stream habitat measurements; and for documenting spawning redd locations. These data will be compiled in a GIS system to create maps of fish movements, hydrogeochemical maps of the Firehole River, habitat and population distributions, and spawning redd distributions. These products will be critical in analyzing how the trout population responds to trends in the geochemical regime of the drainage.

\section{Environmental Management Technical Center, Onalaska, Wisconsin}

\section{Expertise or specialization}

Aerial photointerpretation

Aquatic ecology

ARC/INFO

Botany

Cartography

Database administration

Ecology

Fisheries biology

Forest biology

Geospatial and statistical analysis

GIS analysis

GPS technology

Inventory and monitoring

Mapping

Modeling

Networking

Photogrammetry

Plant ecology

Programming

Remote sensing

Technical editing

Water quality

Wildlife biology

Zoom Transfer Scope operation

\section{Applications}

Automation of historical surveys of the Upper Mississippi River System (UMRS)

Bathymetric (water depth) data sets using an automated hydro survey boat

Biomonitoring Environmental Status and Trends (BEST) Program pilot project

Collection of 1:15,000-scale color infrared aerial photography of the UMRS floodplain

Environmental Protection Agency Region 5 Inland Waterways Spill Response Mapping Program

Georeferencing of Long Term Resource Monitoring Program (LTRMP) data sets: fisheries, macroinvertebrates, sediment surveys, vegetation, water quality

Geospatial data, technology training, and technical assistance to U.S. Fish and Wildlife Service (USFWS) refuges in Region 3
Landcover/land-use data sets for the UMRS floodplain Management Strategy for Migratory Birds on the UMRS Modeling potential for wind effects (fetch) on the UMRS

Modeling sediment and chemical outputs from agriculture watersheds in the UMRS basin

Scientific Assessment and Strategy Team (SAST) project participation

Technology feasibility assessments (photointerpretation/automation techniques, imaging technology)

Training in ArcView GIS version 3.0a

Upper Midwest GAP project coordination

U.S. Army Corps of Engineers (USACE) navigation studies

USGS-NPS Vegetation Mapping Program

\section{Highlights}

The Environmental Management Technical Center (EMTC) is involved in a variety of geospatial projects that use GIS, remote sensing, and GPS technologies. The EMTC manages the largest river-related inventory, monitoring, research, spatial analysis, and information sharing program in the United States (the Long Term Resource Monitoring Program for the Upper Mississippi River System (LTRMP)). Other cooperative programs include coordination of the Upper Midwest GAP project, providing database development and cartographic support to the USEPA Region 5 Inland Waterways Spill Response Mapping Program, and technical and cartographic support to the $\mathrm{Na}$ tional Park Vegetation Mapping Program. Staff at the EMTC have extensive experience in a variety of technical areas, including photointerpretation, photogrammetry, geospatial and statistical analysis, and programming.

Base station and bulletin board service: The EMTC has established a GPS base station and set up a bulletin board service. Many BRD centers routinely use GPS to locate field sampling points and to establish precise control points for photogrammetric applications. The EMTC has also used GPS technology in an automated hydrosurvey system to produce bathymetric data over portions of the Upper Mississippi River.

Biomonitoring of Environmental Status and Trends Program: The EMTC is creating an interface for the BEST Program. This interface will consist of registered aerial photos and spatially located data using hypertext documents. National wildlife refuge managers can access the data via the Internet and can interact with data showing the location of potential environmental hazards and resources.

Collection of aerial photography: The EMTC conducts aerial photo missions for other USGS divisions, NPS, USFWS, USACE, and State wildlife management agency projects in and near the Upper Mississippi River 
floodplain. Flight planning software allows rapid and efficient aerial photo mission planning and creation of a list of coordinates for navigation by airborne GPS. The EMTC currently maintains a library of over 15,000 aerial photos, including historical aerial photos from 1938 and later and photos taken by the EMTC.

Development of ARC Macro Language applications: Production ARCEDIT (PAE) is a UNIX-based ARC Macro Language (AML) application which presents the user with a menu-driven subset of the ARC/INFO module ARCEDIT functionality. It is designed for basic production work: digitizing, editing, and attributing. The application is specifically targeted at beginning users. Many of the details of ARCEDIT are hidden from the PAE user and many of the more complex features are not included. The learning curve for production work is substantially shortened by providing the new user with a friendly and consistent graphical user interface and a small subset of the core ARCEDIT commands. This application has been distributed widely and is currently the main digitizing, editing, and attributing tool adopted by many Federal offices.

The Aquatic Habitat Analysis and Visualization Tool is a UNIX-based AML application developed to provide investigators with an adaptable GIS application to facilitate analysis and visualization of the dynamic mosaic of aquatic habitat patches that occur in the UMRS. This application incorporates spatial data about aquatic habitats in study areas and allows the user to interactively define specific aquatic habitat types, analyze the spatial and temporal occurrence of the habitat patches, and visualize the results. The simple graphical user interface provided can be used effectively with no training or prior GIS knowledge. Phase 1 of this project was completed using data from the Finger Lakes region in Navigation Pool 5 of the UMRS. Phase 2 is currently under way and will incorporate flow velocity and flow direction data from hydraulic models for the Pool 8 study area.

The LTRMP Component Database Spatial Query Tool, an AML application, was developed to automate integration of component data with spatial data. The EMTC stores point-sampled data for fisheries, water quality, and invertebrates in a relational database management system. These component data are collected at fixed and random sites in each of the key LTRMP study pools: 4, 8, 13, 26; the open river reach of the Mississippi River; and La Grange Pool on the Illinois River. The geographic locations of these data are also collected and stored. This application facilitates creation of spatial subsets and visualization of the distribution of sites meeting certain query criteria. The UNIX version of the LTRMP Component Database Spatial Query Tool is an ARC/INFO AML application that integrates the component data with the spatial data by using the graphical display and query capabilities of ARC/INFO. The application features an easy-to-use graphical user interface and requires only very basic knowledge of GIS to use effectively. The PC version of the LTRMP Component Database Spatial Query Tool is an ArcView 2.1 project that integrates the stratified random sampling component data with spatial data by taking advantage of the built-in functionality of the ArcView system. Like its UNIX counterpart, this application also facilitates creation of spatial subsets and visualization of the distribution of sites meeting certain query criteria. A subset of the total number of fields for the component data is included in the PC version, making it substantially easier to construct queries.

The EMTC uses a UNIX-based AML application to generate all stratified random sampling locations for fisheries, water quality, and invertebrates. The application provides a graphical user interface which facilitates easy changes in sampling allocation in different strata. The output from this application is an EPPL7.tag file. The tag file, in conjunction with an EPPL7 mapping routine developed at the EMTC, allows individual field stations to produce hardcopy maps of primary and secondary sites prior to each sampling episode.

Effects of land-use change on water quality: The EMTC is initiating a basinwide study using large-extent spatial databases such as digital elevation models, soil databases, and landcover databases derived from the Gap Analysis Program to investigate the effects of changes in land use on water quality and the effects these water quality changes have on downstream ecosystems. This interagency, multiyear study will have profound effects on how we perceive the interactions between the uplands and the river.

Geospatial technology training: The EMTC provides ARC/INFO GIS training on a quarterly basis. The course and training manual developed by the EMTC are used in training offered by both the EMTC and the NWRC on a regular basis. Other geospatial technology training is also offered at the EMTC, such as in EPPL7, GPS, and photointerpretation.

Inventory and monitoring: Georeferencing of LTRMP field data methodologies includes collection of autonomous GPS data, postprocessed differential GPS data, real-time differential GPS data, and PPS data. Acceptable accuracies are project-related and vary. Sampling projects include vegetation, water quality, fisheries, and macroinvertebrate monitoring, as well as icthyoplankton and sediment analysis.

To assist crews navigating to stratified random sampling sites, the EMTC is in the process of converting from autonomous GPS receivers to real-time differential 
GPS receivers.

Global Positioning System technology is used by crews navigating to and through bathymetric data collection sites (involves use of real-time differential GPS data, or PPS GPS data). This technology is also employed in georeferencing aerial photography, whose interpreted data will be automated using an automated stereo zoom transfer scope (ZTS). The ZTS currently requires postprocessed differentially corrected data, but real-time kinematic data may be used in future projects.

Investigations into emerging technologies: In an effort to quickly and efficiently supply information to floodplain managers, the EMTC is studying the usefulness of emerging remote sensing technologies in creating spatial data. Current efforts include the assessment of videography and hyperspectral airborne scanners to create spatial databases. Center researchers will use neural networks to accurately classify imagery in an efficient manner.

Spatial databases assembled by the EMTC are written to CD-ROM to make them more accessible to river managers and researchers who may not have access to the EMTC's UNIX system. The data on these CDs are readable in both ArcView 1 and ArcView 2. ArcView is provided on the $C D$ for users who may not have access to GIS software.

Landcover classification: The EMTC has classified the land cover of the UMRS floodplain using Landsat TM imagery taken in 1989. This systemic database has been used for many analyses, including determining the longitudinal changes in land cover in the floodplain from north to south and the extent that the levee system has cut off the floodplain from the river. The EMTC has also analyzed the usefulness of SPOT imagery for floodplain mapping and undertook a study using Multi-Spectral Scanner (MSS) data to look at systemic landcover changes over a 25-year period.

Long Term Resource Monitoring Program: Spatial databases have been created from historical data sets of large portions of the Upper Mississippi River System (UMRS) for use in trend analysis. General Land Office survey maps dating to the early nineteenth century have been automated, creating a general picture of the floodplain prior to the large-scale changes in land cover that occurred later. In addition, maps covering large reaches of the floodplain have been automated using Mississippi River Commission surveys completed at the end of the nineteenth century; these maps show general landcover classes.

Bathymetric data are collected for the LTRMP using an automated hydrosurvey system and portable chart recorders, then combined with shoreline data from photointerpreted GIS coverages. The ARC/ INFO TIN module is used to interpolate a continuous surface from these collected data, which are then converted to ARC/INFO GRID format. Complete databases exist for UMRS Navigation Pools 4, 8, 13, and 26, as well as for Lake Onalaska in Navigation Pool 7.

The EMTC is performing an analysis of change in land cover over a 180-year period for extensive reaches of the floodplain using the spatial databases described above. These analyses will be used to predict future conditions of the river to assist decision makers in managing the floodplain.

A statistically sound, easy-to-perform method to quantify the spatial accuracy of point data collected with GPS technology has been developed by the EMTC. This work has been published in the center's technical report series and presentations have been made at professional meetings (e.g., the Second $\mathrm{Na}$ tional Conference on Spatial Accuracy).

Management Strategy for Migratory Birds: Since 1993, the EMTC has been providing technical support to the USFWS Region 3 project for the management of migratory birds within the UMRS corridor. Phase 1 was a pilot project to determine the feasibility of using existing scientific documents and a GIS to locate potential habitat. Literature searches were conducted by USFWS Region 3 and the Upper Mississippi Science Center. All data were sent to the EMTC, where they were compiled and modeled. Potential habitat coverages were created for 17 species of birds, and biologists were provided with spatial interpretation of their data. During 1994, groundtruthing of computer models began. The EMTC participated by using a custom interface program to generate random sampling sites and to provide map products. This migratory bird project has expanded into the Management Strategy for Migratory Birds on the Upper Mississippi River (Korschgen et al. 1996). One of the goals of the Management Strategy is to collect and distribute available GIS data for the UMRS. The EMTC is providing technical and programming support.

MetaMaker: Through a cooperative effort with the Midcontinent Ecological Science Center and the OBIO, the EMTC developed a metadata data entry program, MetaMaker, that allows users to enter metadata in compliance with the FGDC Content Standard for Digital Geospatial Metadata and the NBII Content Standard for National Biological Information Infrastructure metadata. MetaMaker uses Microsoft Access, a PC-based database management system. MetaMaker can be used to collect metadata for biological data and information of all types, including explicitly geospatial biological data; biological data that are not explicitly geospatial (such as those resulting from in vitro research); and biological information products (such as research publications, 
bibliographies, or lists of experts). MetaMaker can also be used to collect FGDC-compliant metadata for nonbiological geospatial data. MetaMaker's capabilities include printing reports, built-in query functions, import/export capabilities, and output to the format required to enter metadata into the NBII Metadata Clearinghouse. The compiled version and user guide can be downloaded via the Internet at no cost from http://www.nbii.gov/metamaker/metamaker.html.

Navigation studies: The EMTC provides technical and GIS support to USACE navigation studies. In 1995, the EMTC conducted a pilot project to determine if a GIS could be used by the USACE to collect data for their hydrology models. Since then, the USACE has implemented EMTC data processing procedures to collect similar data within other areas of the UMRS.

NBII Metadata Clearinghouse: The EMTC hosts the NBII Metadata Clearinghouse at http://www.nbii.gov/ clearinghouse.html. Staff at EMTC coordinate, update, and customize the clearinghouse web interface and serving software. The NBII Metadata Clearinghouse functions as a node within the NSDI Geospatial Data Clearinghouse, but also includes metadata descriptions of data sets and information products that are not explicitly geospatial. It includes metadata descriptions of biological databases and information products developed and maintained by USGS scientists, as well as data and information developed and maintained by other NBII participants, including Federal, State, and local government agencies; private sector organizations; and other partners around the Nation and the world.

Neotropical migratory birds and amphibians in the Upper Midwest: The EMTC is creating GIS databases for researchers doing work on Neotropical migratory birds and amphibians in Wisconsin, Minnesota, and Iowa. These databases are created by the EMTC from original aerial photography and show land cover and land use for monitoring plots. This original research will document populations of birds and amphibians in the Upper Midwest.

Research activities: The EMTC is planning to extend its research activities beyond the Upper Mississippi floodplain, in cooperation with the USEPA and St. Mary's University of Minnesota. From LTRMP studies, researchers found that the Upper Mississippi floodplain is receiving large quantities of sediment load from its watersheds. High nitrate levels have been found in the irrigated sand plains of the Wisconsin and Minnesota watershed as a result of intensive agriculture. In response to growing degradation of river water quality, the EMTC is developing several proposals. In this new effort, the EMTC will undertake the following research activities:
- Existing water quality data will be collected from various agencies and made available to researchers. Based on the availability of data and preliminary studies of the watersheds, a set of potential sites will be identified as water quality monitoring stations. Monitoring stations will collect water quality data (e.g., sediment, nitrate, pesticides) at regular time intervals. The collected data will be stored in the EMTC's public ftp sites in a usable format.

- A map showing the Upper Mississippi watershed and its subwatersheds will be delineated using existing monitoring stations.

- A GIS database consisting of land use, tillage practices, soil type, and slope will be developed for selected subwatersheds. Land use and tillage practices will be derived from Landsat TM data. Slope will be derived from existing USGS digital elevation models. A soil map will be extracted from the STATSGO soil database, which is available in ARC/INFO format. Soil characteristics will be extracted from the Map Unit Use File, a PC-based soil database, using map unit identification as the index.

- The existing water quality simulation models will be evaluated based on the literature, and a suitable model will be selected for predicting agricultural impacts on the Upper Mississippi River at daily, monthly, seasonal, and yearly intervals. The predicted results will be compared with the observed data for calibration.

- The calibrated model will be made available to watershed managers as a potential forecasting tool for determining ecological consequences of landuse changes at the watershed level.

- Preparing and upgrading landcover maps for the Upper Mississippi River floodplain is one of the objectives of the LTRMP. Many traditional computer classification techniques (e.g., unsupervised, supervised, hybrid) are available for preparing landcover maps from remotely sensed data. However, the recent literature has shown that landcover maps developed using neural network classifiers are more accurate than those developed using traditional classifiers; the EMTC is investigating the use of neural network classifiers for landcover map generation and upgrading. After preliminary studies, a funding proposal will be developed if this technique is found suitable.

Scientific Assessment and Strategy Team participation:

The EMTC participated on the SAST, an interagency team which assembled a 250-GB database on the 1993 Midwest flood and performed scientific analyses on the flood's effects. The EMTC supplied two senior 
GIS scientists, as well as extensive data holdings, and performed analyses on the effects of the flood on floodplain habitats. The center is involved in the creation of a Mississippi River Basin spatial database covering the Upper Mississippi and Missouri Rivers as an extension of the SAST effort. This database will be an interagency and interstate cooperative effort, which will use the latest communication, GIS, and database technology. The EMTC is coordinating the initial scoping efforts and will be involved with implementation.

Sea Lamprey Control Program: The EMTC has provided training, automation of several navigation charts (St. Mary's River), and technical support and is one of three sites currently working on the St. Mary's River Treatment Modeling Project. During the past 3 years, the USFWS Marquette Biological Station (Marquette, Michigan) has used GIS technology in the Sea Lamprey Control Program for the Great Lakes. An interface program is being created that will input results from stream flow and population models, then produce products requested by biologists.

Upper Midwest Gap Analysis Program: Upper Midwest GAP coordination efforts have been expanded to include the state of Illinois, and the EMTC is also working with Indiana and Iowa to encourage regionally compatible vegetation classifications. All TM scenes necessary for classification of Michigan, Minnesota, and Wisconsin have been obtained. Scenes were reviewed at the EMTC for quality control and were converted to an ERDAS Imagine format before being distributed to State partners. The Departments of Natural Resources of Minnesota and Wisconsin are in the process of classifying scenes for their respective states. Michigan is contracting to classify the northern half of the Lower Peninsula. The EMTC has retained responsibility for classification of the Upper Peninsula of Michigan and is currently engaged in that effort.

Upper Mississippi River floodplain mapping: The EMTC is mapping the floodplain of the Upper Mississippi River through flight planning, collection of 1:15,000 color-infrared (CIR) aerial photos, interpretation of floodplain vegetation, and data automation. Annual aerial photography of the UMRS is collected using a large-format mapping camera $(1,000-1,500$ aerial photographs annually). Photographs collected in 1989 and 1994 cover the floodplain of the UMRS from Cairo, Illinois, to St. Paul, Minnesota, and the entire Illinois River.

Vegetation cover databases: Using photogrammetric methods, very accurate spatial databases have been created of the vegetation in dynamic areas in the floodplain. These databases show vegetation cover over a series of years and are being analyzed by ecologists to determine vegetation trends in these areas and to generate hypotheses to explain the trends.

U.S. Environmental Protection Agency (USEPA) Inland Waterways Spill Response Project: The EMTC is creating spatial databases and map atlases of potential spill sources and vulnerable resources for navigable waterways within the six states that comprise USEPA Region 5 (Illinois, Indiana, Michigan, Minnesota, Ohio, and Wisconsin). Geographic information systems technology is being used for the USEPA Region 5 Inland Waterways Spill Response Project, which includes areas of all six states. The project's mission is to provide community planners and oil spill responders with spatial information on resources at risk during a spill. Spatial and attribute data about environmentally sensitive areas, tribal lands, locks and dams, boat access points, marinas, water intakes, sensitive species, shoreline sensitivity, transportation corridors, hydrology, pipelines, and potential spill sources are being collected and processed into GIS data layers. These layers are delivered in the form of hardcopy maps and atlases, on CD-ROM, and via the Internet.

\section{Florida Caribbean Science Center, Gainesville Expertise or specialization}

Aquatic ecology

ARC/INFO

Biodiversity

Contaminants research

Endangered species

Fire ecology research

Fisheries biology

GIS analysis

GPS technology

GRASS

Habitat conservation

Herpetology

Inventory and monitoring

Mammalian ecology

Modeling

Mussel culture research

Neotropical avian ecology

Nonindigenous aquatic species

Population dynamics

Terrestrial ecology

West Indian manatee

Zebra mussels

\section{Applications}

Anadromous and Estuarine Research Program

Navigate and document distribution of fishes and mussels

Nonindigenous aquatic species database

Sirenia Project, long-term manatee research 


\section{Highlights}

Documentation of fish and mussel distribution: The Florida Caribbean Science Center (FCSC) uses GPS technology in real-time positioning mode to document the distribution of fishes and mussels throughout the southeastern United States. The emphasis is on endangered, threatened, and candidate species as well as on nonindigenous species. The georeferenced faunal databases are compared with large-scale geographic features (geologic formations, drainage basins, and land-use patterns) to assess trends in these faunal groups. Most of the clients served (USFWS, USGS, USEPA, and Departments of Transportation and Natural Heritage Programs of various states) insist on data that are accurately georeferenced.

Nonindigenous Aquatic Species database: The Nonindigenous Aquatic Species (NAS) database, a central repository for accurate and spatially referenced biogeographic accounts of nonindigenous aquatic species, contains scientific reports, online/real-time queries, spatial data sets, regional contact lists, and general information. Data are made available for use by biologists, interagency groups, and the general public. The primary geographical coverage is North America; however, other regions may be included as the need arises.

\section{Forest and Rangeland Ecosystem Science}

\section{Center, Corvallis, Oregon}

\section{Expertise or specialization}

Airborne pollutants

Aquatic ecology

Conservation genetics

Environmental toxicology

Fire ecology

Forestry

Information science

Inventory and monitoring

Landscape ecology

Metadata

Modeling

Population dynamics

Radio and satellite telemetry

Raptor ecology

Satellite imagery analysis

Satellite imagery classification

Wildlife management

\section{Applications}

Air quality monitoring at Mount Rainier National Park Analysis of open space change

Assessing elk habitat on the Olympic Peninsula

Avian migration

Bat distribution and habitat use at Grand Canyon National Park
Biological assessment in northern Arizona

Biophysical modeling at Petrified Forest National Park

Cowbird movement patterns in Verde Valley and Grand Canyon National Park

Creating a geospatial metadata clearinghouse for the Olympic Peninsula

Delineating traditional trapper regions in Denali National Park

Effect of fragmentation in shrub-steppe habitats on passerine bird reintroduction

Endangered species, Colorado Plateau

Examining the effects of global climate change on vegetation in Olympic National Park

Examining two different old-growth mapping projects

Field testing spotted owl predictive habitat model

GAP landcover accuracy assessment

GAP vertebrate model analysis

Generation of point locations for spotted owls in Grand Canyon National Park

Global climate change projects

Grand Canyon National Park avian community monitoring

Great grey owl distribution at Yosemite National Park

Habitat selection by bighorn sheep

Habitat selection by Arctic breeding birds

Habitat use of goshawks on the Olympic Peninsula

Historical associations between grizzly bear range and human activities

Integration of New Mexico and Utah spotted owl predictive models

Interactions between cattle and bighorn sheep

Military training-natural resource relationships

Modeling habitat suitability of large carnivores (grizzly bears)

Natural resources inventory at Montezuma Castle National Monument

Neotropical migrant bird use of Colorado River corridor

Predictive modeling of spotted owl habitat

Pronghorn movement patterns at Petrified Forest National Park and Wupatki National Monument

Raptor ecology

Seasonal spatial locations of spotted owls in Saguaro National Park

Shrub-steppe community ecology

Southwestern willow flycatcher monitoring at Tuzigoot National Monument

Southwestern willow flycatcher surveys in Arizona, Colorado, New Mexico, Utah, and California

Spatial modeling of fire frequency in the Columbia River basin

Spatial and temporal correlations in shorebird use

Species distribution and habitat relationships at Petrified Forest National Park 
Threatened and endangered species survey at Navajo National Monument

Tropospheric ozone in western Washington

Vegetation and landform database for four national parks in the Pacific Northwest

Vegetation mapping in the Mojave Desert

Wintering bald eagle and peregrine falcon surveys in Grand Canyon National Park

Wintering willow flycatcher surveys in Costa Rica

\section{Highlights}

Colorado Plateau Field Station research support: The Forest and Rangeland Ecosystem Science Center's (FRESC) Colorado Plateau Field Station in Flagstaff, Arizona, is running a 12-channel Trimble community base station and using 8-channel Trimble ProXL, Trimble GeoExplores, and a Rockwell PLGR for a variety of research activities related to threatened and endangered species, vegetation, avian, and other natural resources studies. Global positioning system data are often incorporated into the GIS for spatial analysis modeling to aid in decision making about and management of the region's natural resources. Base station data are updated hourly and posted on the field station's GPS Internet site at http://www.usgs. nau.edu.

Department of Defense partnership activities: Staff from the Snake River Rield Station (SRFS) work with the Department of Defense's (DOD) Legacy program and Strategic Environmental Research and Development Program (SERDP) and the Partners in Flight program to develop and integrate animal survey data, habitat data, wildlife radiotracking data, and maps into a GIS to address natural resource issues relevant to the military services. The SRFS is currently working on a pilot project to develop a methodology to track military activity with GPS while simultaneously tracking raptors using Argos satellite telemetry. Demonstrations of radiotracking and GIS technology with two Neotropical migrants are conducted at four military bases in Idaho, Montana, Nevada, and New Mexico.

Snake River Field Station research activities: The FRESC's SRFS in Boise, Idaho, is using GIS and remote sensing to develop spatial databases on vegetation, landscape characteristics, and animal distributions in the Snake River Birds of Prey National Conservation Area. Vegetation plots located by GPS were used to create and groundtruth a classified map from Landsat TM satellite imagery. In addition, temporal sequences of Landsat MSS imagery are used to detect changes in land cover related to wildfire, military training, and climate change. Data from field research are incorporated into a spatially explicit model of habitats, prey, and raptors to project outcomes of differing disturbance and climate scenarios and to generate management alternatives. Golden eagles, Swainson's hawks, and peregrine falcons are radiotracked by satellites between breeding and wintering grounds.

Snake River Field Station research support: Since 1989, the SRFS has been using GPS as a tool in developing spatial databases. Three Trimble PFINDER Professional units are used to perform differential correction and to locate many different biological and physical features, including raptor nest locations, transect locations, radio receiver locations, and roads. One of the major uses of GPS is groundtruthing vegetation data derived from Landsat TM images.

University of Washington Field Station research activities: The FRESC's University of Washington Field Station (UWFS) in Seattle, Washington, is developing an NSDI and NBII node for natural resource data on the Olympic Peninsula. A comprehensive database of metadata is being constructed for georeferenced information that will be delivered to the Olympic Natural Resources Center (ONRC) and maintained by their GIS lab. This database will be designed to be easily accessible and easily understood by all users and clients who contact ONRC. In addition, a World Wide Web (www) site is being developed for ONRC that will provide access to the database and contain "pointers" for databases at various agencies and nongovernmental organizations. The data clearinghouse will be a single, easy-access point through which land managers, scientists, decision makers and citizens of the Olympic Peninsula can preview and acquire geographic information on natural resources.

In 1992, the Natural Resource Preservation Program of the NPS provided funding for a contract with $\mathrm{Pa}$ cific Meridian Resources to develop and produce a comprehensive GIS vegetation land cover and geomorphologic landform database for four national parks in the Pacific Northwest Region: Olympic, North Cascades, Mt. Rainier, and Crater Lake National Parks. The study, managed by UWFS, was designed to develop a comprehensive, consistent inventory and mapping of the vegetation and landform characteristics for the four parks using digital Landsat TM satellite imagery and field-collected data as the primary information bases.

\section{Great Lakes Science Center, Ann Arbor, Michigan}

\section{Expertise or specialization}

Aerial photointerpretation

Aquatic ecology

$\mathrm{ARC} / \mathrm{INFO}$ and ArcView

Caris GIS

Fire ecology

Fish ecology

GIS analysis 
GPS technology

Habitat analysis and modeling

Inventory and monitoring

Modeling

Nonindigenous aquatic species

Population dynamics

Remote sensing

Remotely operated vehicle

Restoration ecology

Side-scan sonar

Species ecology

Water quality

Wetland ecology

Zebra mussels

\section{Applications}

Analysis of wetland plant communities and hydrological alteration as part of the Marsh Creek wetland restoration project, Seney National Wildlife Refuge

Assessment of first-year drawdown using photointerpretation and GIS as part of a lake ecosystem-level assessment of the Great Marsh at Indiana Dunes National Lakeshore

Assessment of first-year drawdown using photointerpretation and GIS as part of a Lake Erie coastal wetland restoration project

Development of evaluation criteria to assess and protect the biological and ecological integrity of Great Lakes wetlands

Erie Coastal Wetland Restoration Project

GIS mapping of the impact of nonindigenous species on critical spawning habitat

Green Bay transects and zebra mussel studies

Metzgar Marsh restoration project

Ottawa National Wildlife Refuge elevation mapping

Mapping the movements and impacts of a nonindigenous species, the river ruffe, in western Lake Superior

Use of aerial photography, GIS, and GPS to examine wetland plant communities in a Lake Erie coastal marsh restoration project

Use of photointerpretation and GIS to develop a new approach to restoration and management of a Lake Erie coastal wetland

Use of remote sensing technology for GIS mapping of selected underwater habitat within the Great Lakes Basin, including historical lake trout and lake whitefish spawning reefs, nursery grounds, and artificial reefs

Use of remote sensing to monitor the spread of nonindigenous species onto soft substrates in the Great Lakes

\section{Highlights}

GIS mapping of a Great Lakes coastal marsh restoration: As part of the Great Lakes Science Center's
(GLSC) Metzger Marsh restoration project on western Lake Erie, multiple ARC/INFO coverages were created by digitizing wetland vegetation types delineated from aerial photographs. Trimble rovers were then used to determine the precise location of GIS reference points, thus allowing the ARC/INFO coverages to be accurately georeferenced. The rovers have also been used to collect positional data on specific sampling sites within Ottawa National Wildlife Refuge, to input known elevation data, and to create contour maps using ARC/ INFO and PC-TIN. On Green Bay, Lake Michigan, the rovers provided positional data that aided in the definition of and subsequent return to transects (a remotely operated vehicle was then used to search the transects for zebra mussels).

Habitat mapping in the Great Lakes: The GLSC uses remote sensing technology to conduct habitat-related research in the Great Lakes basin. Products of this research include substrate classification and bathymetry maps to identify and quantify the extent of potential spawning and nursery habitat for lake trout and other fish species.

Hydroacoustics: The GLSC uses a BioSonics dualbeam echosounder to map the vertical migration patterns and seasonal movements of several forage fish species in the Great Lakes. These georeferenced data are used to develop and test models relating to the population dynamics of these fish species.

Nonindigenous species monitoring: The center has initiated several studies incorporating GIS and GPS to map and monitor the spread and movements of nonindigenous species in the Great Lakes basin. These include studies on zebra mussel spread and impacts on native unionids in Lake Erie, Ottawa National Wildlife Refuge, and the Huron River (Michigan); mapping the migration of the zebra mussel onto soft substrates in Lake Erie, Lake Ontario, and Green Bay, Lake Michigan; and mapping the impacts and effects of competition by the river ruffe on native yellow perch populations in St. Louis Bay, western Lake Superior.

Remotely operated vehicle: The GLSC uses a Benthos Mini-rover MKII remotely operated vehicle (ROV) to collect underwater video images of the microhabitat structure within side-scan sonar (SSS) map sites. The ROV location is georeferenced using differential GPS to allow for accurate positioning of the video to the SSS map image.

Side-scan sonar: The GLSC uses an Edgetech Model $260,100 \mathrm{kHz}$ side-scan sonar to acquire surficial substrate images of the lake bottom at selected sites within the Great Lakes. Two-hundred-meter wide swaths of substrate are imaged with each transect. Transect locations are georeferenced using differential GPS. Transect information is then mosaicked 
together using Caris SIPS sonar image processing software to create rectified images of the mapped area. These images can then be imported into ARC/INFO GIS software for further processing and analyses.

\section{Leetown Science Center, Kearneysville, West Virginia}

\section{Expertise or specialization}

Aerial photo correction

Aerial photo integration

Aerial photointerpretation

ARC/INFO and ArcView

Fish ecology/behavior

Fish pathology

GIS analysis

GPS technology

IDRISI

Inventory and monitoring

Landscape/stream ecology

Molecular genetics

$\mathrm{PCI}$

Population dynamics

Restoration ecology

Water resources

Watershed science

Wildlife ecology

\section{Applications}

Amphibian breeding pond studies

Aquatic ecology mid-Appalachian watersheds

Delaware Water Gap National Recreation Area studies

Habitat and pond characteristics

Instream habitat studies

Mercury contamination determination

Mussel population characteristics determination

Opequon Creek studies

Riparian zone vegetation studies

Shenandoah National Park studies

USFWS National Conservation Training Center cooperative projects

\section{Highlights}

Amphibian breeding pond selection study: Global Positioning System technology was used extensively for a study of factors affecting amphibian breeding pond selection in Canaan Valley, West Virginia. In this study, over 130 breeding ponds, ranging in size from 0.8 -ha beaver ponds to small road depressions, were mapped with a GPS unit during early spring and late summer conditions. Using differential correction, accuracies of pond edges were mapped with submeter accuracy, allowing calculations of pond edge and area and the extent to which ponds dried during the summer. Because of the small size of many of these ponds, this information would have been difficult, if not impossible, to map using conventional methods such as aerial photography. In addition, 200 water quality and biological sampling sites were located using a GPS receiver. This information is being compiled into a GIS database using ArcView for use by USFWS and local planning personnel.

Aquatic ecology research activities: A GIS lab has been constructed to support research at the Leetown Science Center (LSC). Geographic information systems technology is being used by the center's Aquatic Ecology Laboratory to support aquatic ecology research in mid-Appalachian watersheds, and GIS databases are being constructed to support other studies in aquatic ecology. A database of habitat and pond characteristics was constructed from existing sources and GPS mapping to assess amphibian breeding pond selection in Canaan Valley, West Virginia, site of the Nation's 500th national wildlife refuge. In addition, GIS is being used to map stream segments for a study estimating mussel population characteristics using adaptive sampling.

Assessment of landscape-level influences on fish community structure: A comprehensive GIS database of Opequon Creek, a midsize agricultural watershed, is being built to assess landscape-level influences on fish community structure. Habitat patterning at the catchment, riparian, and instream scale is being mapped from satellite imagery, digital orthophotography, and field measurements. These data are being assembled along with digital elevation models to assess tributary catchment characteristics such as stream size (order), landscape composition, flow networks, area, and others. Data are being analyzed along with field-collected statistics of species richness and abundance to assess the spatial influences of habitat patterning on structuring fish communities.

Determining watershed land-use changes: Remote sensing techniques are being evaluated to determine Opequon Creek watershed land-use changes over the past 20 years that may have influenced current distributions of aquatic species. Satellite imagery was obtained through the North American Landscape Characterization program of the USEPA Environmental Monitoring and Assessment Program (EMAP) and the Multi-Resolution Land Characteristics program of the USGS and USEPA. Landsat MSS imagery from the 1970's, 1980's, and 1990's and TM imagery from 1992 are being processed for change detection and landcover information in support of this study. In addition, riparian zone vegetation is being mapped from aerial photography and digital orthophotography. In areas where digital orthophotography is not available, LSC staff are experimenting with orthocorrection of scanned aerial photography using EASI/PACE. Mapped interpretations are being field-evaluated through vegetation surveys. 
Mapping instream habitat: Instream habitat was mapped from field-collected transects by using a combination of GPS, GIS, and specialized scripts. Variables such as substrate size, debris dams, water velocity, and depth can be mapped using these methods to give a two- or three-dimensional picture of channel characteristics. These fine-scale data are being analyzed with pattern statistics along with landuse maps to determine the influence of habitat patterning on fish species diversity and abundance at multiple scales.

Mercury contamination studies: Global Positioning System technology is being used to study the spatial nature of mercury contamination in Acadia National Park and other sites in Maine.

Mussel bed mapping: Global Positioning System technology is being used to map mussel beds in streams and rivers in West Virginia, Maryland, Pennsylvania, Ohio, and Michigan.

National Park Service partnership activities: A landscape-gradient ("gradsect") sampling scheme is being constructed for Shenandoah National Park and Delaware Water Gap National Recreation Area using GIS maps of vegetation, topography, and hydrology. This sampling scheme will be used by a multidisciplinary research team to assess biodiversity associated with eastern hemlock, an important tree species endangered by the hemlock wooly adelgid, an exotic forest pest. Models of hemlock susceptibility will also be constructed using GIS in support of this project. A GIS is being examined for its usefulness in assessing the fates and effects of mercury in Acadia National Park.

U.S. Fish and Wildlife Service partnership activities: Geographic information systems databases are being constructed to support the USFWS National Conservation Training Center. Maps of habitats, roads, trails, archeological ruins, elevation, hydrology, and other features are being assembled for use in GIS and GPS training activities at the training facility in Shepherdstown, West Virginia.

Watershed and aquatic ecology research activities: The LSC's Aquatic Ecology Laboratory has been making extensive use of GPS technology for watershed and aquatic ecology research activities. Two Trimble field units have been in use for field surveys since 1994. A PLGR is being purchased for locating field plots and other activities not requiring the mapping capabilities of Trimble units. Fish sampling and water quality sites have been pinpointed for a study of landscape factors influencing fish community structure in Opequon Creek. This locational information was also used to register detailed maps of instream habitat to large-scale maps of stream networks and land use.

\section{Midcontinent Ecological Science Center, Fort Collins, Colorado Expertise or specialization}

Aerial photointerpretation

Agricultural policy

Air quality

Amphibians

Animal behavior

Aquatic systems

ARC/INFO

Avian science

Biodiversity

Bioenergetics

Botany

Cartography

Computer applications

Data management

Economics

Ecotoxicology

Endangered and declining species

Environmental policy

Fire ecology

Forest management

Geomorphology

GIS analysis

GPS technology

Habitat analysis and modeling

Habitat restoration

Hydraulic and civil engineering

Hydrology

Impact assessment

Information systems

Instream flow analysis

Inventory and monitoring

Invertebrate ecology

Land-use policy

Landscape ecology

Modeling

Museum collections management

Networks

Plant ecology

Radiotelemetry

Remote sensing

Reservoir operations

Riparian ecology

Riverine habitat monitoring

Smoke management

Soil ecology

Statistics

Stream ecology

Systems modeling

Taxonomy/systematics

Threatened species

Trend analysis 
Vertebrates

Water resource engineering

Water quality

Water routing

Watershed science

Wetland ecology

Wildlife management

\section{Applications}

Black-footed ferret studies

Breeding Bird Survey and Christmas Bird Count

Butterfly transects in Rocky Mountain National Park

Channel geometry/riparian forest along ephemeral streams

Contour and river surface generation

Effects of climate change on fish and wildlife, San Francisco Bay

Elk movement and mortality

Evaluate efficiency of constructed wetlands with $\mathrm{Bu}-$ reau of Reclamation

Grizzly Bear Project

Imaging to conduct customized large-scale mapping of habitats

Institutional atlas, Colorado Plateau

Location of razorback sucker in Lake Mohave

Map prairie dog towns

Model fish habitat in the Yellowstone and Missouri Rivers

Model disturbance patterns and rates

Model glacier dynamics

Model disturbance patterns and rates

Model historical changes

Model snowpack

Monitor amphibian distribution and abundance

Monitor snow leopards in the Gobi Desert

New Mexico land status data layer

Quantify burn effects of Adair Ridge fires

Quantify landscape change dynamics

Radar imaging for estimating fire fuels

Record ranges and locations of rare and endangered species

Riparian corridor analysis, Green and Yampa Rivers, Dinosaur National Monument

River bathymetric profile studies

Roosting of bat species

San Luis Valley vegetation analysis

Satellite-derived digital terrain modeling/habitat potential, Himalayas

Shorebird stopovers in Central Flyway

Smoke dispersion from prescribed fires, Columbia Basin

SPOT imagery integration into Spotted Owl Analysis Project

Spread rate of exotic species

Thematic Mapper (TM) data for validation of MAPPS general circulation model, Wind Cave National Park

Three-dimensional mountain climatology
Time series-based methodology for ecosystem classification

TM data for Bear Trap region, Montana

Use of Airborne Visible Infrared Imaging Spectrometer (AVIRIS) data to estimate snow gain grain size, albedo, and liquid water content

Waterbird use of a wetland complex, San Luis Valley

Whitebark pine distribution

\section{Highlights}

\section{Geographic Information Systems}

Bandelier National Monument studies: Since 1987, biologists at the Midcontinent Ecological Science Center's (MESC's) Jemez Mountains Field Station, in conjunction with NPS personnel at Bandelier National Monument, New Mexico, have been developing geospatial data for the Jemez Mountains area. These data include basic themes (e.g., topography, hydrography, vegetation) and many specialized themes, such as locations of over 2,000 archeological sites, more than 6,500 historical fires, sensitive plant and animal species, and permanent inventory/monitoring/research plots. A GIS has been used extensively to document historical changes in landcover patterns in the Jemez Mountains region. These GIS data are increasingly used by park managers; for example, the 1996 Dome Fire Burned Area Emergency Rehabilitation Plan for Bandelier National Monument relied on this GIS to produce analyses of fire impacts and associated map products. Field station personnel are currently using PC-ARC/INFO, ArcView, and GRASS software.

Breeding bird surveys: Breeding bird survey, banding, and Christmas Bird Count data for the white-tailed kite are being converted into ARC/INFO to model changes in populations and distribution during the 1900 's.

Channel geometry studies: Historical aerial photography, Land Office Survey Notes, and ARC/INFO are being used to investigate changes in channel geometry and riparian forest resulting from extreme floods along ephemeral channels in eastern Colorado.

Colorado Plateau atlas: An institutional atlas for the Colorado Plateau is being developed, which will be a digital GIS representation of the 32 counties that encompass the area. The atlas will be accompanied by documentation regarding institutional authorities and responsibilities. The digital GIS database will be used to analyze conflicting institutional responsibilities, overlaps in jurisdiction, and opportunities for cooperation and to test several hypotheses regarding ecosystem management on the plateau. A series of GIS maps were produced for use in a questionnaire related to endangered species in the Colorado Plateau region. 
Effects of climate change on fish and wildlife habitat: Geographic information system digital data layers are being used with simulation models on sea-level rise to predict the effects of climate change on fish and wildlife habitat in the San Francisco Bay area. The products developed in this study will facilitate longterm planning to acquire and manage habitat for important species in the San Francisco Bay.

Effects of landscape structure on shorebird movements: A GIS database of four shorebird stopovers in the Central Flyway of the United States was developed and used to analyze the effects of landscape structure on shorebird movements during migration for the purpose of better understanding how individual shorebirds view a stopover.

Elk movement and mortality study: In cooperation with the Colorado Division of Wildlife (CDOW), a geospatial database has been developed for a northcentral Colorado elk movement and mortality study. MESC personnel developed and implemented a process to move and convert CDOW's elk tracking data files from a dBASE application to ARC/INFO.

Glacier National Park activities: Since 1983, the MESC's Glacier Field Station has been developing geospatial data for the greater Glacier area. The database contains basic themes (e.g., topography, hydrography, vegetation, transportation) and many specialized themes, such as observations of individual plant and animal species of concern, fire ignition points and burn perimeters, glacier trim lines, research plots, and well sites. In recent years, data development has focused on adding more specialized themes, updating or improving accuracy of existing themes, and expanding the area of coverage to include more area of the greater Glacier ecosystem. This area includes parts of southeastern British Columbia and southwestern Alberta, Flathead National Forest and the Bob Marshall Wilderness, the Blackfeet Indian Reservation, Flathead Lake, and Flathead Valley. Geospatial activities at the Glacier Field Station include:

\section{Research}

- Climate change

- Modeling historical changes in primary productivity in relation to climate.

- Modeling glacier dynamics in relation to climate and the effects of glacier changes on stream hydrology.

- Developing a three-dimensional mountain climatology and validating a spatially explicit microclimate simulation model.

- Modeling snowpack internal dynamics and spatial patterns over time.

- Landscape change and disturbance dynamics
- Quantifying landscape change dynamics of the greater Glacier area.

- Modeling disturbance patterns and rates.

- Developing a time-series methodology for ecosystem classification and process modeling.

- Determining whitebark pine distribution and abundance and impacts of blister rust.

- Mapping whitebark pine populations and mortality throughout the historical range.

- Identifying risk factors and rating vulnerability of plant and wildlife populations.

- Monitoring amphibian distribution and abundance.

\section{- Amphibians}

A park-wide herpetological survey was conducted in the early 1990's to establish which species were park residents, document local distribution, and resolve ambiguities about status of questionable species. This survey relied on GIS processing of species sighting data sorted by drainage. Amphibians and reptiles were recorded at 142 locations from 950 to 2,260 m elevation. A series of species accounts resulted from the survey, as well as GIS species range maps and a complete listing of sighting locations with Universal Transverce Mercator (UTM) and elevation data.

\section{Resource management}

- Developing the geospatial data and mapping required for the Glacier General Management Plan, a 3year project.

- Quantifying burn effects of the 1994 Adair Ridge fires.

- Undertaking an inventory of exotic plants.

- Tracking wildlife observations for selected species of concern.

Past activities include producing various map products, fire and fire history mapping, modeling of fire potential and fuel types, environmental assessments of proposed development areas, wildlife habitat and utilization modeling (e.g., bald eagles, bighorn sheep, grizzly bears, elk winter range), rare plant surveys, hazardous materials containment and optimum access analysis along a river and railroad, evaluation of satellite telemetry performance, and resource and ownership mapping for county planning efforts, among many others.

Kansas Conservation Reserve Program (CRP): Geographic information system digital data layers for a four-county study area in the Delaware River basin, Kansas, are being used with USDA soils data, a GRASS interface, and a sediment yield model to simulate reductions in sediment yields from lands converted from crops to CRP parcels over a 10-year period. 
Landscape heterogeneity and bird abundance: Bird abundance data from an ongoing biodiversity study and a GIS landcover database created from a Landsat TM image are being used to describe patterns of landscape heterogeniety in and around the Boulder Open Space, Colorado. Landscape indices reflecting patch size, shape, and configuration will be analyzed in relation to bird abundance data collected at 66 sample plots for three field seasons.

Landscape-scale analysis of habitat use and ecosystem dynamics in the San Luis Valley: Vegetation data for three study sites in the San Luis Valley, Colorado, were interpreted from 1:12,000-scale CIR photography collected in August 1995 and digitized in ARC/ INFO. This GIS database will be one of the tools used for landscape-scale analysis of habitat use and ecosystem dynamics in the San Luis Valley and will aid in the development of ecosystem management plans for the valley.

New Mexico land status data layer: The MESC contributed to the completion of a New Mexico land status data layer. A staff biologist from the USFWS New Mexico Ecological Services State Office, Albuquerque, was detailed to the MESC to complete the New Mexico land status data layer for use in producing area reports and maps needed by the Mexican Spotted Owl Recovery Team; USGS-BLM 1:100,000-scale surface management status maps were used as source maps for digitizing this data layer.

Riparian corridor analysis, Green and Yampa Rivers: A GIS database of vegetation and topographic data for selected sections of the riparian corridor along the Green and Yampa Rivers in and adjacent to Dinosaur National Monument, Colorado-Utah, is under development. One goal of this research project is to tie vegetation data to contours taken from USGS $7.5-\mathrm{min}$ quads and classify each short section of the Green and Yampa Rivers into a category based on slope of the terrain immediately adjacent to each river. Points collected with a GPS are being used to rectify scanned photos of the riparian corridor for use in the GIS database.

Smoke dispersion model: A terrain-based model of smoke dispersion from prescribed fires is being used by the National Interagency Fire Center to assess air quality impacts from controlled burning. Contributed information is being used to link fire behavior and smoke dispersion models to a GIS for the Columbia Basin Project.

Snow leopard habitat: Using a GIS, the MESC's Technology Applications Team developed a tool to model snow leopard habitat in 13 countries of central Asia with data taken from map-based suitability criteria. The GIS model of potential snow leopard habitat reveals a new picture of the physical and political landscape upon which this species depends. The map includes data about the country boundaries and protected areas and can be used to discover new information about snow leopard habitat, gaps in protected area coverage, priority areas for research and surveys, and future improvements to the model.

Stream surveys: Digitized contour and river data were used to generate a surface with the TOPOGRID surface model and to produce river profiles from the surface and river data using SURFACEPROFILE in ARC/ INFO. The 1:24,000-scale contour data and a 100-m UTM grid were plotted at a scale of $1: 12,000$ to make it easier to use in the field. The field map, the river profile, and river profile tables were used to design an efficient means of sampling seven rivers in upper Michigan. These GIS products reduced sampling time by $60 \%$. The stream survey data will be incorporated with soils, slope, and other relevant data layers to produce a risk analysis model for Pictured Rocks National Lakeshore.

Vegetation Mapping Program and Grizzly Bear Project support: The MESC is providing technical assistance on the use of numerous geospatial databases and radiotelemetry data for the Vegetation Mapping Program for the Greater Yellowstone Area and for the Grizzly Bear Project.

Waterbird wetland use: A GIS is being used to analyze and evaluate waterbird use of a wetland complex in the San Luis Valley, Colorado, during the nesting season in relation to spatial distribution of habitats and habitat structure. Point locations collected at the site were used to register CIR photographs for digitizing. The digital map coverage of the 1,500-ha study area is being used to select 0.25 -ha sample plots for measurement of vegetation structure and to plot the locations of waterbird nests for nine different species to determine various distance measurements (e.g., distance between and among nest sites of various species, distance of nests from semipermanent water).

\section{Remote Sensing}

Long Term Resource Monitoring Program (LTRMP): Between 1989 and 1997, the MESC provided technical support to the EMTC on the LTRMP. The EMTC interpreted landcover and land-use data from a series of key pools using 1:15,000-scale 1989 CIR photography, and the MESC provided zoom transfer, drafting, and digitizing support.

Research studies: A GPS is being used in river bathymetric/profile studies, to determine spread rates of exotic species, for mapping prairie dog towns, and for recording ranges and locations of rare and endangered plants. The MESC, in cooperation with the NASA Jet Propulsion Laboratory, is also investigating the use of radar imaging for estimating fire fuels. 
Surface snow layer studies: Staff at the MESC are participating on an Earth Orbiting Satellite interdisciplinary team investigating use of AVIRIS data to estimate snow grain size, albedo, and liquid water content in the surface snow layer at sites in the Sierra Nevada Mountains, California.

\section{Image Processing}

Central Grasslands Global Change Study: Center staff are developing GIS data themes and processing TM data for use in validation of the MAPPS General Circulation Model for the Central Grasslands Global Change Study at Wind Cave National Park, South Dakota.

Intermountain Wilderness Area Ecosystem Study: A Landsat TM image is being processed for the Bear Trap region in Montana as part of the Intermountain Wilderness Area Ecosystem Study. Another study was initiated to evaluate the utility of satellite-derived digital terrain modeling to map potential habitat in the Himalayas of India. Remotely sensed SPOT satellite imagery is being integrated into the Northern Spotted Owl Analysis Project to verify and update parameters related to land cover and habitat.

Large-scale habitat mapping: Remotely sensed imagery is being used to conduct customized large-scale mapping of habitats in the Pacific Northwest.

U.S. Bureau of Reclamation partnership activities: Staff at the MESC's Denver Field Station are working with the U.S. Bureau of Reclamation's remote sensing group to develop visual tools for evaluating the efficiency of a constructed wetland in improving the quality of wastewater that passes through it. An image software package is being used that scans color-positive film taken from the air to process plant coverage data and plant succession (changes in plant communities) through time. The ARC/INFO GIS software is being used with a raster processing package (Inverse Distance Weighing model) to plot various water quality parameters on the wetland image. Using these tools together, plant coverage can be related to water quality improvement in the system.

\section{Global Positioning System}

Butterfly transects in Rocky Mountain National Park: Differential correction of GPS points was completed to define butterfly transects in Rocky Mountain National Park.

Field digitizing at Glacier National Park: Applications of GPS at the MESC's Glacier Field Station are primarily to acquire point data but also include some field digitizing, such as locations of (1) "permanent" monitoring plots, (2) vegetation plots, (3) climate stations, (4) sample points along random and repeated snow survey transects, (5) glacier margins, (6) fire perimeters from ground and air, (7) trails, (8) perimeters of exotic plant infestations, and (9) control points for remote sensing georeferencing. The MESC is also conducting accuracy testing of satellite telemetry systems.

Fish habitat modeling: The MESC's River Systems Management Section is using GPS with an echosounder to survey the Yellowstone and Missouri Rivers to model fish habitat. The GPS/echosounder data will be used to model the riverbed surface using the TOPOGRID surface model in ARC/INFO. River velocity data for several flow levels will be modeled separately, and habitat data (such as bottom types and tree snags) will be collected with a GPS and combined in ARC/INFO with the modeled surface data to derive fish habitat.

Fish movement modeling: Location data for the razorback sucker in Lake Mohave were collected with a GPS and converted into ARC/INFO format to model movements of introduced fish.

Jemez Mountains Field Station activities: Personnel at the MESC's Jemez Mountains Field Station use GPS equipment, primarily PLGR units, for field mapping of particular resources and research activities, such varied types of permanent plots and transects, fire perimeters, trails, hazard trees, archeological sites, fire scar locations, vegetation, and sensitive species localities. The GPS data are integrated with the field station's GIS operations.

Prairie dog-black-footed ferret studies: Point locations collected with a GPS receiver are being used to assess spatial distribution of prairie dog burrows and to correlate this information with radiotelemetry data on the black-footed ferret.

\section{Radiotelemetry}

Bat studies: Biologists in the MESC's Southern Rocky Mountains Ecosystems Section are using miniaturized radiotransmitters, each weighing about $0.5 \mathrm{~g}$, to study movements and roosting sites of selected bat species of concern. Bats are captured at watering sites using mist nets, and the transmitters are affixed to their backs using a cement that allows the transmitter to drop off in 3-4 weeks. The transmitters have a life of about 2-3 weeks and an effective range of several kilometers under ideal conditions. Work in South Dakota is in the second of 3 years and focuses on species of concern in the southern Black Hills, especially in and near Jewel Cave National Monument. In northern New Mexico, bats are being radiotracked at Los Alamos National Laboratory and Bandelier National Monument. In southern New Mexico, radiotracking is being done in the Cloudcroft District of Lincoln National Forest. To date, bats have been found to roost in a variety of places, including cliff faces, rock walls, mature trees, old snags in forests, and in buildings. 
Black-footed ferret project: The MESC's black-footed ferret project has used radiotelemetry from 1991 to 1995 to monitor the success of ferret reintroduction in Wyoming, Montana, and South Dakota. In October 1996, radiotagged ferrets were released in Arizona. The GPS receivers have been used to map boundaries of prairie dog colonies and locations of thousands of prairie dog burrows, thereby aiding assessment of habitat quality at ferret reintroduction sites.

Snow leopard studies: A staff member on the MESC's Technology Applications Team installed a satellite transmitter to monitor movements of snow leopards in the Gobi Desert of Mongolia. The collar transmits directly to low, Earth-orbiting satellites operated by NOAA.

Wildlife Society: The MESC co-sponsored a Telemetry Forum in conjunction with the 1997 Wildlife Society meeting in Snowmass, Colorado.

National Wetlands Research Center, Lafayette, Louisiana

Expertise or specialization

Aerial photography acquisition

Aerial photointerpretation

Biology

Botany

Cartography

Database development

Decision support systems

Ecology

Education

Geography

Geology

Geomorphology

GIS analysis

GPS technology

Habitat mapping

Image processing

Information management

Land-use/landcover classification

Mapping

Marine biology

Marine science

Metadata

Migration ecology

Modeling

Natural resources management

Oceanography

Photogrammetry

Remote sensing

Spatial analysis

Technical editing

Training

Trend analysis

Wetland classification
Wetland science

Wildlife management

\section{Applications}

Accuracy assessment of mapping and photointerpretation

Big Bend National Park Neotropical bird project

Cache River, Arkansas, forested wetland analysis

Combine Landsat TM and high-resolution photography

Coosawhatchie River, South Carolina, forested wetland analysis

Delta National Wildlife Refuge, Louisiana, database development and sedimentation rates

Detect and monitor wetland stress

Ecosystem modeling

Generate coastal topography within $14 \mathrm{~cm}$

GIS assistance for the Coastal Wetlands Planning, Protection, and Restoration Act (CWPPRA)

GPS sampling of wetland areas for National Park Service units

Gulf Breeze Project Office research and monitoring program

Highly detailed landcover mapping for Padre Island $\mathrm{Na}$ tional Seashore

Jean Lafitte National Historic Preserve natural resource database and modeling

Lacassine and Sabine National Wildlife Refuges mapping and GIS database development

Louisiana GAP project coordination

Merge coarse spatial and high temporal resolution Advanced Very High Resolution Radiometer (AVHRR) to TM and TM to SPOT

Mississippi alluvial plain database development

Mitigating impacts on shellfish

Monitor flood extent and depth

Monitor forest resources recovery

Pearl River, Mississippi, environmental analysis

Restoration projects (32) for CWPPRA

Scanning and rectifying aerial photography for Alabama, Louisiana, and Mississippi

Seagrass baseline mapping

Seagrass trend analysis

Support Louisiana Department of Natural Resources (LDNR) in monitoring programs, GPS site locations, lawsuit support and documentation, and oil and gas infrastructure

Wetland education through maps and aerial photography

Wetlands studies, Florida and south Louisiana

Highlights

Animal Ecology Branch: Researchers are using spatial technology and satellite imagery to address wildlife habitat management objectives within the Mississippi Alluvial Valley (MAV). Land use is classified from TM data. Vector files of public land boundaries are created, and proposed migratory bird conservation zones 
within the MAV are delineated. Geographic information system technology is used to characterize avian habitats within bottomland hardwood forests and to assess distribution and abundance of seasonally flooded wetlands. These research efforts are conducted cooperatively with the USFWS, The Nature Conservancy, the Center for Advanced Spatial Technology (University of Arkansas), and the MAV Working Group of Partners in Flight.

Baton Rouge Project Office: The Baton Rouge Project Office was created through a Memorandum of Understanding and a series of cooperative agreements with the Louisiana Department of Natural Resources (LDNR) to provide GIS support services as follows: (1) providing GIS assistance for Coastal Wetland Planning, Protection, and Restoration Act planning and monitoring activities; (2) providing enterprise-level GIS support to the LDNR; and (3) providing GIS support for addressing and mitigating the impacts of shellfish leasing on wetland restoration efforts in coastal Louisiana.

Big Bend National Park: National Wetlands Research Center staff working in Big Bend National Park are collecting 108 data points for a Neotropical bird study with the NPS and Baylor University using differential correction with Pro-XL (submeter accuracy) and Basic Plus (3-5 $m$ accuracy). Surveys were made at park headquarters for the NPS to use with its equipment.

Database development: The NWRC's Spatial Analysis Branch integrates data from various sources into comprehensive GIS and associated databases. The GIS allows analysis of large and complex databases for trend analysis, natural resource inventory and monitoring, and modeling for the southeastern United States. Once these systems and their data are developed, they are transferred to other government agencies, universities, and the private sector through NSDI participation. The NWRC is in the process of inventorying its extensive spatial data holdings, preparing metadata for these data sets in priority order, and compiling spatial data sets on NWRC's ftp site for participation in the NSDI.

Forest Ecology Branch: Investigators are involved in a multiagency study of the functions of forested wetlands. In collaboration with the Water Resources Division, USFS, USACE, State agencies, universities, and a private landowner, a suite of studies is being carried out using standardized methods on three large tracts of forested wetlands: the Cache River in Arkansas, the Coosawhatchie River in South Carolina, and Iatt Creek in Louisiana. Studies at each site follow protocols agreed upon by all agencies, including inputs to a GIS. A large sampling grid has been established at each site, and every sample of every individual study has a GPS coordinate attached to it. A spatial analysis will be done to correlate various vegetative parameters and bird and insect surveys with microtopography; flooding height, duration, and frequency; soil types; and forest canopy gaps (located and collected with a GPS on the ground and interpreted from aerial photography). Submeter accuracy has not been required; postprocessing has been used for differential correction of GPS data.

Gap Analysis Program analyses: The NWRC is conducting the GAP project for the State of Louisiana. This effort will provide the mechanism to create a Statewide data set for vegetation, species range distributions, and land management areas. These individual maps and digital data will be the end product of this effort, along with a final composite data set that depicts the "gaps" in the current land management scheme for Louisiana. The GIS provides the tools necessary to facilitate the spatial analyses required for use of GAP data by natural resource planners and decision makers.

Geographic information systems-based ecosystem modeling: The NWRC is studying advanced spatial analysis and modeling methods and is using these tools to analyze and understand a variety of ecosystem issues, such as wetland ecosystem restoration, spatial genetic variations of natural populations, distributions of wildlife populations, and disturbances in coastal natural resources. These studies primarily use GIS-based spatial data, including remotely sensed imagery. In addition to spatial models, research products include synthesized ecological data sets and GIS-based spatial decision support systems for implementing model analysis.

Gulf Breeze Project Office: The Gulf Breeze Project Office (GBPO) was created to fulfill an interagency agreement with the USEPA EMAP. The interagency agreement calls for establishment of research and monitoring programs to verify the status of environmental resources of the United States and to track changes over the long term. Staff at the GBPO provide expertise in the areas of statistics, quality assurance and control, GIS, information management, and document and graphics skills in support of the interagency agreement.

Jean Lafitte National Historical Park and Preserve: The NWRC has used GPS for a DOI research project at the Jean Lafitte National Historical Park and Preserve to map and monitor the vegetation, soils, and hydrology of the Barataria Unit marsh in coastal Louisiana. The Barataria Unit covers 8,400 ha of emergent marsh, cypress swamp, and bottomland hardwood typical of the Mississippi River delta. A grid network of sampling stations was established to augment the development of a natural resource database and predictive model for evaluating ecosystem management 
alternatives for the park. The sampling grid consists of a 20 - by 25 -m matrix of sampling locations. A GPS with real-time differential correction was used to survey over 200 permanent sampling locations from an airboat. Spatial resolution of the sampling grid was $250 \mathrm{~m}$ in the east-west direction and $500 \mathrm{~m}$ in the north-south direction to conform with site geomorphology. Each grid point location was resurveyed repeatedly to characterize marsh hydrology, vegetation, and substrate across the park area. Elevation surveys of the park landform were conducted using GPS and laser-level technology. Area delineations of vegetation patchiness and nutria eat-outs also were gathered with GPS receivers. Data from this study are being incorporated into an existing GIS database for the park. The resultant field research and computer model will provide resource managers with a functional framework on which to base management decisions and to monitor management success.

Mapping activities: Staff in the cartography laboratory apply traditional and state-of-the-art techniques for mapping and photographic reproduction in support of the NWRC's overall mission to understand the environment. Aerial photography is the primary data source for information on wetland and associated environments. Various scales of high-altitude and lowlevel photography are obtained through private and government contractors, including NASA (which operates the ER-2 reconnaissance aircraft). In some cases, historical photography is obtained from other government agencies and private sources. Black-andwhite, natural color, and false color (CIR) film is used for establishing baseline information. Photointer-preters use stereoscopes to determine the location and extent of wetland, upland, and seagrass habitats from the photography. These data are transferred to base maps and are subsequently digitized for computer analysis. Aerial photography is being scanned, mosaicked, and rectified to provide orthophoto quality base maps for mapping and research projects for the NWRC, USFWS, and the USACE. Ecologists use this information to analyze the status and trends of coastal wetlands and to monitor resource management projects. Extensive field work, including GPS surveying combined with careful compliance with established mapping conventions and accuracy standards, results in some of the most accurate, up-to-date, and informative maps available. This information is used by researchers at NWRC as well as various local, State, and Federal agencies and the general public. Outreach activities include the Wetlands Education Program, development of a CDROM of the 1995 state of Louisiana CIR aerial photography, and production of three 4-color posters in conjunction with State and nonprofit organizations.
Migratory duck studies: Researchers are collecting points (3-5 m accuracy) with NavBeacon in Arkansas and Mississippi for migratory duck study sites and using real-time NavBeacon (submeter accuracy) to revisit sediment accretion sites on a yearly basis in Delta National Wildlife Refuge. Global Positioning System technology is being used for wetland characterization of sites in Alabama and Georgia for river-level reference points (differential correction 3-5 $\mathrm{m}$ ) and in Pearl River of Mississippi for the USACE.

Research activities: The NWRC's remote sensing section is conducting research in nearshore waters, coastal and inland wetlands, and adjacent upland areas. Studies have produced methods to (1) monitor flood extent and depth in coastal wetlands (radar), (2) detect and monitor acute stresses in wetlands (optical and radar), (3) generate coastal topography within 14-cm accuracy (site-specific measurements and radar), (4) integrate satellite optical and radar data for highly detailed landcover mapping, (5) quickly assess impacts and monitor the recovery of forested resources with NOAA AVHRR data, (6) link the coarse spatial but high temporal resolution AVHRR to Landsat TM data for improved spatial and temporal information, and (7) combine Landsat TM and high-resolution photography to detect and quantify changes in spatially heterogeneous and degrading systems. The NWRC is also involved in a collaborative study with NOAA as part of the national Coastwatch Change Analysis Project to develop and build a standardized GIS to detect and assess changes in land cover and habitat in the wetlands and adjacent uplands and cultivated or developed areas of coastal Louisiana. Protocols and products are being developed as outlined by NOAA.

Restoration projects: As part of the Coastal Wetlands Planning, Protection, and Restoration Act (CWPPRA), orthophoto base maps for 32 restoration projects are being developed using real-time, real-time differential, and differential correction to gather points for aerial photo rectification. While the gulf coast provides the opportunity to use real-time differential correction with Trimble Pro-XR units (NavBeacon capability) for submeter accuracy, GPS horizontal fix data is logged simultaneously or separately with postprocessing for differential correction using local base stations to assure submeter accuracy of the data collected. Although PLGR units are used for some realtime data collection to increase efficiency and in locations outside of the range of NavBeacon, the submeter capable units are the primary equipment used.

Sampling activities: All current field studies are using GPS equipment on a regular basis to record point, 
line, and area locations related to sampling activities. Data are gathered in real-time nondifferential, real-time differential, and postdifferential, depending on equipment availability, function, and purpose at the time. All positions have horizontal fixes, but the center is also interested in vertical datum application of GPS. Studies in remote wetlands in south Florida, northwest Florida, and south Louisiana have been using GPS technology for several years. Data needs and collection are similar for all projects.

Training workshop series: Spatial Analysis Branch staff conduct workshops in GIS, FGDC metadata content standards, GPS, wetland mapping, remote sensing, and image processing for natural resource managers from the public and private sectors. Staff also conduct workshops in the use of technology to study natural resources for secondary and college teachers and students.

\section{National Wildlife Health Center, Madison, Wisconsin}

\author{
Expertise or specialization \\ Animal husbandry \\ Avian health \\ GPS technology \\ Habitat restoration \\ Inventory and monitoring \\ Migratory birds \\ Population management \\ Waterfowl
}

\section{Applications}

Distribution of bison in Greater Yellowstone Area

Site collection for water quality parameters (10)

\section{Highlights}

Avian cholera studies: The National Wildlife Health Center (NWHC) uses PLGR units to study wetlands that experience avian cholera mortality events. Ten wetland sites are being identified for collection of water quality parameters, sediment samples, and samples for isolation of the bacterium that cause avian cholera. The use of GPS technology allows resampling of these wetland sites during subsequent investigations and determination of the area covered by the sample sites.

Bison distribution and habitat use: The NWHC, along with other BRD, State, and Federal collaborators, is using radiocollars equipped with GPS technology to study distribution of and habitat use by bison in the Greater Yellowstone National Park ecosystem. Researchers are assessing the risk of transmission of brucellosis from wildlife to cattle. Brucellosis is a serious disease in cattle, and there is concern about the potential for bison to spread the bacteria by contaminating land that will later be occupied by cattle. Bison can travel long distances throughout and outside the park, and the GPS-equipped collars will help scientists obtain the detailed and accurate data on animal movement and habitat use needed for the risk assessment.

\section{Northern Prairie Wildlife Research Center, Jamestown, North Dakota}

\section{Expertise or specialization}

Amphibian ecology

Ecology of migrant grassland nesting birds

GIS analysis

GPS technology

Grassland ecology and management, including grassland fire ecology

Invertebrate biology

Landscape ecology

Mammalian predator ecology, behavior, and management

Radiotelemetry

Restoration ecology

Satellite remote sensing

Simulation modeling of wildlife populations

Statistics

Videography

Waterfowl ecology, behavior, and population dynamics

Wetland ecology, classification, and management

\section{Applications}

Composition, spatial distribution, and temporal dynamics of waterfowl winter habitats

Develop methods to monitor wetland and ecosystem health in the Prairie Pothole Region

Distribution of exotic plants

Ecology of swift fox

Effects of grassland patch size and edge features on upland bird nest success

Forecasting the annual production of Arctic nesting geese

Improving prairie pond counts using aerial videography

Long-term monitoring of wetlands, Cottonwood Lake

Predator foraging ecology in relation to habitat composition and fragmentation

Survey of black-tailed prairie dog colonies

Waterfowl brood ecology in relation to wetland and upland habitat conditions

Wetland restoration

Highlights

The Northern Prairie Wildlife Research Center (NPWRC) uses geospatial technology in the following activities:

Composition, spatial distribution, and temporal dynamics of waterfowl winter habitats: In cooperation with the Western Ecological Research Center, this study examines the composition, spatial distribution, and temporal dynamics of waterfowl winter habitats in the Central Valley of California using satellite remote sensing imagery and geographic information systems. Multitemporal TM and AVHRR imagery are 
analyzed to provide information on winter habitats at multiple spatial and temporal scales within and among winters.

Developing methods to monitor wetland and ecosystem health in the Prairie Pothole Region: In partnership with the USEPA's EMAP, this project examines indicators of the health of wetlands and wetland-upland complexes in the Prairie Pothole Region. At the landscape scale, organisms dependent on the mosaic of wetlands and wetland complexes, including upland grassland birds, waterfowl, amphibians, and flying insects, are studied. At selected sites, indicators include measures of plant diversity, sediment runoff, invertebrate community composition, and biomarkers indicating stress in invertebrates and amphibians. Models will be developed to relate indicators to the presence and abundance of habitat and landscape features in a geographic information system.

Developing models to forecast the annual production of nesting Arctic geese: In cooperation with the USFWS Migratory Bird Management Office, this study extends the earlier research on monitoring arctic habitats and goose production using AVHRR imagery. The AVHRR imagery is resampled to a map projection, calibrated to reflectance factors and brightness temperatures, and analyzed using a mixture model to estimate the proportions of snow, land, and water in each pixel of the imagery. Imagery from multiple dates each spring is used to monitor the phenology of snow melt, flooding, and availability of nest sites. Regression estimators are developed to predict the immature/adult ratio in the fall flight.

Distribution of exotic plants: This study is conducting an inventory of exotic plants at Theodore Roosevelt and Wind Cave National Parks. Geographic information systems are used in the development of sampling designs and presentation of results. The Global Positioning System is used to locate and record the location of sample units in the field.

Ecology of swift fox: The swift fox has been identified as a candidate for consideration under the Endangered Species Act. In cooperation with the Swift Fox Conservation Team, the USFWS, the Kansas Department of Parks and Wildlife, and the North Dakota Game and Fish Department, this study is developing methods to inventory and monitor swift fox and collecting basic information on swift fox ecology. Radiotelemetry and GIS are used to examine habitat use for foraging and den locations. The study will examine population survival, causes of mortality, productivity, prey availability, and home range size of swift fox.

Effects of grassland patch size and edge features on upland bird nest success: This study examines the preferences of various upland nesting birds for nesting habitats and the interactions between nest habitats, landscape fragmentation, proximity to wetlands, and predation rates. Geographic information systems are used in the analysis of the data collected in this study.

Improving prairie pond counts using aerial videography, GPS, and an optical disk recorder: This study developed a method that combines aerial video, GPS, and an optical disk recorder to assess pond numbers in the Prairie Pothole Region. The system enabled a rapid and accurate assessment of the average number of ponds.

Long-term monitoring of wetlands: In cooperation with the U.S. Bureau of Reclamation, the USFWS, and various universities, the Cottonwood Lake Study is a long-term investigation of the hydrology of a wetland complex, the impact of hydrology on water chemistry and hydroperiod, and the combined influence of hydrology, hydroperiod, and chemistry on wetland flora and fauna. As part of these investigations, wetland vegetation communities are manually photointerpreted and the resulting vegetation maps are used in a GIS to study vegetation change.

Predator foraging ecology in relation to habitat composition and fragmentation: In cooperation with Iowa State University and Ducks Unlimited, this study examines how predators use grasslands in a fragmented landscape, if intensity of use is related to size of the grassland fields, and if proximity of duck nests to habitat edge influences predation rates. Radiotelemetry, GPS, and GIS technologies are used in the investigation.

Survey of black-tailed prairie dog colonies: In cooperation with the USFS and other Federal, State, local, and private agencies, this study will inventory blacktailed prairie dog colonies. The survey is using data in a GIS to develop a sample design for line-intercept sampling of remotely sensed imagery.

Waterfowl brood ecology in relation to wetland and upland habitat conditions: The ability to reliably predict survival rates of broods and ducklings is a critical need in waterfowl management. Because direct measurement of fledging rates is very difficult, this study is developing methods to predict brood and duckling survival in prairie pothole landscapes using habitat information in a GIS. State-of-the art radiotelemetry microtransmitter technology is used to monitor mallard and gadwall ducking survival. Imagery from a digital CIR camera is used to monitor the availability of seasonal wetland habitat and percent of landscape in perennial cover.

Wetland restoration: Two new studies will use data in a GIS to develop sampling designs for field work and to 
account for landscape variables in the analysis and interpretation of the field surveys.

\section{Pacific Island Ecosystems Research Center,} University of Hawaii, Honolulu

\section{Expertise or specialization}

Alpine/subalpine ecology

Avian diseases

Coastal ecology

Forest ecology

GIS analysis

GPS technology

Habitat restoration

Threatened/endangered species

Wetland ecology

Wildlife ecology

\section{Applications}

Breeding habitats, coastal ponds

Breeding habitats, montane wet forest

Fire fuels mapping

Fire history atlas

Geocode Hawaii Volcanoes National Park herbarium

Lava flow maps

Mapping ungulates

Rare plants/invertebrate mapping

Vegetation mapping

\section{Highlights}

Breeding habitats of Megalagrion damselflies, coastal ponds, Island of Hawaii: This project involves spatial analysis of coastal breeding habitats of Megalagrion xanthomelas, a Category 1 Candidate Endangered Species. A database of all available aquatic habitat along the coast within $60 \mathrm{~m}$ in elevation will be linked to digitized maps of ponds. Geographic information system technology will be used to identify clusters of suitable habitat on the island and the conservation status of surrounding lands and to generate detailed habitat maps of four intensive study sites.

Breeding habitats of Megalagrion damselflies, montane wet forest, Island of Hawaii: This project will help summarize habitat relationships of Megalagrion damselflies in rainforests on the Big Island, especially in Hawaii Volcanoes National Park. Two dominant species of Megalagrion occur in this habitat: $M$. calliphya breeds in pools and $M$. amaurodytum peles breeds in the leaf axils of the native lily Astelia. Geographic information systems technology will be used to predict the distribution of Astelia from existing vegetation maps and climatological data. This information will be used to guide surveys for $M$. amaurodytum peles.

Cataloging and geocoding the Hawaii Volcanoes National Park Herbarium: Of the 6,000 vascular plants in the herbarium, only 2,000 have been cataloged. The remaining specimens will be cataloged and records of alien and rare plants will be geocoded. Resultant databases and digital maps will be published via the Internet and will comply with the NBII biological extensions to the FGDC metadata standards.

Fire history atlas of Hawaii Volcanoes National Park: This project will document the history of fire occurrence from the early 1920's to 1996 in Hawaii Volcanoes National Park. A database providing information on each fire's name, date, and cause will be linked to digitized maps.

Fire mapping in Hawaii Volcanoes National Park: Staff members at the Pacific Island Ecosystems Research Center (PIERC) are in the process of developing a method of real-time mapping of park fires using a Rockwell PLGR+96 unit from within a helicopter. Upon returning from the field, fire managers will download the GPS data into ArcView to generate maps showing the location of the fire in relation to existing fire breaks and fuel types.

Lava flow mapping, Mauna Loa Volcano: Lava flow maps are being digitized at the Hawaiian Volcano Observatory. The resultant database will describe the age and morphology of the lava flows and will provide geologists with baseline data for determining the frequency of lava flow coverage for any given area. The geologic data will also provide botanists with valuable substrate information for a wide variety of research projects.

Rare plant/invertebrate mapping of Hawaii Volcanoes National Park: Scientists at the PIERC's Hawaii Field Station are compiling existing data on 44 listed and candidate endangered plant species and 60 candidate endangered invertebrates from Special Ecological Areas and other surveyed sites in the park. A GPS unit was used to map transects; locations of rare plant and invertebrate sightings are entered into a GIS using measured distances along transects. Using GIS technology, additional habitat information about these rare species can be obtained by overlaying the digital maps of rare plants and insects with maps of lava flows, vegetation, and climate.

Surveying and mapping ungulates in the Pohakuloa Training Area: The DOD is funding a project to gather baseline data on the relative frequency of ungulates within the Pohakuloa Training Area. Transects have been established by resource managers; a GPS unit is used to navigate a helicopter along the transects when ungulates are being counted. Information on the location and sex (when possible) of sheep, goats, and mouflon also will be collected. This information will then be used to map ungulate populations relative to vegetation communities and the locally abundant rare plants of the area. 
Vegetation and fuels mapping of Hawaii Volcanoes National Park: Vegetation maps of the park are being digitized and will be used to develop detailed fuel maps. Maps of fuel types will serve as valuable aids in planning suppression strategies.

\section{Patuxent Wildlife Research Center, Laurel, Maryland}

\section{Expertise or specialization}

ARC/INFO

GIS analysis

Habitat analysis

Herpetology

Information management

Inventory and monitoring

Land management

Landscape ecology

Population dynamics

Radiotelemetry

Restoration ecology

Remote sensing

Risk assessment

Statistical evaluation

Statistical modeling

Waterfowl

Watershed science

Wetland ecology

Wildlife ecology

Wildlife toxicology

\section{Applications}

Abundance maps-spatial patterns of bird abundance

Alaskan birds, relative abundance maps

Animation of Carolina wren distributions from 1966 to 1995

Animations of summer/winter bird distributions

Audubon Christmas Bird Count (North America)

Belize, predicted bird abundance maps

Bird banding data (North America)

Bird checklists for U.S. states and Canadian provinces

Bird spring season maps

Bird surveys at Patuxent Wildlife Research Center

Breeding Bird Survey data (clickable map)

Breeding Bird Survey (North America)

Breeding Bird Survey trend maps-spatial patterns of bird population change

Breeding Bird Survey species groups-distribution and change maps

Central American habitat maps

Central American modeled bird range maps

Conservation management for nature reserve, southern Mexico

Cowbirds study, New York State

Ecology of painted bunting

Grassland birds
Gray wolf and white-tailed deer

Landscape planning to retain breeding birds in fragmented environments

Landscape-level determinants of distribution and abundance of black duck wintering

Mapping Avian Productivity and Survivorship (MAPS) Program

Mapping frog and toad calling surveys

Mapping nonindigenous plants, Rock Creek Park

Maps for selected bird species, Cerro San Gil area, Guatemala

Maps of bird abundance during migration

Maryland birds, Miniroute Project

Mean high water shoreline, Cape Cod, Fire Island, Sandy Hook

Midwinter waterfowl survey

Migratory bird research

Migratory bird research project: monitoring birds at several geographic scales

Modeling North American bird summer breeding range maps

North American Amphibian Monitoring Program (NAAMP)

Ohio birds, atlas project

Patterns of host selections by brown-headed cowbirds

Patuxent aerial photograph server (a clickable interface)

Project Birdscape, Washington, D.C.

Shoreline analysis, Cape Cod, Fire Island, Sandy Hook

Storm threat research

Track bird species, Mongolia, Namibia, Saskatchewan, and Siberia

West Point Military Academy bird survey

\section{Highlights}

Analysis of shoreline change: ARC/INFO is used to analyze shoreline pairs for change at Fire Island $\mathrm{Na}$ tional Seashore, Gateway National Recreation Area, and Cape Cod National Seashore. Digital data sets for each park go back more than 100 years as derived from National Ocean Service coastal survey maps ( $T$ sheets) and aerial photography. All data analysis and archiving are done at the University of Rhode Island Environmental Data Center. A UNIX-based analysis of shoreline change at Gateway National Recreation Area has been done cooperatively with the NPS. Also, in collaboration with a Rutgers University scientist, dune crestline changes at Fire Island (from 1976 to 1992) are being analyzed in ARC/INFO based on digitized aerial photos. ARC/INFO TIN surface models of surveyed changes in bathymetry of inlets and topography of barrier islands are used in cooperation with Woods Hole Oceanographic Institution and the University of Rhode Island.

Bioassessment and monitoring framework for public lands and trust resources along the Atlantic coast: 
Geospatial information is being collected to apply a bioassessment and monitoring framework for public lands and trust resources along the Atlantic coast. Retrospective contaminant and environmental quality information is being assembled for terrestrial species residing in estuarine systems from the Gulf of Maine to Florida. The database is organized by species, georeferenced sampling location, date of sample collection, contaminant exposure/effects, and reference source. This information will be made available in tabular and map form. Ultimately, a risk assessment will be conducted to identify and characterize contaminants and other environmental stressors in these estuaries. Specific assessment and measurement endpoints will be used in this exercise to rank and prioritize estuarine ecosystems potentially at risk and to focus future Patuxent Wildlife Research Center (PWRC) biomonitoring and research partnerships. This work involves the University of Maryland, which is providing geospatial technology facilities and expertise.

Conservation and management plan for a newly created private nature reserve in southern Mexico: A PLGR GPS receiver was used to obtain UTM coordinates for several hundred reference points on Rancho Sandoval (Campeche, Mexico). Aerial photographs of Rancho Sandoval were scanned, brought into ARC/INFO as images, and georeferenced using the UTM coordinates. The coordinates also were put into point or line coverages that can be overlaid on the scanned photos. These overlays will be used to develop coverages of vegetation, land uses, fences, and other features. The GIS will then be used to design a survey of bird populations in each habitat type. Occurrence, abundance, and richness of bird species will be mapped in the GIS; maps will be used to develop a conservation and management plan for Rancho Sandoval. Images from the Landsat MSS may be used to document vegetation changes on Rancho Sandoval and to develop a general vegetation map for the Laguna de Terminos region.

Gray wolf-white-tailed deer studies: Radiotelemetry is used in research on gray wolves and white-tailed deer in the central Superior National Forest of Minnesota to monitor population trends, survival, mortality, ecology, and behavior.

Invasive plant mapping: Both GIS and GPS are being used to map nonindigenous plant plots in a study of control methods for nonindigenous invasive plants in Rock Creek Park, located in Washington, D.C.

Landscape-level determinants of the distribution and abundance of black ducks: A GIS is being used in a study on landscape-level determinants of the distribution and abundance of black ducks wintering in habitats along the Atlantic coast. This work initially involves developing a comprehensive listing of Federal and State databases relevant to black ducks and their habitats and determining GIS compatibilities and capabilities among the databases. Next, changes in estuarine habitats will be characterized and related to population trends and distribution of black ducks wintering and breeding along the Atlantic coast.

Landscape planning to retain breeding birds in a fragmented environment: An ARC/INFO GIS which includes a coverage of forests in Prince Georges County, Maryland, is a major component of the PWRC's study titled "Landscape planning to retain breeding birds in a fragmented environment." The GIS is used as the sampling frame from which study sites are selected and to determine the locations of bird sampling points (generally forest centroids). Characteristics of county forests are also measured in the GIS, including area, shape parameters, and percent cover of adjacent habitat types. Logistic regression analysis is then used to model the relation of bird species occurrence in forests and these characteristics and to predict probability of occurrence and bird species richness in unsampled forests. Observed and predicted occurrence and richness are being mapped in the GIS to identify forests that should be priorities for preservation. GIS techniques will be used to devise strategies for consolidating and linking forests to increase the area of contiguous forest. In combination with local forest conservation requirements, zoning, and land ownership (public versus private), a forest conservation plan and implementation strategy will be developed collaboratively with county land-use planners.

Migratory bird tracking: In collaboration with NASA, satellite telemetry is used to track several species of birds to determine their migratory paths and breeding and wintering locations. This work has included determining the winter homes of Siberian cranes from northwestern Siberia, of sandhill cranes breeding in southern Saskatchewan, of Wahlberg's eagles breeding in Namibia, and of steppe eagles breeding in southeastern Mongolia. By this means, additional data have been gathered on dispersal times for harpy eagles, migration routes of Siberian cranes breeding in northeastern Siberia, migration routes of lesser spotted eagles wintering in Namibia, and movements of a golden eagle in Mongolia. Much work has been done to develop backpack harnesses for cranes and eagles, and experiments are under way with a leg band mount for crane transmitters.

Painted bunting survival studies: Investigations of the ecology of painted buntings on coastal barrier islands of Georgia and South Carolina use radiotelemetry to 
determine survival of breeding adults and fledglings. Geographic information systems technology is used in this study to determine optimum breeding habitat that is based on nest productivity as determined by considering changes in habitat at four intervals from 1966 to 1996.

Patterns of host selection by brown-headed cowbirds: ARC/INFO software is used to plot maps in a study of patterns of host selection by brown-headed cowbirds. Universal Transverse Mercator coordinates of parasitized nests and of female cowbirds fitted with radiotransmitters were recorded during 1991-1993. Maps for each year were plotted with overlays of home ranges of individual cowbirds, locations of parasitized nests, and landmarks such as roads, buildings, and lakes.

Storm threats to national parks: Both GIS and GPS technologies are used in current research on storm threats to northeastern United States coastal national parks. Trimble receivers are used in dynamic mode surveys of mean high-water shoreline at least once per year at Fire Island National Seashore (up to six times per year for the high-focus area on Fire Island), at Gateway National Recreation Area since 1993, and at Cape Cod National Seashore since 1994. Baseline data for other geomorphic features delimiting upland resource boundaries (dune toe, bluff toe, bare sand-vegetation boundary) have been obtained for each park, but the PWRC is not yet in a monitoring phase. Also, GPS receivers are used to georeference control points on older aerial photos for improved rectification and digitization of shorelines in all three parks. All data are differentially corrected at the University of Rhode Island under an NPS cooperative agreement.

Submerged vegetation mapping: A GPS has been used to accurately control aerial photos from which maps of submerged vegetation and habitat types are prepared for the shallow estuarine bottom of Great South Bay adjacent to the Otis Pike Wilderness Area of Fire Island National Seashore.

\author{
Upper Mississippi Science Center, La Crosse, \\ Wisconsin \\ Expertise or specialization \\ Analytical chemistry \\ Animal physiology \\ Aquatic ecology \\ Aquatic organisms \\ Aquatic vegetation \\ ARC/INFO \\ Biodiversity \\ Chemical/drug registration \\ Computer science \\ Contaminant studies \\ Ecology
}

\author{
Ecotoxicology \\ Endangered species \\ Environmental contaminants \\ Fish culture \\ Fishery disease control \\ Fish ecology \\ GIS analysis \\ GPS technology \\ Habitat restoration \\ Information transfer \\ Invertebrate ecology \\ Large-river ecology \\ Microbiology \\ Migratory birds \\ Modeling \\ Pharmacology \\ Population studies \\ Radiotelemetry \\ Remote sensing \\ Statistics \\ Toxicology \\ Trend analysis \\ Waterfowl \\ Wildlife biology \\ Zebra mussels \\ Zoology
}

\section{Applications}

Decision Support System (DSS) for national wildlife refuges

Habitat of paddlefish

Habitat alterations

Migratory birds

Mississippi River floodplain

\section{Highlights}

Field research projects: Research scientists in the Wildlife Ecology Section have integrated GPS technology into nearly all field research projects. ARC/ INFO software is used to randomly select sampling points within defined strata contained on digital coverages; a GPS is then used to find those sites within the Mississippi River floodplain. The ability to return to exact points to conduct breeding bird surveys and to characterize the vegetation community has greatly enhanced this effort. Global Positioning System technology is also used during radiotelemetry studies to establish tracking locations and to document sites of mortality, use, and other occurrences.

Radiotelemetry studies: The Upper Mississippi Science Center's (UMSC) Aquatic Ecology Section is using GPS and GIS technology in two radiotelemetry studies: (1) determining habitat use and movement of paddlefish in the Upper Mississippi River and selected tributaries to evaluate the effects of habitat alterations such as dams and (2) evaluating bluegill and black 
crappie movement and habitat use before and after construction of a habitat rehabilitation project. Locations of radiomarked fish are recorded with Rockwell PLGR units. Analyses of fish movement and habitat use are conducted with ARC/INFO on a UNIX platform.

\section{Western Ecological Research Center, Dixon, California}

Expertise or specialization

Avian ecology

Conservation biology

Contaminants

Erosion/sediment transport

Fire ecology

Forest ecology

Global climate change

GIS analysis

Habitat modeling

Herpetology

Invertebrate ecology

Landscape ecology

Marine mammal ecology

Plant ecology

Radiotelemetry

Remote sensing

Restoration ecology

Terrestrial mammal ecology

Threatened and endangered species

Wetland ecology

\section{Applications}

Accurate locations of raven nests

Calculate home range statistics for tortoises

Classification of habitats for terrestrial vertebrate biodiversity

Desert tortoise studies

Determining spring migration routes and breeding area of tule greater white-fronted geese

Fire ecology-determining presettlement forest structure, composition, and fuels in the Sierra Nevada

Fuel assessment (global change)

Giant Garter Snake Ecosystem Initiative

Habitat use and movements of northern pintails wintering in the Suisun Marsh, California

Home range mapping of tule elk at Point Reyes National Seashore

Mapping spatial distribution, magnitude, and intensity of erosional processes through time with aerial photography

Migratory routes of snow geese

Monitor effects of fire on giant saguaros

Mountain lion ingress, Yosemite Valley

Mourning dove call-count route determination

Mourning dove habitat change studies

Population biology study of translocated Washington sea otters using radiotelemetry
Population viability of the San Pablo song sparrow in north San Francisco Bay

Response of Mohave Desert vegetation to elevated $\mathrm{CO}_{2}$ for Department of Energy

Restoration of the Cullinan Ranch to tidal salt marsh

Restoration of the Knapp Unit of San Francisco Bay National Wildlife Refuge

Saguaro National Park fire trend and exotic plant encroachment

Sea-level rise, San Francisco Bay area

Snow goose migration determination

Spatial relationships between sea otter distribution and abundance and various habitat parameters along the central California coast

Status and distribution of rare mammals in Yosemite National Park

Tidal wetlands restoration, San Francisco Bay

Vegetation mapping of Sequoia and Kings Canyon National Park

Waterbird use of harvested rice fields in the Sacramento Valley

Winter ecology of northern pintails

Yosemite National Park vegetation mapping

\section{Highlights}

Biannual relocation of sampling sites: The real-time capabilities of a Rockwell International PLGR unit document UTM coordinates for field sites, thus increasing the efficiency of biannual relocation of sampling sites. Using Trimble equipment, the Western Ecology Research Center (WERC) works with NPS partners if differential processing is needed for mapping purposes. Results are tied in with Yosemite National Park's GIS.

Desert tortoise studies: Precision lightweight GPS receivers are being used to lay out study plots and to map transects to compare two techniques, linedistance sampling and 1-ha study plots, to estimate abundance of desert tortoises over large geographic areas. Sampling is being conducted in Piute Valley, Nevada, and Ivanpah Valley, California.

Radiotelemetry has been used at the WERC's St. George Field Station, Utah, since 1989 to understand the intra- and interannual movements and home range size of the desert tortoise in the northeast Mojave Desert. Global Positioning System and GIS technologies are being used to understand diet selection, habitat use, hibemation behavior, and social interactions of desert tortoises. Radiotelemetry and GPS/GIS are being used in collaboration with the BRD Cooperative Park Studies Unit, University of Arizona, to understand the effects of fire and habitat change on desert tortoises at Saguaro National Park.

Effects of sea-level rise: Geographic information system and GPS technologies are being used to investigate the 
effects of sea-level rise on tidal marshes in the San Francisco Bay area.

Fire trends and exotic plant encroachment in Saguaro National Park: In collaboration with the BRD Cooperative Park Studies Unit at the University of Arizona, WERC staff at the St. George, Utah, field station are using GIS to help managers at Saguaro National Park understand fire trends and patterns of exotic plant encroachment in the park.

Giant Garter Snake Ecosystem Initiative: Radiotelemetry is being used in the WERC's Giant Garter Snake Ecosystem Initiative to monitor snake movements and habitat use. Snake locations are georeferenced using encrypted Y-code GPS for inclusion into a GIS developed for the study areas. Data layers for this project are digitized from aerial photography and are then rectified using GPS technology.

Location of field plots using Global Positioning System technology: Real-time readings are used to locate and relocate field plots for vegetation mapping, fuel assessment, and global change studies. Postprocessed data delineate fire perimeters for verification of large fire spread models.

Migratory route assessment of lesser snow geese and greater white-fronted geese: A DOD world coverage (1:1,000,000 scale) was used as a background map to examine migratory routes in the United States, Canada, Russia, and Japan of lesser snow geese and greater white-fronted geese marked with satellite transmitters.

Mountain lion tracking: Radiotelemetry is being used to document how often mountain lions enter Yosemite Valley, how much time they spend there, and what they do while they are there. A GIS will be used to overlay point locations with land-use layers to determine to what extent the lions go into populated areas.

Mourning dove habitat change: Using black-and-white aerial photography and GIS technology, habitat change along mourning dove call-count routes is being evaluated. Findings will be correlated with changes in dove density.

Riverside Field Station: Staff biologists at the WERC's Canyon Crest Field Station in Riverside, California, are using GPS to obtain accurate locations of raven nests, major attraction sites (e.g., landfills, night roosts, sewage ponds), and marked (radio and patagial tagged) ravens to collect information on the ecology and behavior of ravens in the Mojave Desert. Various GIS data layers will be used to model raven habitat use at the landscape level. Global Positioning System technology is also being used to map the home range and long-distance movements of radiotagged desert tortoises in the Mojave Desert to determine the nature of tortoise movements and how those movements may increase the level of highway mortality in desert tortoise populations.

Sea otter and kelp distribution: A GIS database is being developed for sea otter and kelp distribution along a portion of the central California coast. Data layers include, but are not limited to, sea otter distribution, kelp bed distribution, water depth, and substrate type. A contractor is developing the database using data and input provided by WERC staff.

Short-Term Habitat Conservation Plan: Under the ShortTerm Habitat Conservation Plan, which is part of the Habitat Conservation Plan and Settlement Agreement with the USFWS, biologists at the WERC's Las Vegas Field Station have gathered desert tortoises within the Las Vegas Valley. Under the Long-Term Desert Conservation Plan, additional tortoises will be collected as development progresses. These displaced tortoises will be translocated to habitat south of the Las Vegas Valley. A number of these animals will be part of a translocation study to evaluate the reproduction of animals that inhabit three $1.5-\mathrm{km}^{2}$ study plots. Resident and translocated animals will be equipped with radiotransmitters to allow monitoring of activity and calculation of home range statistics. Female tortoises equipped with transmitters will be sampled periodically so that reproductive status can be evaluated using ultrasound and $\mathrm{x}$-ray technologies. Locations of tortoises with radiotransmitters will be recorded using PLGR units. Study plots were set using PLGR units to outline a 500-m grid network and an inner 100-m grid system for 1-ha study plots to evaluate tortoise density.

St. George Field Station activities: Biologists at the WERC's St. George, Utah, field station are using GPS equipment to:

- Record the range and location of rare and endangered plants (e.g., Astragalus spp.) on BLM land in Utah.

- Monitor the effects of wildfires on approximately 1,000 giant saguaros and desert tortoises in Arizona upland habitats at Saguaro National Park. Giant saguaros in burned and unburned habitats were located to determine long-term annualized mortality subsequent to the Mother's Day Burn.

- Locate fifteen 416- $\mathrm{m}^{2}$ plots at the Department of Energy's Nevada Test Site to determine the response of Mojave Desert vegetation to elevated atmospheric $\mathrm{CO}_{2}$. The long-term FACE (free atmosphere carbon dioxide enhancement) facility was located and mapped, and the data were used to select research plots based on a priori spatial criteria. Spatial data were used to accurately estimate costs of installing the facility by determining 
the length of PVC pipe and fiber optic lines needed. All perennial vegetation within all research plots is being located and mapped so that plant population and community dynamics can be monitored after long-term exposure to elevated $\mathrm{CO}_{2}$.

Terrestrial vertebrate biodiversity: Landsat TM and SPOT panchromatic data are being used to classify habitats for terrestrial vertebrate biodiversity using a Silicon Graphics Indy platform with GRASS and ARC/ INFO. This work is being done in cooperation with the GIS unit of Golden Gate National Recreation Area and the remote sensing/GIS lab at San Francisco State University, where the WERC supports graduate work related to its research activities.

Tidal wetland restoration: Digital orthophotography, USFWS National Wetlands Inventory (NWI) data, and TM satellite imagery were used as base layers for mapping tidal wetland restoration sites in San Francisco Bay. The digital orthophotography was also used to generate topographic data that were entered into a hydrological model to examine sedimentation rates. A GPS unit was used to locate predetermined randomized sampling sites for plants, birds, and mammals and to georeference these data for inclusion in a GIS. Biological information is presented in a $0.25-1.0$ $\mathrm{km}^{2}$ grid format.

Winter ecology of northern pintails: Biologists from the Dixon Field Station have been using radiotelemetry and GIS to study the winter ecology of northern pintails in California. Locations of radiotagged pintails are overlaid with habitat coverages to detect habitat selection and movement patterns. Data have been used to identify important habitats and to assist land managers.

\section{Western Fisheries Research Center, Seattle, Washington \\ Expertise or specialization}

Anadromous fish

Desert fishes ecology

Fish disease

Forest ecology

GIS analysis

GPS technology

Molecular biology

Radio and sonic telemetry

Rare and endangered fish

Remote sensing

Riverine ecology

Underwater videography

\section{Applications}

Assessing riverine preimpoundment conditions via spatial analyses of historical data and maps

Extensive aquatic telemetry studies with radio and acoustic receivers and transmitters
Habitat use by endangered Lost River and shortnose suckers

Mapping direction and magnitude of water velocities near dams with acoustic Doppler current profilers

Migration paths of juvenile salmonids through reservoirs as determined through hydroacoustics

Migratory behavior of endangered Lost River and shortnose suckers during the spawning season

Role of fungi in ecosystem dynamics

Seasonal habitat use and movements of white sturgeon Substrate mapping

Using fixed-station and mobile telemetry to evaluate juvenile salmonid bypass facilities

Using GPS to assist with research vessel navigation

Using GPS to map sampling efforts and fish distributions

Vertical distribution of outmigrating juvenile salmon and steelhead

Highlights

Aquatic telemetry studies: The Western Fisheries Research Center (WFRC) conducts extensive aquatic telemetry studies at the Columbia River Research Laboratory (CRRL) using radio and acoustic transmitters and receivers. Tracking is done from boats, planes, and fixed datalogging stations. Studies focus on obtaining a better understanding of the physical effects of water velocities, dam operations, and other factors on the distribution, movements, and habitat use by anadromous and resident fishes. The time span between contacts for the various study objectives ranges from minutes to months.

Distributions and migratory paths of juvenile salmonids and American shad: Using hydroacoustics, the CRRL is mapping the distributions and migratory paths of juvenile salmonids and American shad through several reservoirs on the Columbia and Snake Rivers. The CRRL is also mapping the direction and magnitude of water velocities near several dams by using vessel-mounted acoustic Doppler current profilers. Graphics depicting magnitude and direction of water velocities and distribution of migratory fishes at various depths in response to changes in river discharge and dam operation (e.g., spilling or no spill) are used to determine the best dam operating procedures.

Evaluations of the effectiveness of juvenile fish bypass facilities at dam sites: The USACE and the Bonneville Power Administration fund several studies at the CRRL to evaluate the effectiveness of juvenile fish bypass facilities constructed at the dams. These studies address the effects of differing dam operations (patterns of spill and turbine discharge) and prototype bypass facilities on the movements of juvenile salmonids and the distribution of predators. These studies use extensive arrays of fixed datalogging receivers and mobile tracking with boats and planes to determine the 
rate of movement and passage routes of fishes at dams. Fixed receivers with multiple antennas and frequency scanning capabilities are strategically placed along the periphery of the dams to learn whether migratory fishes pass through the turbines, spill gates, or bypass facilities. These receivers are also used to define areas where predatory fish congregate. Mobile tracking is used to determine migration routes used by juvenile fish as they approach the dams and to identify habitats used by predatory fish. The USACE uses results of these studies to locate juvenile bypass outfalls, to operate the dams in a "fish friendly" manner, and to investigate new juvenile bypass designs.

Genetic diversity of fungal populations: The WFRC collaborates with the University of Washington and Yellowstone National Park, which have extensive GIS capabilities, in studies of the role of fungi in ecosystem dynamics. Data collected by WFRC researchers are used to determine the genetic diversity of fungal populations representing different functional groups and to assess the role of fungal plant pathogens in and mycorrhizal fungi on plant community structure.

Global Positioning System base station operation: The CRRL uses a GPS for vessel navigation and data collection. The WFRC has a reference station that broadcasts signals for real-time differential corrections and a second base station to log data for postprocessing of the position data collected. Real-time differential corrected positions are used as input to a variety of vessel-mounted instruments, including acoustic Doppler current profilers and hydroacoustic systems, enabling the instruments to append a position to realtime data. The logging base station is used in remote areas where the distance or topography prohibits the use of base stations operated by other agencies.

Hydropower system effects on fishes: The CRRL uses GIS to investigate the effects of hydropower system development and operations on the distributions and abundances of fishes in the reservoirs of the Columbia and Snake Rivers. The CRRL has assembled a spatial database of bathymetry, substrates, river shorelines, islands, navigation markers, boat ramps, river miles, and dam construction details along the lower 396 miles of the Columbia River and the lower 108 miles of the Snake River. Bathymetric data, river shorelines, and islands were digitized from NOAA navigation charts and USGS 7.5 -min quadrangles. Substrates were determined from preimpoundment aerial photos, past field studies, underwater videography, and through grab sampling. Navigation. markers, boat ramps, and river mile indicators can be used as annotations in output or as part of an analysis. Additional data showing construction details of the mainstem dams and water velocity magnitude and direction in dam forebays and tailraces were obtained as computer-aided-design (CAD) files from the USACE. Historical preimpoundment data are being acquired from maps dating from the 1920's and 1930's.

The CRRL uses these data with a GIS to help in research study designs and to investigate the effects on distribution and movements of fish of microhabitats created by the construction and daily operations of the dams. Analysis results include estimates of available suitable habitat for a variety of resident fish, the best sites for placing juvenile salmonid bypass facilities, and evaluations of prototype bypass facilities.

Researchers at the WFRC collect point-sampled data on terrestrial and aquatic systems and store this information in relational databases and spreadsheets. Data are collected at fixed and random locations and at locations where target organisms are found. Collected variables include vegetation type, soil type, water depth, substrate, water velocity, water temperature over time, and fish community composition.

Juvenile salmonid tracking: The USACE funds a telemetry study to investigate the depth distribution of migrating juvenile salmonids. This study uses miniature depth-indicating transmitters placed in juvenile salmonids. Mobile tracking provides information on the rate and depth of movement for individual fishes. Results of this study are used to determine the effects of gas supersaturated conditions on the physiological performance of fishes.

Mapping of fungi: Global Positioning System technology is also used to relocate and map sites for studies on the role of fungi in ecosystem dynamics. All fungi at each site are located and mapped by measuring the distance and azimuth from permanent benchmarks identified with coordinates from a GPS receiver. The receivers enable researchers to periodically return to benchmarks.

Using GPS in biological surveys: The WFRC has 16 portable GPS receivers ( 15 at the CRRL) that are used to collect position information during biological surveys. Attributes are either logged at the time positions are collected or appended to the coordinates later. Commercial software is used to perform coordinate transformations.

White sturgeon tracking: Acoustic telemetry is used to track movements and determine habitats used by white sturgeons in the Columbia and Snake Rivers. This study, funded by the Bonneville Power Administration, uses mobile tracking via boats to locate fishes fitted with transmitters. Results of this work are used to define the seasonal movements and microhabitats used by adult and subadult white sturgeons. 


\section{Infrastructure}

\section{Programs}

\section{Cooperative Research Units Program}

The Cooperative Research Units coordinate the technical facilities of states and universities on issues of importance to unit cooperators and client agencies and organizations. Cooperative programs are maintained with universities and State fish and game departments by each of the 40 Cooperative Research Units and represent a wide range of technical facilities devoted to geospatial issues. Units may augment facilities at their host universities for specialized applications and needs. For example, the Texas Cooperative Fish and Wildlife Research Unit has developed and staffed a GIS and remote sensing facility through research efforts and cooperation with Texas Tech University. ARC/ INFO, ArcView, and IDRISI GIS software programs are maintained on Sun UNIX workstations and on PCs. Most cooperative units now have access to similar facilities, hardware, and software in partnership with host universities and use GIS and other geospatial technologies regularly in their research programs. Capabilities vary by unit, depending on the information needs of local unit cooperators.

\section{Gap Analysis Program}

An inventory of the hardware and software in use by GAP projects would constitute more than 50 pages of text. A typical GAP State project uses a remote sensing/GIS laboratory that has an array of UNIX-based workstations, PCs, mass data storage devices, printers, plotters, still and video cameras, video-to-digital capture devices, digitizers, scanners, flat files, hardcopy libraries, and GPS units. An estimated 500 people are directly involved in conducting gap analysis work, although not all of these individuals are in full-time positions dedicated exclusively to the program.

The GAP maintains four sets of airborne video reconnaissance units consisting of two cameras per set (wide angle and zoom); GPS units; flight recorders; door, wing, and belly mounting brackets; and cabling.

The GAP project office in Idaho maintains the GAP Home Page on the World Wide Web, sharing a Pentium $200 \mathrm{MHZ}$ computer with $9 \mathrm{~GB}$ of storage. Gap Analysis Program staff use four Macintosh computers in a local area network configuration (about $2.3 \mathrm{~GB}$ of storage). All GAP-related facilities have Internet access, and many GAP state projects maintain their own home pages. Headquarters also has an:Intranet for use among state GAP projects as a project tracking and accounting database.

\section{Science and Technical Centers}

Alaska Biological Science Center, Anchorage
Hardware (UNIX-based)
- Color printer, Tektronics Phaser-III (1)
- Digitizing table (2)
- Hard disk (70 Gb)

- Sun SPARCstations, $1+$ to 20 s (12)

- 4-mm DAT tape (4)

- 8-mm Exabyte tape (2)

- 9-track tape (1)

Software (UNIX-based)

- ARC/INFO and assorted modules (6)

- ERDAS/Imagine and assorted modules (2)

- SAS (1)

- Terascan (AVHRR-processing) (1)

\section{Center for Biological Informatics, Denver,} Colorado

Hardware

UNIX environment

- Sun IPX (2)

- Sun SPARCstation $2(1)$

- Sun SPARCstation 5 (1)

- Sun SPARCstation 10 (5)

- Sun UltraSPARC (1) Peripherals

- Altec 3 by 4 digitizer (1)

- CD-ROM reader (8)

- CD-ROM recorder (1)

- Hard disk storage $30 \mathrm{~GB}$

- Hewlett-Packard 750CM color plotter (1)

- Read-write optical drive (1)

- Tektronix Phaser III color printer (1)

- 1/4-inch cartridge-QIC 150 (2)

- 4-mm tape drive (1)

- 8-mm tape drive (3)

- 9-track tape drives (2)

- 35-mm Polaroid film recorder (1)

$\mathrm{PC}$ environment

- 386(5)

- 386 laptop (1)

- N486(12)

- N486 laptop (3)

- Pentium-P5 (5)

Peripherals

- CD-ROM reader (14)

- Hard disk storage - $15 \mathrm{~GB}$

- Laser printer (3)

- Legal-size flatbed color scanner (1)

- 9-track tape drive (1)

\section{Other equipment}

- Cartographic quality Tangent 24 - by 38 -inch color scanner with supporting workstation, scanning software package, and network connection

- $\mathrm{CBI}$ houses, maintains, and supports the BRD-wide hub for cc:Mail

- Macintosh 840Av (1)

- Office-wide Ethernet LAN, connecting UNIX, PC, and Mac environments and the Tangent scanner

- PPS Global Positioning System receivers (3) 
- Use of secure facilities and equipment provided by the Civil Applications Committee, co-located in same building as $\mathrm{CBI}$

\section{Software}

GIS applications

- GRASS 4.1 for UNIX (unlimited)

- GRASS/LAS for PC (1 license)

- PCARC/INFO (1 license)

- PCArcView2 (1 license)

- PC Atlas GIS (1 license)

- UNIX ARC/INFO (2 licenses)

Orthophoto and Digital Elevation Model production

- ERDAS OrthoMAX 8.2 with stereo editing capability (1 license)

Remote sensing/image processing

- ELAS (unlimited users)

- ERDAS Imagine 8.2 (1 license)

- PCI for Windows 95 with radar, hyperspectral, neural network classifiers, terrain analysis, atmospheric correction and terrain analysis modules (1 license)

- TAE/LAS (unlimited users)

Statistical applications

- S-plus 3.4 UNIX (1 license)

Database applications

- dBase-3, dBase-4 for Windows

- Informix for UNIX

Office automation

- Microsoft Office Suite (Word, Excel, Access, Powerpoint)

- WordPerfect 5.1 for UNIX

- WordPerfect 6.1 for Windows

- WordPerfect 7.0 for Windows

Miscellaneous

- Variety of html editors

- Variety of UNIX and PC graphics editors (CorelDraw, Freelance, XV, LView)

\section{Environmental and Contaminants Research}

Center, Columbia, Missouri

Harctware

- Altek table

- Analytical stereo plotter

- Digital video cameras

- Disk storage (6l GB)

- GPS base station

- GPS-based bathymetric surveying equipment

- Hewlett-Packard 650C and 755CM plotters

- Innerspace hydrographic survey system

- Pentium PC workstations (10)

- Rockwell PLGR(5)

- Stereoscopes

- Sun SPARCstations

- Trimble PFINDER Pro XLs (2), PLGR units (5)

- Trimble Pro-XL (2)
- Trimble 12-channel Maxwell-based receiver

- Zoom transfer scopes

Software

- Adobe Photoshop

- ARC/INFO

- ArcView

- ERDAS Imagine

- Fragstats.

- Geolink

- Optimas

- Oracle

- PCI

- S-Plus ARC/INFO LINK

- S-Plus SpatialStats

- S-Plus

- SAS

- Trimble HYDRO

Environmental Management Technical Center, Onalaska, Wisconsin

Hardware

- GPS receivers, GPS base station

- Hardware and software to support color printing, plotting, digitizing, scanning, electronic photointerpretation, manual zoom transfer and automated stereo zoom transfer, manual digitizing and automated scanning, and cartographic map production

- Pentium PC workstations

- Stereoscopes

- UNIX workstations and servers

Software

- ARC/INFO-PC

- ARC/INFO-UNIX

- ArcView

- EPPL-7

- IDRISI

- PCI

- SAS

Florida Caribbean Science Center, Gainesville Hardware

- Color inkjet, paintjet and b/w printers

- Data General Aviion workstations (3)

- Data General 6200 server

- Data General 9500 server

- Dell Poweredge 4100 Server (Win NT)

- Digitizing tablet

- Novell 4.1 servers (2)

- NT workstations (5)

- NT Server

- PCs (52)

- Polaroid Pallete

- Ricoh color scanner

- Sun SPARCstations (3)

- Versatec electrostatic plotter 


\section{Software}

- ARC/INFO-PC

- ARC/NFO-UNIX

- ArcView 3.0

- Arc Press 2.0

- Ingres DBMS

- Various PC applications

Forest and Rangeland Ecosystem Science Center, Corvallis, Oregon

Hardware

- 1/4-inch cartridge-QIC 150

- 8-mm Exabyte tape (2)

- 8-mm Exabyte jukebox back-up

- Altek AC40 36- by 48 -inch digitizing table (2)

- CD-ROM recorder

- Digital palette film recorder

- Flat-bed scanner

- Hard Disk (130 GB)

- Hewlett-Packard DesignJet 650C plotter

- Hewlett-Packard DesignJet 2500 color plotter

- Hewlett-Packard ScanJet 6100C with slide-scanning capabilities

- Linux Platforms $(3 ; 1$ on a notebook)

- Macintosh Power PC

- Multiple Pentium PCs, some communicate via Xserver software to the SPARC stations

- Rockwell PLGR+96 (3)

- Slide Scanner

- Sun Microsystems SPARCstations 2, 10, 20

- Trimble GPS Community Base Station

- Trimble ProXL GPS

- Trimble GeoExplorer

- Trimble PFINDER Professional (2)

- Windows NT server (27GB)

Software

- Adobe Illustrator

- Adobe Photoshop

- ARC/INFO UNDX and NT for version 7.1.1 with all modules, multiple licenses

- ArcView 3.0a UNIX and NT for with all modules, multiple licenses

- ERDAS Imagine (2)

- ESRI Internet Map Server

- FRAGSTATS

- Geographic Calculator

- GRASS version 4.2.1, including version 2.2 for landscape ecology functions

- IDRISI

- Image Alchemy version 1.9.1

- S-Plus ARC/INFO link

- S-Plus (2)

- Timble Pfinder Office, multiple copies

- Workstation SAS version 6.12, various PC statistical packages
Great Lakes Science Center, Ann Arbor, Michigan

Hardware

- GTCO Accutab 36- by 48-inch digitizer

- Rockwell PLGR unit

- Trimble GeoExplorer rovers (2)

- Trimble PFINDER software

- Trimble ProXR with TCDI and Asset Surveyor

- 12-channel Trimble community base station

\section{Software}

- ARC/INFO for PC and NT

- ArcView with Spatial Analyst

- Coris SIPS

Leetown Science Center, Kearneysville, West

Virginia

\section{Hardware}

- Hewlett-Packard 650c plotter

- Large-format digitizer

- Networked PCs (running X-terminal software)

- PLGR unit

- UNIX workstations (2)

Software

- ARC/INFO

- ArcView

- EASI/PACE

- IDRISI

- PCI

Midcontinent Ecological Science Center, Fort Collins, Colorado

Hardware

Minicomputers

- Data General (1)

- SPARC IPX (1)

- SPARCstation $2(7)$

- SPARCstation $5(1)$

- SPARCstation $10(2)$

- SPARCstation $20(2)$

- SPARCserver 1000 (1)

- SPARC Ultra 1 (1)

- SPARC Ultra 2 (2)

Microcomputers (306)

- Laptops -286, 386 (46)

- Notebooks - 386, 486, 586 (33)

- Macintosh (4)

- Pentiums (55)

- $286 \mathrm{~s}(21)$

- $386 \mathrm{~s}(54)$

- 486s (93)

Peripherals

- Alphanumeric (3)

- Altek digitizing tablets (4)

- Calcomp digitizing tablets (4)

- Color graphics (2)

- Ink jet printers (30) 
- Laser printers (69)

- Other digitizing tablets (3)

- Other printers (26)

- Plotters (5)

- X-terminals (8)

External drives

- Bernoulli disk drives (21)

- CD-ROM(8)

- Fax modems (11)

- Modems (16)

- Video disks (4)

Other devices

- Dataloggers (6)

- External modems (48)

- Facsimile machines (7)

- GPS receivers (48)

- Radio receivers (26)

- Radios (51)

- Readers (11)

- Telemetry receivers (23)

- 11-by 14-inch scanner

\section{Software}

Database management systems software $(70$ licenses)

- ARC/INFO-PC (3)

- ARC/INFO-UNIX - multiple-user (1)

- ARC/INFO-UNIX - single-user (5)

- ARC/INFO-UNIX - three-user (2)

- ArcView (8)

- dBase 3Plus v1.X(16)

- dBase 4 vl.X(10)

- Oracle un v7.9(2)

- Oracle C v1.0/4.5(9)

- Paradox v3.5/4.0(5)

- Paradox for Windows v1.0/4.5 (9)

Graphics software (42)

- Corel (10)

- Cricket Draw/Graph - various versions (3)

- Freelance Graphics - various versions (17)

- GEM (4)

- Harvard Graphics (4)

- PC Paint (4)

Literature organizers (17)

- Papyrus (2)

- Procite (8)

- Reference Manager (7)

Spreadsheet software (116)

- Excel, various versions (11)

- Lotus 1-2-3, various versions (59)

- Multiplan (1)

- QuatroPro, various versions (45)

Statistical analysis software (49)

- SAS(18)
- SAS for UNIX (1)

- Systat (28)

- S Plus (2)

Web browsers (97 licenses)

- Internet Explorer (45)

- Mosaic (21)

- Netscape (28)

- SPRY(3)

\section{National Wetlands Research Center, Lafayette,} Louisiana

Hardware

- 4-mm data tape (2)

- 8-mm Exabyte tape (4)

- 9-track tape (1)

- Apple Laserwriter

- Color plotters: LaserMaster DisplayMaker, Calcomp 6800

- Data General workstations, 13 GB disk space (10)

- Digitizing tables (5)

- GPS units: Trimble PFINDER Basic + (2), PRO XL, and Trimble 4000ST base station, Corvallis MC5

- Hewlett-Packard Printer

- LaserGraphics slide maker

- Power Macintosh (1), Macintosh

- Scanners: Howtek 11-by 17 -inch, Sharp 12-by 18 -inch and 11-by 17-inch

- Silicon Graphics workstations, 87 GB disk space (6)

- Sun SPARCstations, $50 \mathrm{~GB}$ disk space (6)

- Tektronix Phaser PostScript color printer

- Yamaha 4X CD-R Writer

- Zoom transfer scope (5), stereo scope

Software

- Adobe Photoshop for UNIX, PC, and Macintosh

- AGIS

- ARC/INFO for UNIX

- ArcView for UNIX and PC

- Atlas GIS

- AUTOCAD

- ERDAS

- GIS Plus

- IDRISI

- Imagine

- MapGraphix

- MapInfo

- Mapix

- Mapmaker

- PCI

- SAS

- SPANS

\section{National Wildlife Health Center, Madison, Wisconsin}

Hardware and software

- Lotek Engineering, GPS-1000AL collars (Bison) (4)

- Rockwell PLGR+ 96 receivers (2) 
- Trimble Pro XL, with tcdi 16851-70(1)

\section{Northern Prairie Wildlife Research Center, Jamestown, North Dakota \\ Hardware}

- Howtek Scanmaster III 11-by 17-inch color scanner

- Nikon 35-mm slide scanner

- Optical disc recorder

- Pentium PCs (6)

- Rockwell PLGR units (3)

- Sun SPARCstation UNIX (3)

- Tektronics Phaser III color printer

- Trimble PFINDER Professional GPS units (2)

- Trimble GeoExplorer GPS units (2)

Software

- ARC/INFO

- GRASS

- MIPS

- $\mathrm{PCI}$

Stand-alone image processing softwareacquired from other facilities or developed at NPWRC

- CALIBRATE (programs for radiometric calibration of AVHRR images)

- CLASSIFY (maximum likelihood classification with the option to create posterior probability images)

- FIVES (an atmospheric radiative transfer program)

- FRAGSTATS (a spatial pattern analysis system for quantifying landscape structure)

- MIXTURE (mixture model analysis of multispectral images)

- NAVIGATE (programs for georegistration and resampling of AVHRR images to map projections)

Pacific Island Ecosystems Research Center, University of Hawaii, Honolulu

Hardware

- Altek digitizer (36- by 44-inch)

- Calcomp Drawing Board III digitizing tablet (1)

- Hewlett-Packard 755CM (E-size plotter)

- IBM InkJet (maximum 11- by 17-inch prints)

- Pentium computer (networked to the Sun SPARCstation)

- Rockwell PLGR 96

- Sun SPARCstation 20

- Trimble PFINDER

Software

- ARC/INFO for PC and UNIX

- ArcView (interface to ARC/INFO)

Patuxent Wildlife Research Center, Laurel, Maryland

Hardware

- Accelawriter 8100 printer

- Hewlett-Packard DesignJet 650C plotter
- Itek C004AR digitizer

- PLGR+ units (8)

- Rockies (rugged notebook computers used to run the Geolink software and collect field data; 3 units)

- Tektronix Phaser II SDX color printer

- UNIX-based Data General Aviion 6240

\section{Software}

- ARC/NFO

- ArcView

- Geolink software (3)

Upper Mississippi Science Center, La Crosse, Wisconsin

Hardware

- Hewlett-Packard B/W flatbed scanner with optical recognition

- Hewlett-Packard color flatbed scanner

- Hewlett-Packard color LaserJet printer

- Hewlett-Packard DesignJet plotter

- Hewlett-Packard LaserJet printers

- Nikon 35-mm slide scanner

- $\operatorname{PCs}(50-60)$

- Radio (miniature) and satellite telemetry

- Rockwell PLGR 96 units (15-20)

- Sun SPARCstation 2 (1)

- Sun SPARCstation 20 (1)

- T-1 line

Software

- $\mathrm{ARC} / \mathrm{INFO}$, multiuser license

Western Ecological Research Center, Davis, California

Hardware

- Hewlett-Packard IIc color scanner

- Hewlett-Packard DesignJet 650c e-size plotter

- Hewlett-Packard Laserjet 5SiMx PostScript printer

- Nikon slide scanner

- Pentium 200 (64 MB RAM), with 2 GB disk space, 20inch color monitor (2)

- Polaroid Digital Palette film recorder

- Sun UltraSPARCstation 1 (64 MB RAM), with 8-bit ram buffer, 20 -inch color monitor, $10 \mathrm{~GB}$ disk space

- Sun SPARCstation 10 (96 MB RAM), with 24-bit frame buffer, 20 -inch color monitor, $7 \mathrm{~GB}$ disk space

- Talos 8000 36- by 48 -inch digitizing table

- Tektronix Phaser 300i PostScript color printer

Software

- ERDAS Imagine 8.2 image processing software

- Hummingbird Maestro NFS software for Windows 95

- Hummingbird Exceed X-emulation software for Windows 95

- SAS for PC

- UNIX ARC/INFO 7.0.4 multiuser, single CPU (six seats) 


\section{Western Fisheries Research Center, Seattle, Washington}

\section{Hardware}

- 420-kHz Biosonics DT5000 digital dual-beam echosounder

- 420-kHz Biosonics ES2000 dual-beam echosounder with multiplexing capabilities

- 420-kHz Biosonics Model 105 echosounder

- 600-kHz Acoustic Doppler Current Profilers (2)

- Calcomp Drawing Board III digitizing tablet (1)

- Hewlett-Packard ScanJet 3c document scanner

- HTI splitbeam echosounder capable of operating at 200 and $420 \mathrm{kHz}$

- Lotek SRX 400 radiotelemetry receivers (79; 14 with Digital Spectrum Processors)

- Motorola LGT receivers (5)

- Motorola Six-Gun Base Station (1)

- Numerous Pentium PCs

- Rockwell PLGRs FED96 version (11)

- Sonotronics USR-90 Scan sonic telemetry receiver (1)

- Sonotronics USR-91 sonic telemetry receivers (2)

- Trimble GeoExplorer (1)

- Trimble Navtracs (4)

- Trimble PFINDER Basic (1)

- Trimble PFINDERs(2)

- Trimble Pro XL receiver (1)

- Trimble RS4000 reference station (1) with two Motorola radios and two modems for real-time differential correction

- Windows NT Server, PII 300, RAID level V

Software

- ARC/INFO

- EPPL7 version 3.0

- Geolink

- PowerMap

- TecPlot software

\section{Acknowledgments}

The Geospatial Technology Applications and Infrastructure report was reviewed by many BRD staff members. The final version of this document is largely the result of their efforts, and we thank them for their contributions. In particular, we thank the Geospatial Technology Coordinators, who consolidated comments from geospatial technology users at their respective centers and programs, and who were vital partners in organizing and fine-tuning this report. We also thank the publications specialists whose expertise contributed to the clarity and usefulness of this document.

\section{Literature Cited}

Biological Resources Division. 1996. Biological Resources Division Strategic Science Plan, September 1996. 14 pp. (http://biology.usgs.gov/)

D'Erchia, F., T. D'Erchia, J. Getter, M. McNiff, R. Root, S. Stitt, and B. White. 1997. Biological Resources Division geospatial technology strategic plan. U.S. Department of the Interior, U.S. Geological Survey, Biological Resources Division, Reston, Virginia. (Information and Technology Report: USGS/BRD/ITR-1997-0003). 33 pp.

Federal Geographic Data Committee. 1994. Draft content standards for digital geospatial metadata. Federal Geographic Data Committee, Washington, D.C. 54 pp. + Appendixes A-C.

Getter, J.R., and D. Wickland. 1998. DOI use of AVIRIS data in natural resources management-a technology transfer project status report. Seventh Airborne Earth Science Workshop, NASA Jet Propulsion Laboratory, Pasadena, California. 10 pp.

Jennings, M.D., E. Brackney, P. Crist, and B. Sorbel. 1995. National Gap Analysis Program status report: 1994 and 1995 fiscal years. National Gap Analysis Program, Moscow, Idaho. $158 \mathrm{pp}$.

Korschgen, C., L. Hill, T. D'Erchia, and S. Dreiband. 1996. The great river flyway: the management strategy for migratory birds on the Mississippi River. National Biological Service and U.S. Fish and Wildlife Service. $20 \mathrm{pp}$.

Maroney, S. 1995. AIBS Review to National Biological Service: Content Standard for Non-Geospatial Metadata Workshop. American Institute of Biological Sciences, Reston, Virginia. $25 \mathrm{pp}$.

National Biological Service. 1996. A geographic approach to planning for biological diversity. Gap Analysis Program Bulletin \#5. Gap Analysis Program, Moscow, Idaho.

National Biological Service. 1995. Draft content standard for NBII. National Biological Service. Available via ftp at ftp.nbs.gov/pub/nbii/nbiimeta.wp.

National Spatial Data Infrastructure. 1994. National Spatial Data Infrastructure strategic plan. Federal Geographic Data Committee, Reston, Virginia.

Scott, J.M., F. Davis, B. Csuti, R. Noss, B. Butterfield, C. Groves, H. Anderson, S. Caicco, F. D'Erchia, T.C. Edwards, Jr., J. Ulliman, and R. G. Wright. 1993. Gap Analysis: a geographic approach to protection of biological diversity. Wildlife Monographs 123. 


\section{Glossary}

\section{Acronyms and Abbreviations}

\begin{tabular}{|c|c|}
\hline $\begin{array}{l}\text { ABSC } \\
\text { AML } \\
\text { AVHRR } \\
\text { AVIRIS }\end{array}$ & $\begin{array}{l}\text { Alaska Biological Science Center } \\
\text { ARC Macro Language } \\
\text { Advanced Very High Resolution Radiometer } \\
\text { Airborne Visible/Infrared Imaging Spectrometer }\end{array}$ \\
\hline $\begin{array}{l}\text { BEST } \\
\text { BRD }\end{array}$ & $\begin{array}{l}\text { Biomonitoring of Environmental Status and Trends } \\
\text { Biological Resources Division }\end{array}$ \\
\hline $\begin{array}{l}\text { CAC } \\
\text { CAD } \\
\text { CBI } \\
\text { CBS } \\
\text { CDOW } \\
\text { CERES } \\
\text { CIMAS } \\
\text { CIR } \\
\text { CORS } \\
\text { CRP } \\
\text { CRRL } \\
\text { CWPPRA }\end{array}$ & $\begin{array}{l}\text { Civil Applications Committee } \\
\text { Computer-aided design } \\
\text { Center for Biological Informatics } \\
\text { Community Base Station } \\
\text { Colorado Division of Wildlife } \\
\text { California Environmental Resources Evaluation System } \\
\text { Contaminant Information Management and Analysis System } \\
\text { Color-infrared } \\
\text { Continually operating reference stations } \\
\text { Conservation Reserve Program } \\
\text { Columbia River Research Laboratory } \\
\text { Coastal Wetlands Planning, Protection and Restoration Act }\end{array}$ \\
\hline $\begin{array}{l}\text { DOD } \\
\text { DOI } \\
\text { DSS }\end{array}$ & $\begin{array}{l}\text { Department of Defense } \\
\text { Department of the Interior } \\
\text { Decision Support System }\end{array}$ \\
\hline $\begin{array}{l}\text { ECRC } \\
\text { EMAP } \\
\text { EMTC } \\
\text { EOSDIS }\end{array}$ & $\begin{array}{l}\text { Environmental and Contaminants Research Center } \\
\text { Environmental Monitoring and Assessment Program } \\
\text { Environmental Management Technical Center } \\
\text { Earth Observing System Data and Information System }\end{array}$ \\
\hline $\begin{array}{l}\text { FACE } \\
\text { FCSC } \\
\text { FGCS } \\
\text { FGDC } \\
\text { FLIR } \\
\text { FRESC }\end{array}$ & $\begin{array}{l}\text { Free atmosphere carbon dioxide enchancement } \\
\text { Florida Caribbean Science Center } \\
\text { Federal Geodetic Control Subcommittee } \\
\text { Federal Geographic Data Committee } \\
\text { Forward-looking infrared } \\
\text { Forest and Rangeland Ecosystem Research Center }\end{array}$ \\
\hline $\begin{array}{l}\text { GAP } \\
\text { GBPO } \\
\text { GIS } \\
\text { GLSC } \\
\text { GPS } \\
\text { GSGDC } \\
\text { GTOG }\end{array}$ & $\begin{array}{l}\text { Gap Analysis Program } \\
\text { GulfBreeze Project Office } \\
\text { Geographic information systems } \\
\text { Great Lakes Science Center } \\
\text { Global Positioning System } \\
\text { U.S. Geological Survey Geographic Data Committee } \\
\text { Geospatial Technology Coordinating Group }\end{array}$ \\
\hline $\begin{array}{l}\text { IGDC } \\
\text { ITIS }\end{array}$ & $\begin{array}{l}\text { Interior Geographic Data Committee } \\
\text { Integrated Taxonomic Information System }\end{array}$ \\
\hline $\begin{array}{l}\text { LAN } \\
\text { LDNR } \\
\text { LCD } \\
\text { LSC } \\
\text { LTRMP } \\
\text { LUHNA }\end{array}$ & $\begin{array}{l}\text { Local area network } \\
\text { Louisiana Department of Natural Resources } \\
\text { Land Cover Data Working Group } \\
\text { Leetown Science Center } \\
\text { Long Term Resource Monitoring Program } \\
\text { Land Use History of North America }\end{array}$ \\
\hline $\begin{array}{l}\text { MAPS } \\
\text { MAV }\end{array}$ & $\begin{array}{l}\text { allivity and Survivorship program } \\
\text { alley }\end{array}$ \\
\hline
\end{tabular}




\begin{tabular}{|c|c|}
\hline $\begin{array}{l}\text { MESC } \\
\text { MoRAP } \\
\text { MRLC } \\
\text { MSS }\end{array}$ & $\begin{array}{l}\text { Midcontinent Ecological Science Center } \\
\text { Missouri Resource Assessment Partnership } \\
\text { Multi-Resolution Land Characteristics } \\
\text { Multi-Spectral Scanner }\end{array}$ \\
\hline $\begin{array}{l}\text { NAAMP } \\
\text { NARSAP } \\
\text { NAS } \\
\text { NASA } \\
\text { NBII } \\
\text { NGO } \\
\text { NOAA } \\
\text { NPS } \\
\text { NPWRC } \\
\text { NRCS } \\
\text { NSDI } \\
\text { NTM } \\
\text { NWHC } \\
\text { NWI } \\
\text { NWRC }\end{array}$ & $\begin{array}{l}\text { North American Amphibian Monitoring Program } \\
\text { National Advanced Remote Sensing Applications Program } \\
\text { Nonindigenous Aquatic Species database } \\
\text { National Aeronautics and Space Administration } \\
\text { National Biological Information Infrastructure } \\
\text { Nongovernment organization } \\
\text { National Oceanic and Atmospheric Administration } \\
\text { National Park Service } \\
\text { Northern Prairie Wildlife Research Center } \\
\text { Natural Resource Conservation Service } \\
\text { National Spatial Data Infrastructure } \\
\text { National Technical Means } \\
\text { National Wildlife Health Center } \\
\text { National Wetlands Inventory } \\
\text { National Wetlands Research Center }\end{array}$ \\
\hline $\begin{array}{l}\text { OBIO } \\
\text { OES } \\
\text { OMB } \\
\text { ONRC }\end{array}$ & $\begin{array}{l}\text { Office of Biological Informatics and Outreach } \\
\text { Office of Earth Science (NASA) } \\
\text { Office of Management and Budget } \\
\text { Olympic Natural Resources Center }\end{array}$ \\
\hline $\begin{array}{l}\text { PAE } \\
\text { PC } \\
\text { PIERC } \\
\text { PLGR } \\
\text { PPS } \\
\text { PWRC }\end{array}$ & $\begin{array}{l}\text { Production ARCEDIT } \\
\text { Personal computer } \\
\text { Pacific Island Ecosystems Research Center } \\
\text { Precision lightweight GPS receiver } \\
\text { Precise Positioning Service } \\
\text { Patuxent Wildlife Research Center }\end{array}$ \\
\hline QA/QC & Quality assurance/quality control \\
\hline ROV & Remotely operated vehicle \\
\hline $\begin{array}{l}\text { SAF } \\
\text { SAST } \\
\text { SERDP } \\
\text { SRFS } \\
\text { SST }\end{array}$ & $\begin{array}{l}\text { Secured Applications Facility } \\
\text { Scientific Assessment and Strategy Team } \\
\text { Strategic Environmental Research and Development Program } \\
\text { Snake River Field Station } \\
\text { Sea-surface temperature }\end{array}$ \\
\hline TM & Thematic Mapper \\
\hline $\begin{array}{l}\text { UMRS } \\
\text { UMSC } \\
\text { USACE } \\
\text { USDA } \\
\text { USEPA } \\
\text { USFS } \\
\text { USFWS } \\
\text { USGS } \\
\text { UTM } \\
\text { UWFS }\end{array}$ & $\begin{array}{l}\text { Upper Mississippi River System } \\
\text { Upper Mississippi Science Center } \\
\text { U.S. Army Corps of Engineers } \\
\text { U.S. Department of Agriculture } \\
\text { U.S. Environmental Protection Agency } \\
\text { U.S. Forest Service } \\
\text { U.S. Fish and Wildlife Service } \\
\text { U.S. Geological Survey } \\
\text { Universal Transverse Mercator } \\
\text { University of Washington Field Station }\end{array}$ \\
\hline $\begin{array}{l}\text { WERC } \\
\text { WFRC } \\
\text { WWW }\end{array}$ & $\begin{array}{l}\text { Western Ecological Research Center } \\
\text { Western Fisheries Research Center } \\
\text { World Wide Web }\end{array}$ \\
\hline & Zoom transfer scope \\
\hline
\end{tabular}




\section{Appendix}

\section{Geospatial Technology Coordinators}

The BRD has established a Geospatial Technology Coordinator for each of its science and technology centers and major program areas. The Geospatial Technology Coordinator provides technical assistance to end-users at the center or program and associated field offices.

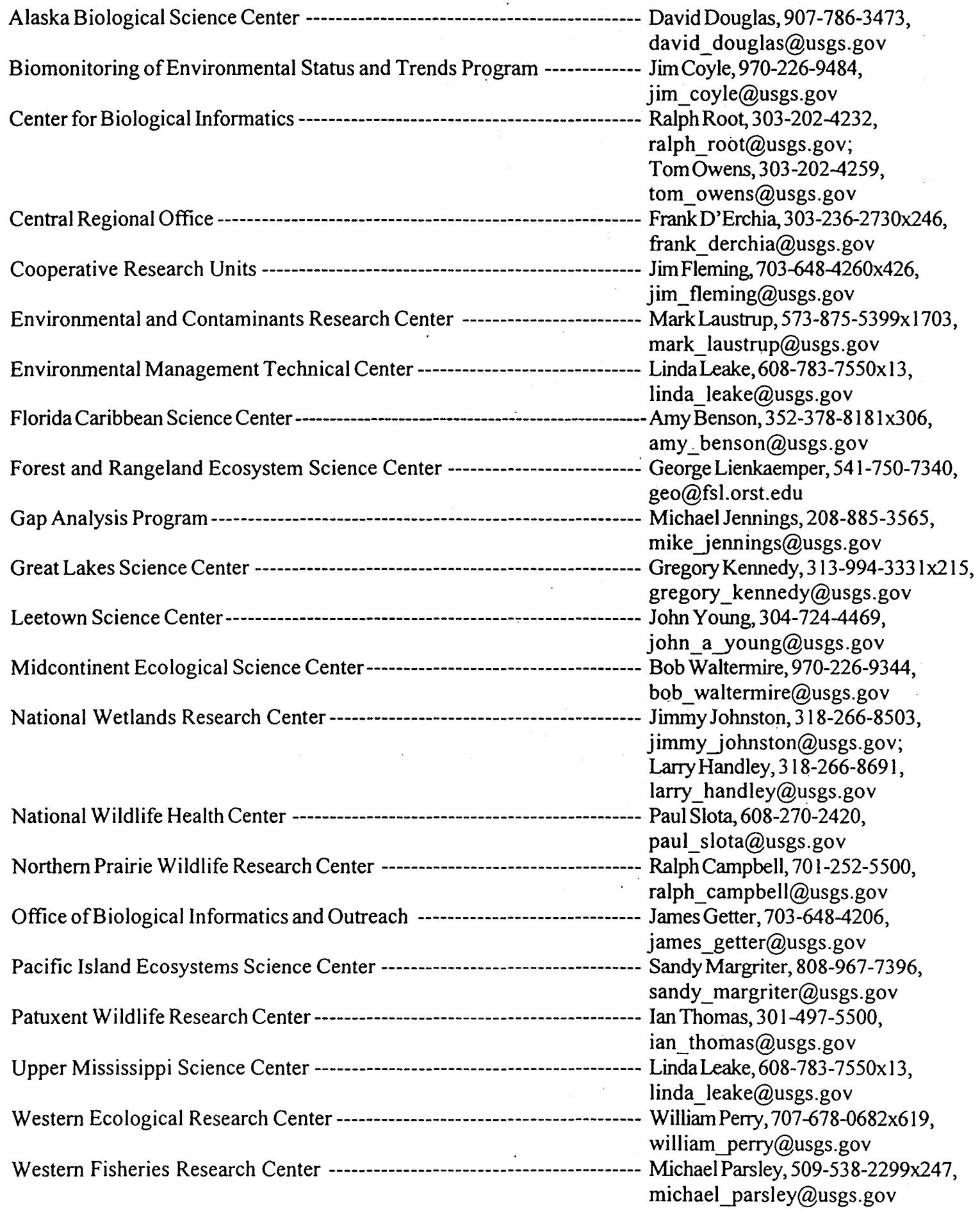




\section{Geospatial Technology Council}

This rotating membership team serves as an advisory group that assists the Geospatial Technology Coordinating Group with recommendations on policy issues, standards, and guidelines. The council also acts as a steering committee for the BRD geospatial technology function. Membership includes nonvoting Office of Biological Informatics and Outreach representatives. To maintain continuity, the council has been formed so that at least half the members will overlap with new members.

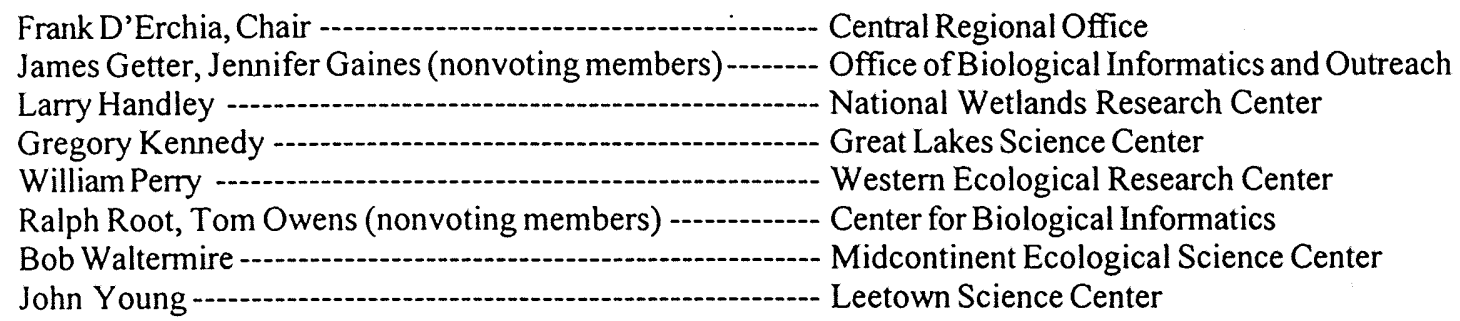


Public reporting burden for this collection is estimated to average 1 hour per response, including time for reviewing instructions, searching existing data sources. gathering and maintaining the data needed, and completing and reviewing the collection of information. Send comments regarding this burden estimate or any other aspect of this collection of information, including suggestions for reducing this burden, to Washington Headquarters Services. Directorate for Information Operations and Reports, 1215 Jefferson Davis Highway, Suite 1204, Artington, VA 22202-4302, and to the Office of Management and Budget, Paperwork Reduction Project (0704-0188) Washington, DC 20503.

\begin{tabular}{|l|l|l}
\hline $\begin{array}{l}\text { 1. AGENCY USE ONLY (Leave } \\
\text { Blank) }\end{array}$ & $\begin{array}{l}\text { 2. REPORT DATE } \\
\text { September } 1998\end{array}$ & $\begin{array}{l}\text { 3. REPORT TYPE AND DATES COVERED } \\
\text { Information and Technology Report }\end{array}$
\end{tabular}

4. TITLE AND SUBTTTLE

Geospatial technology applications and infrastructure in the Biological Resources Division

\section{AUTHOR(S)}

Geospatial Technology Strategic Planning Development Team

7. PERFORMING ORGANIZATION NAME(S) AND ADDRESSES

U.S. Department of the Interior

U.S. Geological Survey

Biological Resources Division

9. SPONSORING/MONITORING AGENCY NAME(S) AND ADDRESSES

U.S. Department of the Interior

U.S. Geological Survey

\section{SUPPLEMENTARY NOTES}

\section{2a. DISTRIBUTION/AVAILABILITY STATEMENT}

Release unlimited. Available from the National Technical Informartion Service, 5285 Port Royal Road, Springfield, VA 22161 (1-800-553-6847 or 703-487-4650). Available to registered users from the Defense Technical Information Center, Attn: Help Desk, 8722 Kingman Road, Suite 0944, Fort Belvoir, VA 22060-6218 (1-800-225-3842 or 703-767-9050).

13. ABSTRACT (Maximum 200 words)

This report addresses the use and applications of geospatial technology in the Biological Resources Division (BRD) of the U.S. Geological Survey. Information on geospatial technology activities and resources at BRD centers and programs is linked to the BRD Geospatial Technology Strategic Plan. Activities listed represent only a sampling of ongoing geospatial applications and infrastrucutre; new projects are implemented on a regular basis. The use and application of geospatial technology is rapidly expanding Division-wide, as demonstrated by the breadth of applications discussed. This document provides an inventory of geospatial capabilities that currently exist within the centers, field stations, and programs of the BRD. 12b. DISTRIBUTION CODE

Unlimited

\section{SUBJECT TERMS (Keywords)}

Biological Resources Division, geographic information systems, geospatial technology, Global Positioning System, metadata, remote sensing, satellite positioning systems, telemetry, U.S. Geological Survey

\begin{tabular}{|l|l|}
\hline $\begin{array}{l}\text { 17. SECURITY CLASSIFICATION } \\
\text { OF REPORT } \\
\text { Unclassified }\end{array}$ & $\begin{array}{l}\text { 18. SECURITY CLASSIFICATION OF } \\
\text { THIS PAGE }\end{array}$ \\
Unclassified
\end{tabular}
18. SECURITY CLASSIFICATION OF
Unclassified

19. SECURTY CLASSIFICATION OF ABSTRACT

Unclassified

Unclassified

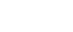

(n) - .

\begin{tabular}{|c|}
\hline $\begin{array}{l}\text { 15. NUMBER OF PAGES } \\
v+53\end{array}$ \\
\hline 16. PRICE CODE \\
\hline 20. LMITATION OF ABSTRACT \\
\hline Unlimited \\
\hline
\end{tabular}




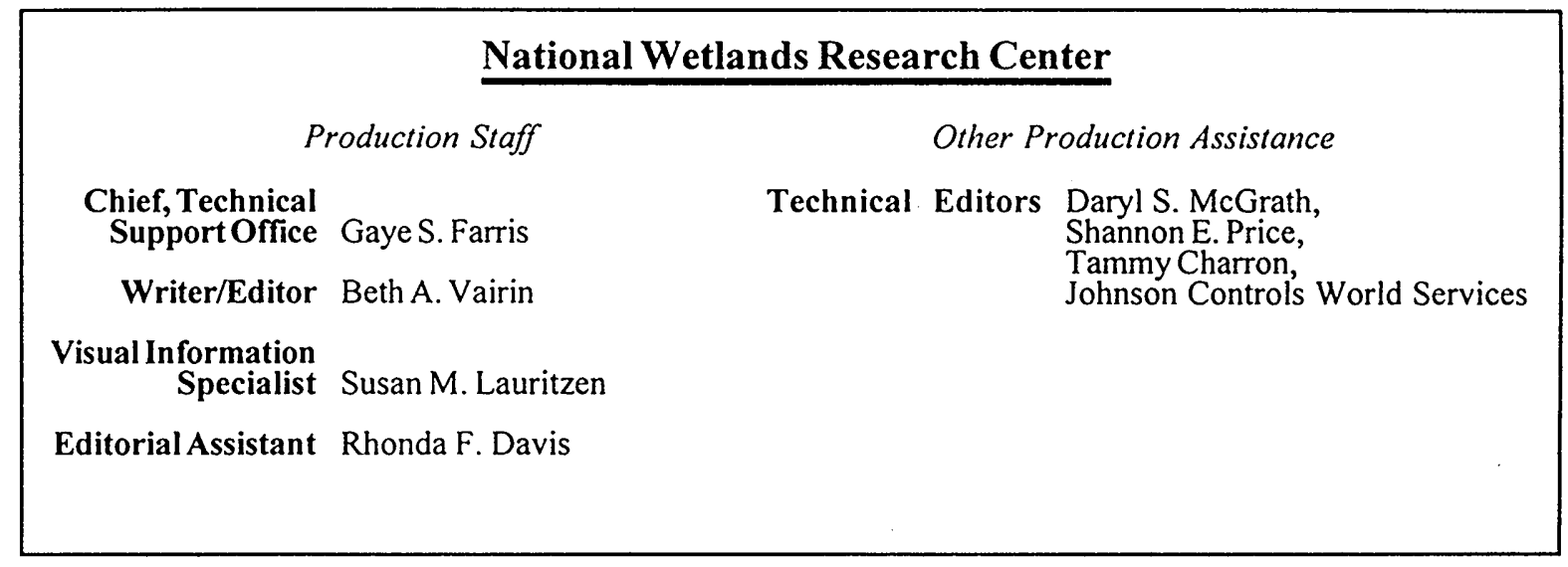

NOTE: The mention of trade names does not constitute endorsement or recommendation for use by the Federal Government. 


\section{U.S. Department of the Interior U.S. Geological Survey}

As the Nation's principal conservation agency, the Department of the Interior has responsibility for most of our nationally owned public lands and natural resources. This responsibility includes fostering the sound use of our lands and water resources; protecting our fish, wildlife, and biological diversity; preserving the environmental and cultural values of our national parks and historical places; and providing for the enjoyment of life through outdoor recreation. The Department assesses our energy and mineral resources and works to ensure that their development is in the best interests of all our people by encouraging stewardship and citizen participation in their care. The Department also has a major responsibility for American Indian reservation communities.

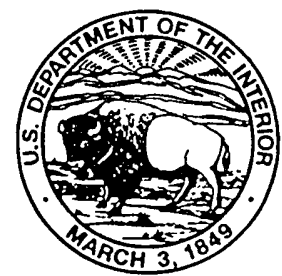

